Florida International University

FIU Digital Commons

FIU Electronic Theses and Dissertations

University Graduate School

6-20-2012

\title{
The Use of Computer Graphic Organizers For Narrative Writing By Elementary School Students With Specific Learning Disabilities
}

Mary K. Gonzalez-Ledo

Florida International University, mkgonzalez@dadeschools.net

DOI: $10.25148 /$ etd.FI12080632

Follow this and additional works at: https://digitalcommons.fiu.edu/etd

\section{Recommended Citation}

Gonzalez-Ledo, Mary K., "The Use of Computer Graphic Organizers For Narrative Writing By Elementary School Students With Specific Learning Disabilities" (2012). FIU Electronic Theses and Dissertations. 675.

https://digitalcommons.fiu.edu/etd/675 


\section{FLORIDA INTERNATIONAL UNIVERSITY \\ Miami, Florida}

\section{THE USE OF COMPUTER GRAPHIC ORGANIZERS FOR NARRATIVE WRITING BY ELEMENTARY SCHOOL STUDENTS WITH SPECIFIC LEARNING DISABILITIES}

A dissertation submitted in partial fulfillment of the requirements for the degree of DOCTOR OF EDUCATION

in

EXCEPTIONAL STUDENT EDUCATION

By

Mary Kristina Gonzalez-Ledo

2012 
To: Dean Delia C. Garcia

College of Education

This dissertation, written by Mary Kristina Gonzalez-Ledo, and entitled, The Use of a Computer Graphic Organizer for Narrative Writing by Elementary Students with Specific Learning Disabilities, having been approved in respect to style and intellectual content, is referred to you for judgment.

We have read this dissertation and recommend that it be approved.

Elizabeth Cramer

Diana Valle-Riestra

Linda Spears-Bunton

Kyle Bennett

Patricia M. Barbetta, Major Professor

Date of Defense: June 20, 2012

The dissertation of Mary Kristina Gonzalez-Ledo is approved.

Dean Delia C. Garcia

College of Education

Dean Lakshmi N. Reddi

University Graduate School

Florida International University, 2012 
C Copyright 2012 by Mary Kristina Gonzalez-Ledo

All rights reserved. 


\section{DEDICATION}

I dedicate this dissertation to my boys; Jaden, Joshua, and Julian. Everything I do in this world, I do it for you. Mommy loves you more than words can express. 


\section{ACKNOWLEDGMENTS}

First and foremost, I would like to thank the members of my committee for their time and energy. I appreciate all comments and suggestions. Without your assistance and expertise, this dissertation would not have been possible. I would like to thank Dr. Kyle Bennett for his assistance in my graphs and understanding the intricacies in displaying the results in single subject design. A very special thank you should be extended to Dr. Cary Unzueta who was such an asset to this study in many ways. Finally, a thank you is not enough for my major professor, Dr. Patricia Barbetta. Without her firm yet unfailing support and confidence that I could do this, I would have never gotten through. Her guidance, knowledge, support, high expectations and at times, a firm hand, have helped me in more ways than just the completion of this degree. She has helped shaped me to be a better person.

I would also like to bestow a special thank you to my husband, Jose. His patience and understanding during some of the more stressful times during this long process is much appreciated. Jose, I love you! I would also like to acknowledge that it was a promise made to my father over 12 years ago that was the impetus for this journey. To my Aunt Norka, you are an inspiration to me in so many ways. Thank you for being a part of my life. Finally I would like to thank my mother, the person who single-handedly has more confidence and belief in me than any other person on the planet. Thanks for always being there and believing in me unconditionally. 


\begin{abstract}
OF THE DISSERTATION
THE USE OF COMPUTER GRAPHIC ORGANIZERS FOR NARRATIVE WRITING BY ELEMENTARY SCHOOL STUDENTS WITH SPECIFIC LEARNING
\end{abstract}

DISABILITIES

by

Mary Kristina Gonzalez-Ledo

Florida International University, 2012

Miami, Florida

Professor Patricia M. Barbetta, Major Professor

Writing is an academic skill critical to students in today's schools as it serves as a predominant means for demonstrating knowledge during school years (Graham, 2008). However, for many students with Specific Learning Disabilities (SLD), learning to write is a challenging, complex process (Lane, Graham, Harris, \& Weisenbach, 2006). Students SLD have substantial writing challenges related to the nature of their disability (Mayes \& Calhoun, 2005).

This study investigated the effects of computer graphic organizer software on the narrative writing compositions of four, fourth- and fifth-grade, elementary-level boys with SLD. A multiple baseline design across subjects was used to explore the effects of the computer graphic organizer software on four dependent variables: total number of words, total planning time, number of common story elements, and overall organization.

Prior to baseline, participants were taught the fundamentals of narrative writing. Throughout baseline and intervention, participants were read a narrative writing prompt and were allowed up to 10 minutes to plan their writing, followed by 15 minutes for 
writing, and 5 minutes of editing. During baseline, all planning was done using paper and pencil. During intervention, planning was done on the computer using a graphic organizer developed from the software program Kidspiration 3.0 (2011). All compositions were written and editing was done using paper and pencil during baseline and intervention.

The results of this study indicated that to varying degrees computer graphic organizers had a positive effect on the narrative writing abilities of elementary aged students with SLD. Participants wrote more words (from 54.74 to 96.60 more), planned for longer periods of time (from 4.50 to 9.50 more minutes), and included more story elements in their compositions (from 2.00 to 5.10 more out of a possible 6 ). There were nominal to no improvements in overall organization across the 4 participants.

The results suggest that teachers of students with SLD should considering use computer graphic organizers in their narrative writing instruction, perhaps in conjunction with remedial writing strategies. Future investigations can include other types of writing genres, other stages of writing, participants with varied demographics and their use combined with remedial writing instruction. 


\section{TABLE OF CONTENTS}

CHAPTER

PAGE

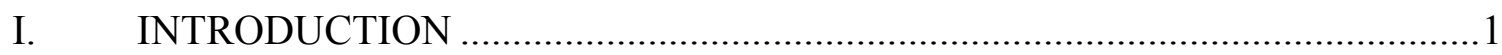

Educational Profiles for Students with Specific Learning Disabilities..................2

Writing Profiles for Students with Specific Learning Disabilities ........................4

Writing Strategies for Students with Specific Learning Disabilities .....................5

Purpose of the Study ..................................................................................6

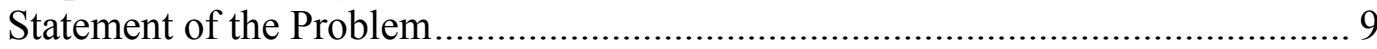

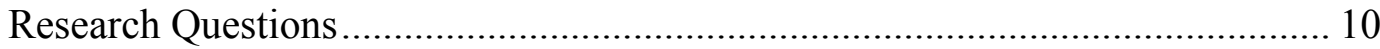

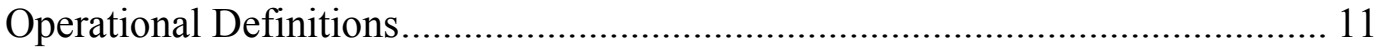

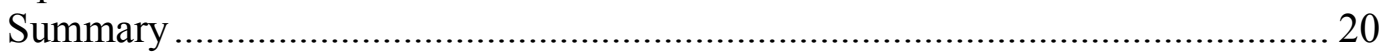

II. LITERATURE REVIEW ...................................................................... 21

Writing Genres in Elementary School ............................................................ 22

Educational Profiles of Students with Specific Learning Disabilities ................. 23

Writing Profiles of Students with Specific Learning Disabilities....................... 25

Writing Strategies of Students with Specific Learning Disabilities .................... 27

Definition of Graphic Organizers and Their Benefits....................................... 27

Graphic Organizers in Teaching and Learning .............................................. 28

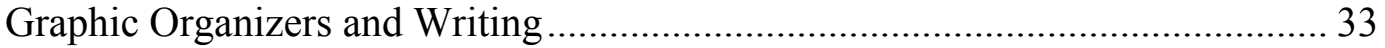

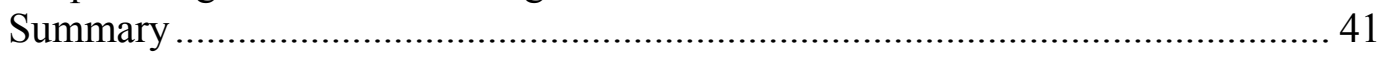

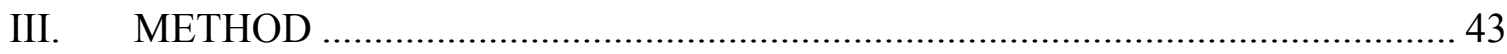

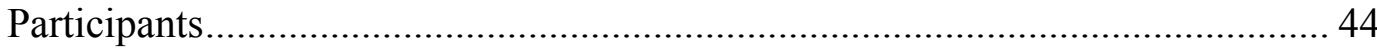

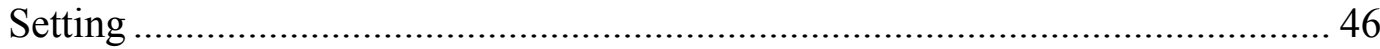

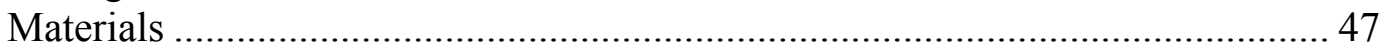

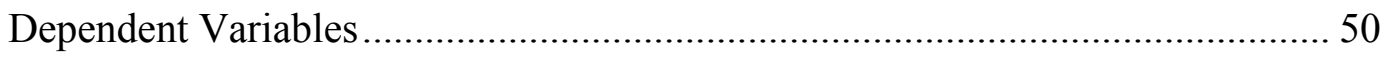

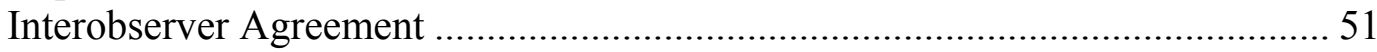

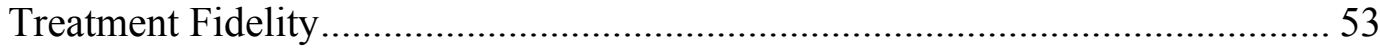

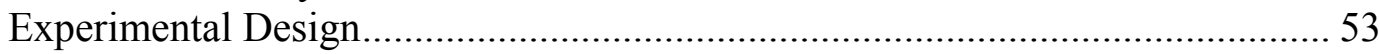

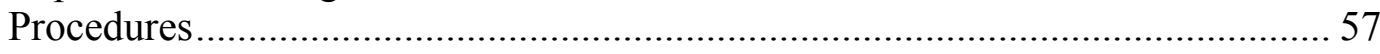

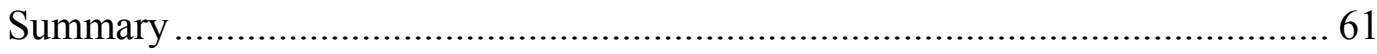

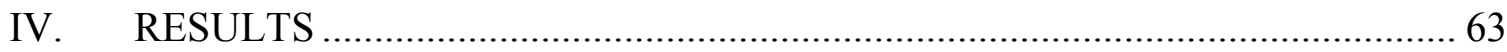

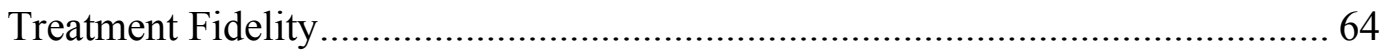

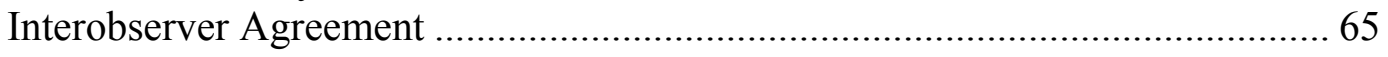

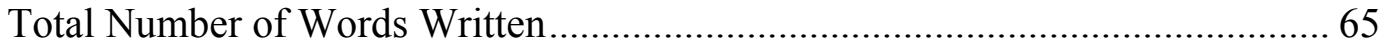

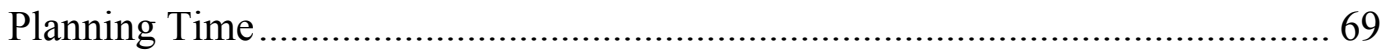

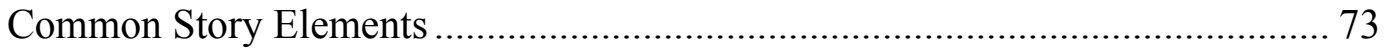

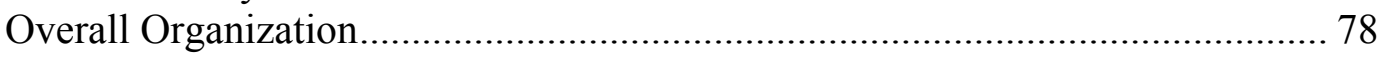

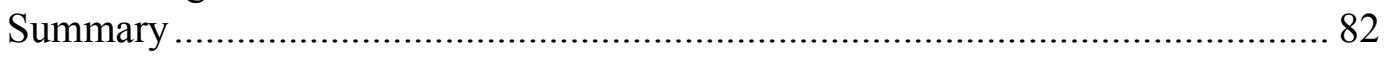




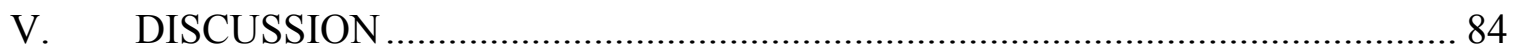

Total Words Written ..................................................................................... 85

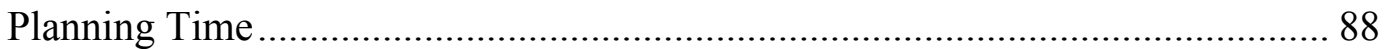

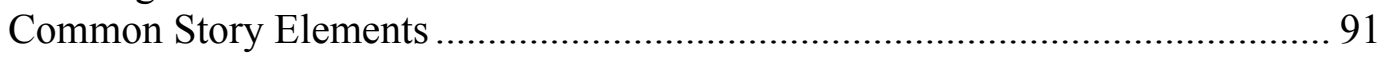

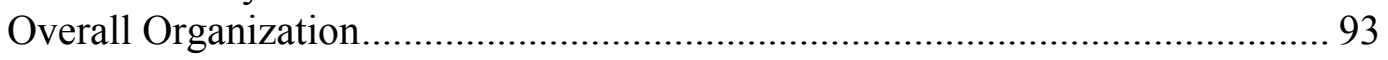

Summary of Results Across Dependent Variables ......................................... 95

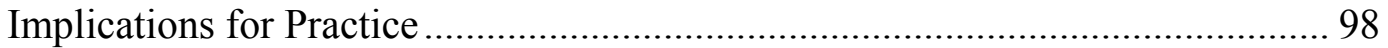

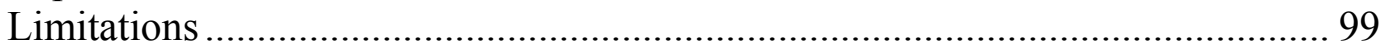

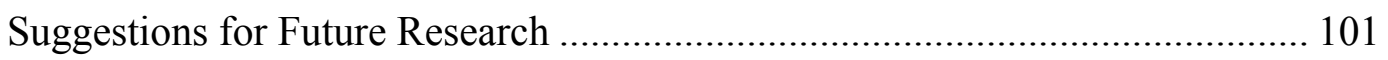

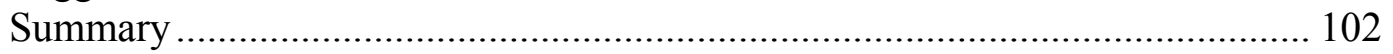

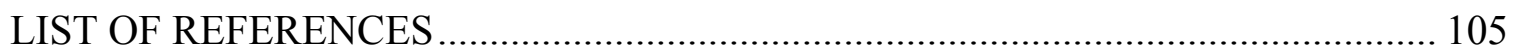

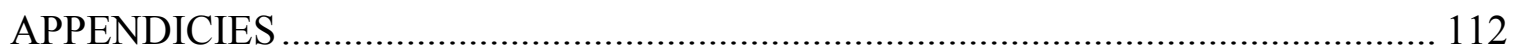

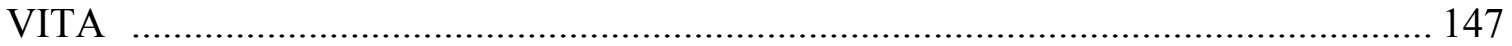




\section{LIST OF TABLES}

TABLE

PAGE

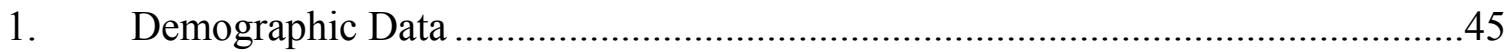

2. Total Words Written ....................................................................................68

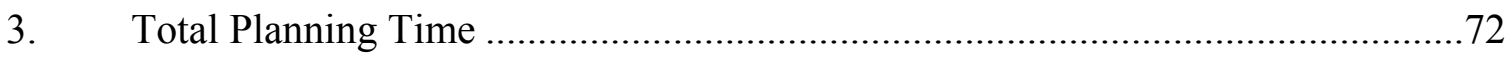

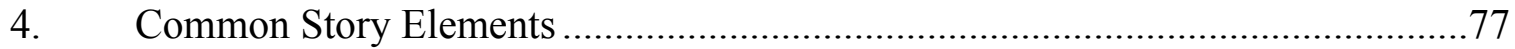

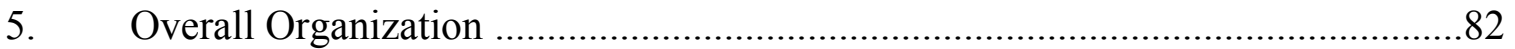




\section{CHAPTER I}

\section{INTRODUCTION}

Writing is an academic skill critical to students in today's schools as it serves as a predominant means for demonstrating knowledge during the elementary, intermediate, and secondary school years (Graham, 2008). However, for many students, learning to write is a challenging, complex process (Lane, Graham, Harris, \& Weisenbach, 2006). The National Assessment of Educational Progress (NAEP) Writing Assessment results showed that only $28 \%$ of all the fourth-grade students in the nation scored at or above the proficient level in writing (National Writing Project, 2003). As stated by Persky, Daane, and Jin (2003), by the fourth grade, half of the students who took the NAEP wrote so poorly that their writing skills did not meet the academic skills needed to master classroom expectations. Many students with specific learning disabilities (SLD) have substantial writing challenges largely related to the nature of their disability (Mayes \& Calhoun, 2005; Sitko, Laine, \& Sitko, 2005; Troia \& Graham, 2002).

SLD can be defined as one or more disorders that interfere with proper functioning of the brain, which affects the students' academic and or functioning skills which can be demonstrated as difficulties in the ability to listen, think, speak, read, write, spell, or perform mathematical calculations (Individuals with Disabilities Education Improvement Act (IDEIA; U.S. Department of Education, 2004). During the 2007-08 school years, approximately 6.6 million students received special education services. This total represents $13 \%$ of the nation's public school children. Of these students receiving special education services $39 \%$ received services related to a specific learning disability (U.S. Department of Education, National Center for Education Statistics, 2011). 


\section{Educational Profiles for Students with SLD}

Of the 6.6 million children with disabilities in the public school system, over 2.5 million of them have a SLD (U.S. Department of Education, National Center for Education Statistics, 2011). Many of these students struggle to learn at the same rate as their non-disabled peers. These challenges, as well as other difficulties associated with SLD, such as processing issues and perceptive discrepancies may cause many students with SLD to feel shame, frustration, and embarrassment (Chalk, Hagan-Burke, \& Burke, 2005).

The educational profile of students with SLD is generally one of increased difficulties in school when compared with the general student population (Swanson, 2000). This is likely due in part to the fact that many students with SLD have an underlying information-processing disability that interferes with their abilities to process the phonological aspects of language, thereby limiting success across academic subjects (Kuder, 2002).

Many students with SLD have difficulty with areas of cognition including perceptual organization, memory, concept formation, attention, and problem solving (National Joint Committee on Learning Disabilities, 2006). Communication skills, including speech/language form and content, for receptive and expressive purposes also tend to be weaker in students with SLD than their typical learning peers (Kuder, 2002). Often weaknesses in literacy including phonological awareness and awareness of print are evident. Some students with SLD suffer from social-emotional adjustment issues, including behavior, temperament, affect, self-regulation, play, and failing to exhibit appropriate social interaction (Kirk, Gallagher, \& Anastasiow, 2000; Olson \& Platt, 
2004). Related to their many challenges in school, some students with SLD begin to harbor resentment and tend to dislike school further intensifying their feelings of frustration (Kamps \& Greenwood, 2005). These emotions can manifest themselves in behaviors such as acting out, defiance, and/or a lack of focus. In fact, Mayer, Calhoun, and Crowell (2005) found that as many as $40 \%$ of students with SLD have poor attention skills, and that these students lacked academic focus. Ignoring this behavioral aspect of students with SLD can create a climate where the student is left further behind because of their poor behaviors as well as their academic abilities (Lane, Harris, Graham, Weisenbach, Brindle, \& Morphy, 2008).

Eventually feelings of frustration and pervasive off-task behaviors can create a discord with the educational system that can result in the students dropping out of school (Chalk et al., 2005). In fact, according to the Department of Education's Office of Special Education Programs (OSEP), only 32\% of students with disabilities graduate from high school. Given that a large portion of students with disabilities are categorized as SLD, it is safe to assume that many who are part of this $32 \%$ who fail to graduate have a SLD.

Fortunately, there is documented evidence of effective approaches to the education of students with SLD. For example, Swanson (2000) found that instruction that breaks learning into small steps with frequent monitoring and regular feedback is effective for students with SLD. Furthermore, the use of diagrams, graphics, and pictures to augment what students with SLD are saying in words as well as providing ample independent, well-designed, intensive practice are also documented as effective strategies. 
The Learning Disabilities Association of America (LDA; 2012) highlights that the practice of scaffolding (i.e., building on prior knowledge in order to facilitate new learning) has been proven to be highly effective with students with SLD. The LDA also indicates that effective practices includes focusing on individual achievement, individual progress, and individual learning combined with specific, directed, individualized, intensive remedial instruction.

\section{Writing Profiles for Students with SLD}

In numerous comparisons to typically-achieving students, students with SLD show moderate to severe academic skill deficits; particularly in the areas of literacy, language, and writing (Nelson, Benner, Neil, \& Stage, 2006). Particularly, these students tend to display deficits with written expression skills, have difficulty composing complete, grammatical sentences, and tend to have poor writing fluency (Chalk et al., 2005). Also, some students with SLD have difficulty organizing written information and struggle with poor handwriting and extremely poor alignment (Saddler, 2006). Research suggests students with SLD are becoming poorer writers (Mayes \& Calhoun, 2005).

According to Saddler (2006), students with SLD struggle with the execution of writing on two levels. The lower level includes grammar and spelling, and the higher level includes the planning and execution of writing as a process. Other writing challenges also noted by Saddler, include organizational skills, penmanship, spelling errors, issues with elaboration, and poor self-confidence. Also, many students with SLD have difficulty navigating the five stages of the writing process, including planning, organization, revising, editing, and publishing (Englert, Zhao, Dunsmore, Collings, \& Wolbers, 2007; Graham, Harris, \& Mason, 2005; McCormick, 2003; Saddler, 2006). 
As examples, students with SLD typically lack the academic skills needed to successfully formulate an idea or a topic, elaborate on the topic, remain on-topic, and ultimately put these thoughts in written form (Englert et al. 2007; Graham, Harris, \& Larsen, 2001; Monroe \& Troia, 2006; Nelson et al., 2006). These students typically stop after a first attempt between the stages of organization and revising and often fail to reach the editing or publishing stages of their written work products (Graham et al., 2001; Wong, 2000). Students with SLD often view writing as a one-time task and fail to realize that the writing process is cyclic in nature (Englert et al., 2007; Wong, 2000). Finally, they typically produce compositions that lack an awareness of the audience, are short in length, and lack substance (Deatline-Buchman \& Jitendra, 2006).

\section{Writing Instructional Strategies for Students with SLD}

Overall, strategies that utilize explicit instruction of text structure combined with the use of tools that organize ideas into expected relationships have been shown to be highly effective in teaching writing to student with SLD (Baker, Gersten, \& Graham, 2003; Englert et al., 2007). There are a variety of approaches with these characteristics including scaffolding (a process which involves segmenting instructions into smaller more manageable parts), Self-Regulated Strategy Development (SRSD; a process of teaching children to monitor their own progress in certain procedures and /or selfregulation of academic behaviors), and graphic organizers (Ayers, Boon, Fore, \& Spencer, 2005; Birbili, 2006; Blair, Ormsbee, \& Brandes, 2002; Boon, Fore, \& Spencer, 2007; DiCecco \& Gleason, 2002; Englert et al., 2007; Graham et. al, 2005; Lin, Strickland, Ray, \& Denner, 2004; Lorber, 2004; Sturm \& Rankin-Erickson, 2002; Unzueta \& Barbetta, 2012; Zollman, 2009). 
This study focused on the use of graphic organizers as a strategy for helping the writing of student with SLD. Graphic organizers are visual representations that portray relationships among key concepts and form a schematic mapping for this information (DiCecco \& Gleason, 2002). Only five studies were found that investigated the use of graphic organizers as a writing strategy (i.e., Blair et al., 2002; Lin et al. et al., 2004; Lorber, 2004; Sturm \& Rankin-Erickson, 2002; Unzueta \& Barbetta, 2012). Of these studies, only three were with students with disabilities (i.e., Blair et al., 2002; Sturm \& Rankin-Erickson, 2002; Unzueta \& Barbetta, 2012). All studies found that there was a positive correlation between the use of graphic organizers and an improvement in student writing.

\section{Purpose of the Study}

Writing is especially difficult for students with SLD (Harris, Graham, \& Mason, 2006). These students score well below average on the NAEP and other standardized writing assessments (Salahu-Din, Persky, \& Miller, 2008). Given the importance of writing during the academic years, having significant difficulties in writing places students with SLD at a disadvantage (Graham, 2008). As cited by Graham, these students are less likely than their more skilled classmates to use writing to support and extend learning Their grades are likely to suffer, particularly in classes where writing (e.g., through tests, reports) is the primary means for assessing students' knowledge (Graham, 2008), and they are less likely to attend college, as writing is now commonly used to evaluate applicants' qualifications (Martin, Martin, \& Carvahlo, 2008).

Given that deficits in writing can negatively affect students throughout their school years and beyond (Graham et al., 2001), it is especially important that the writing 
needs of students be addressed in the primary grades. There is a growing consensus that waiting until later in a student's school career to address literacy difficulties that began in early elementary school is not particularly successful (Slavin \& Madden, 2001).

Providing effective writing instruction to young students should reduce the number of students who fail to develop the writing skills needed to fully meet classroom demands in higher grades (Graham et al., 2001). Of the many types of writing genres that students are required to produce in schools, narrative writing is one of the more difficult to master. Narrative writing involves the production of stories or personal compositions, and it requires that the writers use their creativity and powers of observation to develop stories. However, students with SLD have difficulty planning, generating ideas, revising, and transcribing words onto paper (Graham et al., 2005; Monroe \& Troia, 2006) all of which are skills needed for narrative writing. Often students with SLD tend to produce stories that are evaluated as poorer than those written by students without SLD (Graham et al., 2005). The stories produced by students with SLD are usually shorter, less well-organized, and contain a greater number of mechanical errors than those compositions produced by their non-disabled peers (Dockrell, Lindsay, Connelly, \& Mackie, 2007). Furthermore, many students with SLD lack the knowledge base of the various components of a story and thus produce compositions that are more difficult to follow (Swanson, Harris, \& Graham, 2003). A promising approach to support the narrative writing skills of students with SLD is the use of computer graphic organizers, as research has shown that their use can assist students in organizing information and creating an increased understanding across subject areas (DiCecco \& Gleason, 2001). Graphic organizers have been shown to assist in the connection of key 
concepts and in the building of schema (Vaughn, Bos, \& Schumm, 2011) and have been researched extensively with reading comprehension and across multiple other subjects (e.g., DiCecco \& Gleason, 2002; Kim, Vaughn, Wanzek, \& Wei, 2004; Sitko et al., 2005). However, its use as an intervention for improving students' writing has not been as well documented.

Only five studies were identified that involved the use of computer graphic organizers in order to assist students with disabilities with writing (i.e., Blair et al., 2002; Lin et al., 2004; Lorber, 2004; Sturm \& Rankin-Erickson, 2002; Unzueta \& Barbetta, 2012). Of these five studies, two focused on narrative writing (i.e., Blair et al., 2002; Lin et al., 2004). Sturm and Rankin-Erickson focused on expository writing styles, and Unzueta and Barbetta focused on the persuasive writing genre. Of the aforementioned studies, Blair et al., Sturm and Rankin-Erickson, and Unzueta and Barbetta all had students with SLD as participants and employed the use of computer graphic organizers for the planning phase of writing. All of the studies concluded that graphic organizers positively influenced the word count, syntactical maturity, and organization of the participants' compositions.

Regardless of the genre that each respective study chose to research, all the authors recommended that additional research is needed to further demonstrate the use of computer graphic organizers in writing. This is because in most cases, single subject design research was utilized in these studies and direct and systematic replications are necessary for generalization of results (Cooper, Heron, \& Heward, 2007).

Furthermore, single subject designs provide a means to provide repeated experimentation in order to provide evidence if an intervention or teaching strategy can 
be deemed as effective. Single-subject design is a useful research tool that investigates interventions with systematic replication, ultimately providing evidence that an intervention is effective (Horner, Carr, Halle, McGee, Odom, \& Wolery, 2005). This study was guided by the continued need to research effective strategies to improve the writing skills of students SLD and was designed as an extension of Unzueta and Barbetta (2012) on the use of computer graphic organizers by students with SLD. This study investigated the use of graphic organizers to improve the narrative writing skills of elementary school students with SLD, and as such extended the limited existing literature.

In conclusion, students with SLD have many problems academically, including difficulties with their writing. Many strategies, such as scaffolding and SRSD have been researched with some promise of assisting these students. Also, graphic organizers have been found to be effective in a limited number of research studies. This study was guided by the need to improve the narrative writing skills of students with SLD. Furthermore, it was designed to extend the limited research on the use of computer graphic organizers by students with SLD.

\section{Statement of the Problem}

This study investigated the effects of the computer graphic organizer software, Kidspiration 3.0 (2011, on the narrative writing skills of elementary school students with SLD. This study extends the limited research conducted on the use of computer graphic organizers and writing with students with SLD. Most specifically, this study extends the work of Unzueta and Barbetta (2012) which investigated the effects of computer graphic organizers on the persuasive writing skills of four middle school Hispanic students with 
SLD. Generally speaking, they measured the participants' time spent planning, number of arguments and supporting details found in planning with and without computer graphic organizers and in the written composition, and the number of arguments and supporting details that transferred from the planning to the written composition. Also measured in their study were fluency, word count, and syntax.

Similar to Unzueta and Barbetta (2012), this study focused on students with SLD and also had four participants with SLD. Unlike Unzueta and Barbetta's study which focused on persuasive writing, the current study focused on narrative writing. Further differentiation is that this study had participants at the elementary level, whereas the participants in Unzueta and Barbetta were at the middle school level. This research measured the number of words written in compositions, participant time spent planning, and overall organization as was measured in Unzueta and Barbetta's study. Unique to this study, however, was the measurement of common story elements. Finally, this study used Kidspiration 3.0 (2011) instead of Inspiration 8.0 (2008) which was used by Unzueta and Barbetta. Kidspiration 3.0 is a computer-based program that creates a method of putting academic concepts in graphic organizers designed for students from kindergarten through fifth grade, while Inspiration 8.0, a similar program made by the same company, is designed for grades sixth through 12 th.

\section{Research Questions}

The following research questions were investigated:

With or without the use of the computer graphic organizer software Kidspiration 3.0 (2011) during the planning stage of writing and maintaining writing time as a constant: 
1. Is there a difference in the total number of words written in narrative writing compositions by elementary participants with SLD?

2. Given as much as 10 minutes to plan their writing, is there a difference in how long the participants spend on planning?

3. Is there a difference in the number of common story elements generated during planning that appeared in the compositions?

4. Is there a difference in the overall organization of their narrative writing as measured by an analytical scoring rubric?

\section{Delimitations of the Study}

Due the nature of single subject design research, the results had certain built-in exclusions, and generalization is limited. The findings are preliminary in nature with initial results concentrated solely on elementary students with SLD while planning and composing narrative writing. Participants were given the topic to write about and were not permitted to share ideas amongst their classmates. Further, only two parts of the writing process were investigated in this study, planning and organization. Thereby, generalization of results cannot be extended to other parts of the writing process.

\section{Operational Definitions}

\section{Analytical Scoring Rubric}

A means of measuring performance of students by assigning specific criterion in scoring. The analytical scoring guide used in this study was adapted from Monroe and Troia (2006) and Unzueta and Barbetta (2012). 


\section{Beginning}

For the purposes of this study, the beginning is a part of common story elements. Beginning is the start or origin of the story and can appear in planning and/or the composition. Beginning was measured using a scoring guide where a rater evaluated planning and determined if a beginning was evident, they then proceeded to check of a beginning. Then the rater evaluated the final composition, if this beginning, that originally appeared in planning was in the composition, the rater scored it as an occurrence. If beginning appeared in both the planning and the composition then it counted as having the common story element of beginning.

\section{Character}

For the purposes of this study, characters are a part of common story elements. Characters are who the story is about and can appear in planning and/or the composition. Character was measured using a scoring guide where a rater evaluated planning and determined if a character was evident, they then proceeded to check the box for character. Then the rater evaluated the final composition. If this character that originally appeared in planning was in the composition, the rater indicated evidence of character. If a character appeared in both the planning and the composition, then the rater scored it as an occurrence.

\section{Common Story Elements (Character, Setting, Beginning, Middle, End, and Conflict}

For the purposes of this study, common story elements refer to the (a) characters or the "who," (b) the setting or the "where" and 'when" of the story or novel, (c) beginning, the start of the story, (d) the middle or the plot of the story which took place 
after the beginning, (e) the end or how the story was culminated, and (f) conflict, the "problem."

\section{Computer Graphic Organizers}

Computer graphic organizers are graphic organizers (visual representations of knowledge, concepts or ideas) created using computer software. In this study the computer graphic organizer was created using the Kispiration 3.0 (2011) program. The researcher developed the template using the program and incorporated the tenets of narrative writing.

\section{Conflict}

For the purposes of this study, conflict is one of common story elements. Conflict is the problem of the story. Conflict was measured using a scoring guide where a rater evaluated planning and determined if a conflict was evident. If so, that was recorded. Then the rater evaluated the final composition, if a conflict that originally appeared in planning was in the composition, the rater scored it as an occurrence. If a character appeared in both the planning and the composition then it counted as having the common story element of conflict.

\section{Disagreement}

Disagreement is when the researcher and the rater differ in the scoring of the dependent variables (Cooper et al., 2007).

\section{Editing}

Editing is the process of making meaningful and thoughtful changes in the organization of the writing and adding statements that need more supports (Wong, 2000). 
After reorganization has occurred, corrections to grammatical errors and spelling are also included in the editing phase.

\section{Ending}

For the purposes of this study, ending is one of common story elements. The ending of the story is what culminates the story arc. It follows the middle of the study, and for the purposes of this study was how the conflict, if available, was solved. In this study, ending was measured using a scoring guide where a rater evaluated the participant's planning document and determined if an ending was evident. Then the rater evaluated the final composition. If this ending that appeared in planning was also in the composition, the rater checked the ending box on the scoring guide. If an ending appeared in both the planning and the composition then it counted as having the common story element of end.

\section{Exact Agreement Interobserver Agreement}

In this type of interobserver agreement (IOA), the observation of the exact same and number of occurrences was noted for each observer. Then the smaller number was divided by the larger number and divided by 100 (Cooper et al., 2007).

\section{Graphic Organizers}

Graphic organizers are organizational frameworks which the identification, organization, and structure of ideas becomes a visual component of learning. In writing, graphic organizers help brainstorm new ideas that connect to the main theme of the writing piece, create concept maps relating the new ideas, and outline the ideas to help write an essay. These frameworks provide students a vehicle that becomes a component 
of the planning stage in writing (Baker et al., 2003; Englert et al. 2007; Vaughn et al., 2000).

\section{Inspiration Software}

A software program that utilizes picture-based graphic organizers as a means in displaying academic concepts designed for students from sixth through twelfth grade.

\section{Instructor}

Refers to either the researcher or teacher research assistant when each was leading the research session.

\section{Interobserver Agreement (IOA)}

IOA is the degree of agreement between two independent observers (Cooper et al., 2007). For the purposes of this study, two methods of collecting agreement were employed: Exact Agreement and Total Count Agreement. See operational definitions of Exact Agreement IOA and Total Count IOA.

\section{Kidspiration 3.0 (2011) Software}

A software program that utilizes picture based graphic organizers as a means in displaying academic concepts designed for students from kindergarten through fifth grade.

\section{Middle}

For the purposes of this study, middle is a common story element. The middle of the story is what happens after the beginning of a story and before the culmination of the story. Middle was measured using a scoring guide where a rater evaluated planning and determined if a middle was evident. Then the rater evaluated the final composition, if this middle, that originally appeared in planning was in the composition, the rater 
checked the middle box on the scoring sheet. If a middle appeared in both the planning and the composition then the rater scored it as an occurrence.

\section{Multiple Baseline Design Across Subjects Design}

A multiple baseline design across subjects is a type of single subject design. In this design, the treatment variable is applied to the same behavior of two or more subjects in the same setting in a staggered fashion (Cooper et al., 2007). A multiple baseline design allows for the prediction, verification, and replication of behaviors (Cooper et al., 2007). Prediction was achieves when baseline conditions continued for other participants while simultaneously a treatment effect was observed for the participant under intervention conditions. Verification will be achieved by comparing the treatment results among the participants. Replication was achieved by following this process multiple times for each participant.

\section{Narrative Writing}

The primary purpose of narrative writing is to describe an experience, event, or sequence of events in the form of a story. The purpose is to tell and /or entertain a reader. For the purposes of this study the type of narrative writing that will be utilized is story-telling.

\section{Organization}

Organization refers to the overall structure of a composition. For the purposes of this study, overall organization was measured using an analytic scoring guide. The analytical rubric focused on six areas in each of the essays: content, sentence fluency, organization, word choice, conventions, and presentation. These six areas were scored from one through six with one being poor and six being excellent. The average of these 
six areas gave the essay its score. Other aspects of narrative writing, such as voice and intent were purposefully left out of this rubric.

\section{Planning}

Planning is the work a writer does, such as, thinking, brainstorming, or outlining, before he or she begins to actually write (Kunka et al., 2007).

\section{Publishing}

Publishing is the fifth stage of the writing process. This is where the writer prepares his or her writing to be shared with an audience (Graham et al., 2001).

Publishing in school could consist of presentations to the class or others, posting of work, or actual submission of work to competitions or magazine

\section{Resource Room}

For the purposes of this study, a resource room is a separate classroom or lab where students with disabilities receive special education services outside of the regular education classroom. It is sometimes referred to as a pull-out approach.

\section{Scaffolding}

Scaffolding is an instructional technique in which the teacher models a learning strategy and then teaches the strategy in sequential steps to the student. The student works on each part of the strategy with the teacher providing assistance and support as needed until independence is reached (Hammond \& Gibbons, 2001).

\section{Self-Regulated Strategic Planning}

Self-regulated strategic planning (SRSD) is when the student is monitoring his or her own writing and motivation for writing (Graham et al., 2005). Goal setting and selfmonitoring of writing progress are major components of SRSD. 


\section{Specific Learning Disabilities (SLD)}

Specific Learning Disabilities (SLD) is the term used to describe a disorder in one or more of the basic psychological processes needed to understand or use language, spoken or written. This disorder may manifest itself in the imperfect ability to listen, think, speak, read, write, spell, or do mathematical calculations (U.S. Department of Education, 2004).

\section{Total Count Interobserver Agreement (IOA)}

For the purpose of this study total count IOA was utilized for the dependent variables of total words written, minutes planning, and overall organization. Each of these dependent variables was observed by the researcher and the teacher research assistant. The smaller number counted was divided by the larger of the number counted and then that sum was multiplied by 100. This number was the Interobserver Agreement.

\section{Writing}

Writing has been widely accepted as a process oriented approach requiring the coordination and integration of the writing process which consists of planning, organization, revising, editing, and publishing (Scott \& Vitale, 2003). In this study, writing refers to the formal composition writing found in school which is composed of having and knowing how to use prior knowledge on topics, writing genres and conventions while using the writing process (Scott \& Vitale, 2003).

\section{Writing Process}

The writing process is a cyclical process generally composed of five stages: prewriting, drafting or organization, revising, editing, and publishing (Wong, 2000). The 
writing process as defined in this study follows three stages: planning, organization, and revising and editing (Englert et al., 2007).

\section{Summary}

Writing is a critical academic skill to possess. Failure to write effectively can ultimately be a precursor to academic failure and poor adult outcomes. Given that only $28 \%$ of fourth grade students scored at or above the proficient level in writing (Englert et al., 2007) and half of the fourth-grade students who took the NAEP wrote so poorly that their writing skills are not meeting the academic skills needed to master classroom expectations (Persky et al., 2003), there clearly is a need for the identification of effective writing strategies that can easily be utilized by teachers.

Research demonstrates that many students with SLD have difficulty navigating the writing process (Englert et al., 2007; Graham et al., 2001; Kunka, et al., 2007; McCormick, 2003). In general, these students have difficulty with all aspects of writing including transcription skills of handwriting, spelling, punctuation, language skills needed for sentence formation, and planning and revising processes (Monroe \& Troia, 2006). In comparison to typically-achieving peers, the compositions of students with SLD are generally shorter, less organized, lower in quality, less varied in vocabulary, and contain more spelling and sentence-formation errors (Troia \& Graham, 2002). In addition, students with SLD have a less sophisticated understanding of the requirements of good writing and less knowledge about genre and text structure organization (Englert et al., 2007).

A strategy that has been particularly successful with students with SLD across a variety of subject areas is graphic organizers (DiCecco \& Gleason, 2002). Graphic 
organizers are pictorial or graphical methods to organize information and thoughts. Graphic organizers can be used to create meaningful diagrams to assist the writer to expand and explain a concept, create clear and concise relationships, and improve his or her organization (DiCecco \& Gleason, 2002; Kim et al., 2004).

Only five prominent studies were found that investigated the effects of computer graphic organizers on students' writing (Blair et al., 2002; Lin et al., 2004; Lorber, 2004; Sturm \& Rankin-Erickson, 2002; Unzueta \& Barbetta, 2012). Of these, only three were used with students with disabilities (Blair et al., 2002; Sturm \& Rankin-Erickson, 2002; Unzueta \& Barbetta, 2012). All five of the aforementioned studies demonstrated an improvement in students' writing.

As an extension of a previous study conducted by Unzueta and Barbetta (2012) and others, this study used a multiple baseline design across subjects to examine the effects of the computer graphic organizer on the narrative writing of elementary school students with SLD. In particular, this study specifically investigated the time spent planning, number of commonly accepted story elements in the planning and writing stages, total number of words written, common story elements, and overall organization of the writing. 


\section{CHAPTER II}

\section{LITERATURE REVIEW}

Many students experience difficulties mastering the process of writing. Data from the National Assessment of Educational Progress (NAEP) demonstrates that three-of-four 4th-, 8th-, and 12th-grade students exhibit only partial mastery of necessary skills needed to write effectively. Only $1 \%$ of students with Specific Learning Disabilities (SLD) demonstrate "advanced" skills in writing (Persky et al., 2003).

Writing can be challenging because learning to write requires a student to plan, generate content, organize their compositions, place content into written language, and revise and improve their initial draft (Swanson et al., 2003). Students who are at particular risk for difficulties with written expression are students with SLD. Students with SLD are generally at risk for academic underachievement (Barry, Lyman, \& Klinger, 2002) and are likely to experience difficulties with all aspects of the writing process. Subsequently, this study was designed to identify effective writing strategies for students with SLD.

This chapter contains a review of the literature as it relates to this study. First, presented is a discussion of the writing genres in elementary schools, with more detail paid to narrative writing, the focus of this study. This is followed by a discussion on the educational profiles of students with SLD, the writing profiles of these students, and a review of relevant research related to writing strategies. An in-depth review of the definitional characteristics of graphic organizers follows. In this section there is a summary of how graphic organizers are effectively utilized in teaching. Finally, a 
synopsis of the research available on the use of graphic organizers and computer graphic organizers to assist writing is presented.

\section{Writing Genres in Elementary School}

The NAEP Writing Assessment examines the writing of students across three major writing genres: (a) narrative, (b) expository, and (c) persuasive. Each writing genre requires the use of an introduction, supporting details, and a conclusion. In general, the skills needed for writing in each area are similar. However, each genre has unique requirements that should be taught. The differences among these genres are in the purpose, style, and format of the written essay.

The focus of this study was the narrative writing genre. Mastering this genre of writing is critical in elementary school as it is the most utilized both in standardized testing, in the creation of reports, and it is used in many different subject areas (Wong, 2000). Examples of this genre are articles, reports, creative writing prompts, and answers to formal and informal assessment questions. With narrative writing, the writer tells a story to the reader and, as such, can be described as story-telling writing. Narrative writing has clear ideas, a purpose or focus, and should include specific ideas and details.

There are two distinctive kinds of narrative writing, creative and non-fictional. Nonfictional narrative writing is often used to recount a person's life story, important historical events, or news stories. For the purpose of this study the form of creative writing that was utilized is story-telling writing. Story telling narrative writing has a plot, a setting (where and when the story happens), and characters with motives (reasons) for what they do. 
Narrative writing incorporates distinctive traits that make this genre necessary for all children to master. For example, narrative writing must be organized, have voice or appeal to an audience, have correct word choice, have sentence fluency and finally, have correct grammatical conventions.

\section{Educational Profiles of Students with Specific Learning Disabilities}

SLD can be defined as one or more disorders that interfere with proper functioning of the brain, which affects the students' academic and/or functioning skills which can be demonstrated as difficulties in the ability to listen, think, speak, read, write, spell, or perform mathematical calculations (U.S. Department of Education, 2004). During the 2007-08 school year, approximately 6.6 million children and youth received special education services. This total represents $13 \%$ of the Nation's public school children. Of these children receiving special education services, $39 \%$ received them for a SLD (U.S. Department of Education, National Center for Education Statistics, 2011).

Of the 6.6 million children with disabilities in the public school system, over 2.5 million of them have SLD (U.S. Department of Education, National Center for Education Statistics, 2011). Many of these students struggle to learn at the same rate as their nondisabled peers (U.S. Department of Education, National Center for Education Statistics, 2011), and they have increased difficulties in school when compared with the general student population (Swanson, 2000). This is likely due in part to the fact that many students with SLD have an underlying information-processing disability that interferes with their abilities to process the phonological aspects of language, thereby limiting success across subject areas (Kuder, 2002). Many students with SLD perform below their peers in the basic academic skills of reading, mathematics, and writing (Olson \& Platt, 
2004). Problems in processing information are also typical of students with SLD. Memory problems, for example, are common among students with learning and intellectual disabilities (Raymond, 2004) and could interfere with recall information presented in lecture and class discussion. Other examples of processing deficits common among students with learning and other mild disabilities include problems with visual processing and auditory processing (Kirk et al., 2000). Visual processing problems make it difficult for students to understand science illustrations and demonstrations shown to the class, whereas auditory processing deficits interfere with the ability to follow class discussions of science experiments, hypotheses, results, and conclusions.

Organizational deficits are also symptoms of students with SLD (Kirk et al., 2000). This difficulty often leads to problems in school when students are required to follow certain timelines for assignments and lessons. They may have trouble organizing the materials, keeping their notes in the appropriate format, and putting materials in the proper locations for safety and efficiency in the classroom (Raymond, 2004).

Attention problems are typical of many students with intellectual, learning, and behavioral disabilities (Olson \& Platt, 2004). These students have difficulties, for example, following directions, following through on all steps for an assignment, and attending to lessons that require extended periods of concentration. Furthermore, generalization is a difficult task for students with SLD (Raymond, 2004). A student who has trouble generalizing will not be able to apply these same steps in a variety of situations. The steps only seem applicable to the specific situation in which they were learned and first practiced. 
Behaviors such as acting out, defiance, and a lack of focus are common. In fact, Mayer et al. (2005) found that up to $40 \%$ of students with SLD also have poor attention skills. They found that many of these students lack focus, increasing the difficulty in all academic areas. These challenges, as well as other difficulties associated with SLD cause many of these students to feel shame, frustration, and embarrassment (Chalk et al., 2005). Many students with SLD begin to harbor resentment, and they tend to dislike school further intensifying their feeling of frustration (Kamps \& Greenwood, 2005). These emotions can manifest themselves in behaviors such as acting out, defiance, and a lack of focus.

\section{Writing Profiles of Students with SLD}

Many students with SLD have difficulties at each stage of the writing process. In the planning stage, many students with SLD often simply focus on the spelling and syntax (Graham et al., 2001; Wong, 2000). They struggle in formulating their ideas and expanding on the subtopics (Englert et al., 2007; Graham et al., 2001; Montgomery \& Moreau, 2004). During the second stage of the writing process, organization, some students with SLD have problems logically organizing a paragraph in a sequential manner (Englert et al., 2007; Graham et al., 2001; Wong, 2000). In the next stage of the writing process, revising, many of these students do not look for ways to improve their compositions, (i.e., improving word choice), but rather search for grammatical errors merging into the fourth stage, editing (De la Paz \& Graham, 2002; Graham et al., 2001; Wong, 2000). Many students with SLD never reach the final stage of writing, publishing, due to the problems encountered in the previous stages (Graham et al., 2001; Wong, 2000). 
A multitude of studies have investigated the writing of students with SLD and have found that these students consistently show difficulties with their regulating strategies (i.e., Englert et al., 2007; Graham, 2008; Saddler, Moran, Graham, \& Harris, 2004; Wong, 2000). Graham et al., (2005) found that students with SLD have difficulties approaching the writing task with regards to text composition in a measured capacity. In other words, they have difficulty ultimately planning their writing as a process. A similar study by Saddler et al. found students with SLD have difficulty in generating ideas that can be put in written form, and that they have difficulties putting together thoughts in written form so that they make sense. Instead, Saddler et al. found that quite often students with SLD put together their writing topics in an associative manner, creating compositions that are unclear and a jumble of semi-related information. Students with SLD also lack knowledge of text structure (Englert et al., 2007).

Research indicates there are several underlying issues that interfere with the attainment of proficiency levels in writing for students with SLD. In numerous comparisons to typically-achieving students, students with SLD show moderate to severe academic skill deficits, particularly in the areas of literacy, language, and writing (Mattison, Spitznagel, \& Felix, 1998; Nelson et al., 2006). These students tend to display deficits with written expression skills, have difficulty composing complete, grammatical sentences, and tend to have poor writing fluency (Chalk et al., 2006). Also, students with SLD may struggle with poor handwriting and poor alignment (Saddler, 2006). Graham et al., (2005) investigated writing and found that students with SLD have issues with planning, launching, presenting, and advancing a writer's thought in a clear consistent fashion. 


\section{Writing Strategies for Students with Specific Learning Disabilities}

Research on writing instruction for students with SLD has led to the development of various writing strategies used in schools today. For example, scaffolding involves the technique of having the student work on each part of a lesson with the teacher providing assistance and support as needed until independence is reached (Hammond \& Gibbons, 2001). Another important strategy, self-regulated strategic planning (SRSD), involves a student self-monitoring their own writing by creating goals and following checklists in order to create writing samples (Graham, 2008). Finally, graphic organizers have been shown to be an effective strategy in teaching writing (i.e., Ayers et al., 2005; Boon et al., 2007; Birbili, 2006; Blair et al., 2002; DiCecco \& Gleason, 2002; Englert et al., 2007; Lin et al., 2004; Lorber, 2004; Sturm \& Rankin-Erickson, 2002; Unzueta \& Barbetta, 2012; Zollman, 2009). However, for the purpose of this study only graphic organizers will be reviewed.

\section{Definition of Graphic Organizers and their Benefits}

A graphic organizer can be defined as a visual and graphic display that depicts the relationships between facts, terms, and ideas within a learning task. Graphic organizers are also referred to as knowledge maps, concept maps, story maps, cognitive organizers, advance organizers, or concept diagrams (Strangman, Hall, \& Meyer, 2003). Graphic organizers have multiple benefits. These benefits include helping learners grasp the material by assisting in seeing the relationships between ideas, concepts, or authors. Graphic organizers also assist in memory recall. Finally, graphic organizers encourage the use of developing higher-level thinking skills by assisting students to synthesize and integrate information, ideas, and concepts. Ellis and Howard (2007) stated that graphic 
organizers are effective across subject areas because they provide visual cues designed to assist students in their understanding of information by organizing information. According to Yin, Vanides, Ruiz-Primo Ayala, and Shavelson (2005), graphic organizers allow students a means of creating connections by visually showing relationships among concepts.

\section{Graphic Organizers in Teaching and Learning}

Graphic organizers have been used successfully across subject areas for many years (e.g., Boon et al., 2007; Lenz, Adams, Bulgren, Pouliot, \& Laraux, 2007; Zollman, 2009). Students with and without SLD have been shown to benefit from their use in helping to organize information and assist in the recalling of previous information (DiCecco \& Gleason, 2002). Numerous studies have been conducted that demonstrated a positive correlation between the use of graphic organizers and students' recalling of information. A few will be highlighted across various subjects.

In a meta-analysis review of graphic organizer research in reading, Kim et al., (2004) revealed that a variety of types of graphic organizers are used in reading. Graphic organizers such as story mapping, and webbing that elaborated on comprehension, and story structure were used in the variety of research studies. Their research further indicated that all graphic organizer types were associated with improved reading comprehension for students with SLD.

In mathematics, graphic organizers have been used as a means to systematically practice equations, outline real-world math processes, and put into mimic form word problems that students sometimes have problems visualizing (Zollman, 2009). For example, Zollman conducted an action research project that examined the use of 
modified graphic organizers by third- through fifth-grade students. Graphic organizers were used in lieu of conventional problem-solving in mathematics. There were approximately 240 participants in grades 3 through 5 . Students were given pre- and posttests comparing the results between problems solved using a graphic organizer and problems solved using conventional problem solving (paper and pencil). The results of the study revealed that the use of graphic organizers produced a 44 percentage point increase in participants' achievement on open-response mathematical problem solving.

Graphic organizers have been used in social studies as well. Mastropieri, Scruggs, Abdulrahman, and Gardizi (2002) implemented a study in secondary world history classes comparing the effects of using graphic organizers created using the Inspiration (2008) software and a more traditional teacher lecture instructional approach. The study utilized a crossover design where inclusive tenth-grade classes containing students with and without disabilities were taught how to use the software to study world history content. Templates were developed using Inspiration software that organized the content conceptually from all of the chapters in the study. There were two conditions throughout the study. In the first condition, spatial organization, students spent time in the computer lab learning to use the software. All students were given disks containing the directions and practice templates for learning to use the software. Once the actual unit of instruction began, students were given spatial organizers containing the general outline with blank boxes for the content for their respective chapters. During teachers' presentation of the content in the classroom, students were asked to take notes using their spatial organizers. After the lecture, the students then transferred their notes into saved templates. Following this, they printed out spatially organized and outline views of the content for studying 
independently. In the second condition, the traditional instruction condition, teachers presented information relevant to the respective chapters, but they did not use any spatially organized framework. Pre- and post-testing indicated that students learned significantly more (about 32 percentage points more) world history content when they were allowed to use the spatial organizers that were developed using the Inspiration (2008) software.

Ayres et al. (2005) piloted a study that implemented a one-group, nonrandomized, pre-posttest design. One group of students was observed to evaluate the effectiveness of technology-based instruction using a cognitive organizer designed using the Inspiration 8 (2008) software. A pretest/posttest treatment control group methodology was used to examine the impact of cognitive organizers, with the integration of technology (i.e., Inspiration 6 software) content-area learning in high school inclusive social studies classes. Twenty-nine, tenth-grade students in general education and 20 students with mild disabilities were randomly assigned to receive instruction using a graphic organizer generated by the Inspiration software. The graphic organizer was printed out and handed to the students to use as a note-taking device during the lectures. Dependent measures included a 35-item, open-ended pre/posttest of declarative social studies knowledge to assess the effectiveness of the intervention. This resulted in a mean pretest score during the graphic organizer condition of $0.4(S D=.9661$, range $0-3)$; while the posttest score was $20.11(S D=5.46$, range 11-28); and the delayed posttest score was $19.10(S D=6.60$, range 12-30). These results indicated students who utilized a graphic organizer as the intervention significantly outperformed students as opposed to using traditional textbook instruction. 
Another study that focused on social studies and graphic organizers was conducted by (Boon et al., 2007). This study used a pre-and post-group design with 10 participants all with a mild learning disability. This study was designed as an extension of the Ayres et al. (2005) and investigated the use of Inspiration (2008) and social studies lessons. In Ayres et al., a hard copy of the graphic organizer was printed from the software and the participants filled in the information with pencil during the teacherpresented lesson. In Boon et al., however, the researchers had the participants fill out the Inspiration graphic organizer on a computer instead of on paper. The results of Boon et al. demonstrated an increase of the recall of content-area learning tasks for students with mild disabilities with the use of graphic organizers. Students who used the Inspiration software condition had a mean pretest of $11.60[S D=12.708)$, whereas the mean pretest score for the students in the control condition was 13.08 [SD=9.604). However, after the introduction of the Inspiration software, the mean posttest score of students who used the software was $52.54[S D=13.305)$, the mean posttest score for students in the control condition was $26.84[S D=14.860)$. Data from an informal survey indicated that the participants were motivated in social studies class and liked to use the Inspiration 6 software to record, organize, edit, and summarize the most important information from the chapter.

Graphic organizers have been used in language arts classes as well. For example, Lenz et al. (2007) conducted a study with 30 secondary students with SLD who were randomly selected from two high schools. The student participants were comprised of 20 males and 10 females (total 30 ). There were twenty 9th graders, seven 10th graders, two 11th graders, and one 12th grader. Seventeen of the students where White, eight were 
Black, three were Hispanic, and two were Asian. Fourteen of the students were receiving the majority of their education in special education classes, and six of them were mainstreamed into general education classes for all classes except for one resource-room special education support class. The 30 participating students were randomly assigned to six groups with five students in each.

Each student participated in three intervention conditions which included a review, guiding questions, and the curriculum mapping condition. In the review intervention condition, the instructor repeated key information throughout the lesson without the use of visual graphic organizers, visual representations of the information, or guiding questions. In the guiding question intervention condition, guiding questions covering key concepts of the lesson were posted and written on an overhead transparency. Students were then asked to list what key components of information that were needed to answer the guiding questions. Throughout the lessons, the presenter listed information on the overhead transparency so that students could see them.

Finally, the curriculum map intervention condition included the use of a graphic organizer depicting the structure of the content of the lesson. Throughout the curriculum map intervention lesson, the instructor displayed a graphic organizer and evoked a summary of critical points from the students based on the structure, and clarified any misunderstandings. Key words from the students were added to the graphic organizer. At the end of the lesson, the instructor then reviewed the lesson with the students using the curriculum map and the students were then asked to summarize the lesson independently using the organizer as a guide. 
Each participant was given the pre-test about information covered in all three lessons, and then participated in all three lessons in their assigned sequence. The mean pretest for the students at the start of the interventions was 3.80 answers correct. After the sequence of three lessons was completed, all students were given the posttest covering the information presented across all three lessons. The mean posttest score for the curriculum map intervention was $8.07(S D=2.33)$, which was an approximate 5point increase from the pre-test. The guided question intervention post-test results demonstrated an approximate 3.00 point increase from the pre-test. Finally, the mean posttest score for the traditional periodic review intervention was $3.27(S D=1.80)$, which indicates little to no change from pre-test to post-test.

In summary, the researchers were looking at language arts lessons across three strategies (curriculum mapping, guiding questions, and traditional lecture format). A pretest was given before each of the strategies was utilized. The results of this study demonstrated that the curriculum map intervention provided the largest increase from pre-test to post-test in terms of correct answers based on the language arts lessons. A post-hoc analysis showed that each of the differences between the three groups was significant at the .001 level. These results indicated that the use of the graphic organizer increased learning for students with SLD more than the use of guiding questions and more than the traditional periodic review.

\section{Graphic Organizers and Writing}

As previously mentioned graphic organizers portray visual relationships among key concepts and form schematic mappings for these concepts; creating meaningful diagrams that allow the user to expand and explain concepts (DiCecco \& Gleason, 2002). 
It has been suggested that the use of graphic organizing during writing can be useful to brainstorm new ideas that connect to the main theme of the writing piece, create concept maps relating the new ideas, and outline the ideas to help write a composition. There are two methods in which to create graphic organizers: handwritten and by computer. Limited research has been conducted on the use of either type of graphic organizer for writing (Nesbit \& Andescope, 2006).

\section{Research of Handwritten Graphic Organizers}

Handwritten graphic organizers employ the use of paper and pencil to create the visual representations of information. Although there have been several studies regarding reading comprehension and handwritten graphic organizers, there is limited research on the effects on their use with writing (Nesbit \& Adescope, 2006). Two major studies were found that involved the use of handwritten graphic organizers and writing (e.g., Capretz, Ricker, \& Sasek, 2003; DiCecco \& Gleason, 2002).

Capretz et al. (2003) conducted a 16-week programmatic study focusing on the use of handwritten graphic organizers and their effect in improving expository, persuasive, and narrative writing. The study included participants from Grades 2, 3, and 5 who all attended the same Midwestern-suburban elementary school. The students had weekly writing instruction on each writing genre and completed graphic organizers first as a class then as individual students. Every two weeks the students were expected to complete an individual composition with the help of a corresponding graphic organizer. At the end of the 16-week project, the students were interviewed with surveys regarding their feelings toward writing. Posttest data were also collected and compared to previous writing samples. The pre-test score showed that fluency increased fifteen percentage 
points from $80-95 \%$. Organization increased sixteen percentage points from $64-84 \%$.

The results of the study showed that graphic organizers can increase word count, fluency, and overall quality of writing. Students' perceptions on the writing process had a negative correlation after the introduction of the graphic organizers. The authors were unable to determine if that was due to the use of graphic organizers or the rigor of the project on the students.

DiCecco and Gleason (2002) investigated the effects of handwritten graphic organizers study with 26 middle school students with SLD. The intent was to investigate the use of graphic organizers as a means to improving their expository writing. The study collected baseline data with a pre-test using an essay format. The students were divided into an experimental and a control group. The experimental group received explicit writing instruction in conjunction with instruction on using the graphic organizers. The control group received explicit instruction on expository writing in social studies. The handwritten graphic organizers were found to be effective. Using a rubric to compare the post-test essays using handwritten graphic organizers, the results showed that the experimental group that used the graphic organizer had a gain of over three points on a five point scale from the pre- to post-test composition, while the control group had a gain of only one point.

Overall, the limited research on handwritten graphic organizers found them to be effective in helping students organize their writing. The results of DiCecco and Gleason's (2002) study found that the use of handwritten organizers would be beneficial both in a general-education classroom and with students with SLD. With the increased use of 
computers in the classroom, computer graphic organizers have become an alternative to handwritten graphic organizers. Thus, more recently, research has been done in this area.

\section{Research of Computer Graphic Organizers}

As compared to handwritten graphic organizers, a computer graphic organizer employs computer software as a vehicle for creating a graphic organizer, usually in the form of concept maps or visual diagrams. A benefit of a computer graphic organizer (as compared to handwritten) is that a student can make changes to information quickly without having to redo the whole organizer (Sitko et al., 2005). Another strength of computer graphic organizers is that a student can design their own visual map or concept map and effectively convert it into an outline and just as quickly export that into a word processing program (Sitko et al., 2005).

The research on the use of computer graphic organizers in conjunction with the writing process is limited. Only five studies were found that involved the computer graphic organizers and writing (i.e., Blair et al., 2002; Lin et al., 2004; Lorber, 2004; Sturm \& Rankin-Erickson, 2002; Unzueta \& Barbetta, 2012). All five studies reviewed below focused on middle school students. Participants in the first two studies, Lin et al. and Lorber were general-education students. The three subsequent studies (i.e., Blair et

al., 2002; Sturm \& Rankin-Erickson, 2002; Unzueta \& Barbetta, 2012) each investigated the effects of computer graphic organizers with students with SLD as their participants.

Lin et al. (2004) compared the use of handwritten and computer graphic organizers with 226 general-education students on persuasive writing. The 226 students were divided into 14 classes, seven classes represented a control group and seven classes represented an experimental group. At the beginning of the investigation, all 226 students 
received explicit instruction on the use of hand written graphic organizers in order to create a persuasive essay, and 226 students required to use a graphic organizer during their planning stage. The experimental classes were additionally instructed and received training on Inspiration (2008), a computer graphic organizer, to write their persuasive essays. Two evaluation rubrics were used in this study. After collecting the data, the investigators compared the number of ideas generated. The results showed that students who used computer graphic organizers generated more ideas $(M=12.27)$ than the students who used handwritten graphic organizers $(M=10.26)$.

Lorber (2004) investigated the use of computer graphic organizers with expository writing with eighth grade general-education students. In Lorber's study, 67 students were divided into three groups: (a) an experimental group, (b) a combination control and then second experimental group, and (c) a third control group. A baseline of all students' writing ability was collected at the start of the study. The study investigated the use of Inspiration (2008) on student's overall organization and how the program affected student's personal feelings towards writing. The students in the first experimental group received instruction on how to use Inspiration over the course of five weeks. Then, data were collected on the control groups and the first experimental group's compositions. The second control group subsequently became the second experimental group by receiving a 5-week instruction using Inspiration. The three groups then were asked to write a second composition, and these were compared within the three groups. The third group then received five-week instruction on Inspiration. A third and final composition was written and compared between all three groups. The study investigated the effects of the conditions on the main ideas and organization of the compositions, 
along with students' attitudes towards writing. Each of the compositions were compared and scored using a six-trait analytical writing rubric developed by Spandel (as cited in, Lorber, 2004). The writing rubric measured ideas, organization, voice, word choice, sentence fluency, and conventions. Lorber noted increases in the organization, as well as students' perceptions in the writings of students who used the computer graphic organizer $(M=5.25)$ as compared to those who were not given the intervention $(M=4.84)$.

Blair et al. (2002) investigated the use of computer graphic organizers on the narrative writing tasks of 24 middle school students with SLD. This study spanned four weeks and consisted of two groups, experimental and control. Like the subsequent studies mentioned, baseline data were collected in the form of pre-tests of writing. During the first two weeks, the control group received instruction only in writing techniques. During that same 2-week period, the experimental group received instruction on the use of Inspiration (2008) in conjunction with instruction on writing techniques and story webbing. At the end of this two-week period, all students were required to submit samples of their writing. Then, the control group was taught to use of Inspiration conjunction with instruction on writing techniques and story webbing. The results of Blair's study were limited. Although Blair indicated that the use of computer graphic organizers improved the student's attitudes about writing and increased the length of the students' essays, the researchers did not present the data representing student growth in writing. They stated that a lengthier study would be required to see changes in the students' compositions. Instead, the researchers suggested that further research should be conducted. 
Sturm and Rankin-Erickson (2002) compared 27 students' with SLD writing when using handwritten graphic organizers, computer generated graphic organizers, and no graphic organizers. Results for 12 of the students were presented at the end of the study. All students wrote two baseline compositions during the first week. During the second and third weeks, all the students received instruction, first in handwritten graphic organizers and then in computer graphic organizers. At the end of the third week, the students were divided into three equal groups (no organizers, handwritten organizers, and computer-generated organizers). The three groups were then asked to write at least two writing samples, and data were collected from each group for the following dependent variables: number of words, syntactic maturity, and holistic writing. After reviewing each of the writing samples, the writing samples that were written with the help of the computer graphic organizer $(M=9.06)$ in the third group's final weeks of the study, were slightly better, than those written with handwritten graphic organizers $(M=6.56)$ and no graphic organizers $(M=8.63)$ or baseline $(M=4.44)$. There is some ambiguity as to what improved the writing, the explicit teaching of writing or the use of the graphic organizers as effective writing was taught after achieving baseline for all three groups.

A recent study conducted by Unzueta and Barbetta (2012) involved four middle school Hispanic students with SLD. This study utilized a multiple baseline across subjects design to investigate the effects of Inspiration 8.0 (2008), a computer graphic organizer program, on the students' abilities in the planning and subsequent writing stage of persuasive writing. Specifically, data were collected on writing fluency, organization, syntax, time spent planning, and the percentages of arguments and details presented in the planning stages transferred to the written composition. 
In this study, participants were given instruction on the components of persuasive writing prior to baseline and were taught to the use Inspiration8.0 (2008) to plan their persuasive writing prior to intervention. At the culmination of the study, Unzueta and Barbetta (2012) found that Inspiration8.0 had a positive effect on the students' writing. In fact, at the conclusion of the study, the four participants improved in all writing areas measured which included time spent prewriting, number of supporting details planned, percentage of planned supporting details transferred to the composition, total number of words written, and syntactical maturity as measured by the number of T-units. In terms of time spent planning their writing, the group had a mean increase of 7.50 minutes. All participants increased their mean number of supporting details as represented by a mean increase of 5.04 more supporting details written in intervention than baseline compositions. During intervention, the group transferred $96 \%$ of their supporting details to their final compositions in comparison to $86 \%$ of supporting details being transferred during baseline. During baseline, the participants' mean overall organization score as measured by a rubric was 2.16 (range 1.00-3.60). During intervention, their score was 3.83 (range 2.00-5.20). This represents an increase of 1.67 points in their overall organization score in writing. Total number of words written increased overall among the four participants by a mean increase of 138.1 words per composition between baseline and intervention conditions. Syntactical maturity was measured with a T-score unit which is the shortest grammatically allowed sentence without creating fragments. Overall, the participants increased a mean of 12.20 T-units per composition between baseline and intervention conditions. 


\section{Summary}

Many students with SLD have difficulties at each stage of the writing process. During the planning stage, many often simply focus on the spelling and syntax (Graham et al., 2001; Wong, 2000). During the second stage of the writing process, organization, some students with SLD have problems logically organizing a paragraph in a sequential manner (Englert et al. 2007; Graham et al., 2001; Wong, 2000). During the revising stage, many of these students do not look for ways to improve their compositions, (e.g., improving word choice), but rather search for grammatical errors merging into the fourth stage editing (De la Paz and Graham, 2002; Graham et al., 2001; Montgomery \& Moreau, 2004; Wong, 2000). Many do not reach the final stage of writing, publishing, due to the problems encountered in the previous stages (Graham et al., 2001; Wong, 2000). Across all genres of writing for both groups, students with SLD need to improve their writing skills.

There are a variety of research strategies for assisting students in learning how to write effectively. One successful strategy that has been utilized for students with disabilities includes the use of graphic organizers (e.g., Ayers et al., 2005; Boon et al., 2007; Capretz et al., 2003; DiCecco \& Gleason, 2002; Lenz et al., 2007; Mastropieri et al., 2002; Zollman, 2009) Graphic organizers have been used across student populations and subject areas with notable success, perhaps because they provide visual frameworks to help students identify and recall important information. In writing, graphic organizers help create visual representations of main ideas and topics that can be used in writing and can be used to assist in brainstorming new ideas that connect to the main theme of the writing piece, create concept maps relating the new ideas, and outline the ideas to help 
write a composition (Ellis \& Howard, 2007). Computer graphic organizers employ the use of computer software programs to develop concept maps. Five studies were found that involved the computer graphic organizers and writing (i.e., Blair et al., 2002; Lin et al., 2004; Lorber, 2004; Sturm \& Rankin-Erickson, 2002; Unzueta \& Barbetta, 2012). The five studies all found that computer graphic organizers as a prewriting strategy aided in the improvement of students' writing.

Computer graphic organizers have shown promise in their ability to help students plan effectively and organize their writings. However, more research is needed to determine the extent of their effects on the writing of elementary students with SLD, particularly with narrative writing. Therefore, the purpose of this study was to investigate the use of computer graphic organizers with elementary students and examined how their use affected the narrative writing samples of these students. In that vein, this study set out to investigate how many words were written as well as planning time. Finally, common story elements and overall organization was also measured in order to examine the effectiveness that the computer graphic organizer had on the narrative writing samples of the participants. 


\section{CHAPTER III}

\section{METHOD}

This study examined the effects of computer graphic organizers on narrative writing by elementary students with specific learning disabilities (SLD). More specifically, this study investigated the effects of the use of the computer graphic organizer software, Kidspiration 3.0 (2011), on the narrative writings of students with SLD in an elementary setting. In this chapter, there is information about the study's participants, setting, materials, dependent measures, general procedures, and experimental design. A summary of the methodology is found at the end of the chapter.

\section{Participants}

The four participants were fourth and fifth-grade, elementary-level boys with a (SLD), who were enrolled in a suburban private religious elementary school located in a Southern Florida community. The participants were students serviced in a resource room setting where they received specialized instruction in writing. The school's student population, grades pre-kindergarten through Grade 8, is $90 \%$ Hispanic.

Each participant was identified as having a SLD as his primary disability as indicated by an Individual Education Plan (IEP). The students' writing performance on a norm referenced standardized academic achievement test was used in order to assist in choosing participants. The participants selected were at least one grade level below on both the reading/literacy based subtest and the writing subtest. All assessments were found in the participants' cumulative record. Finally, teacher recommendations for study participants were taken into account. 


\section{Participant 1}

Bob (pseudonym) was a fourth grader who attended this same school since Kindergarten (see Table 1). He had a private evaluation conducted that indicated he had an SLD, predominantly with reading and writing. In concordance with the private evaluation, an Individual Education Plan (IEP) was developed in order to address Bob's SLD, as his IEP included literacy-based goals. According to the Woodcock Johnson Test of Academic Achievement (WJ-III; Woodcock, McGrew, \& Mather, 2002), Bob was functioning at a first-grade level in terms of reading and language arts. He accessed his reading, language arts, and writing curriculum in resource room where he and four peers receive specialized instruction from a special education teacher. He then returned to his homeroom class to receive instruction on the remainder of his subjects.

Table 1

Participant Demographic Information

$\begin{array}{cccccc}\text { Participant** } & \text { Gender } & \text { Age } & \text { Grade } & \text { Disability } & \text { Grade Equivalent** } \\ \text { Bob } & \text { M } & 9 & 4 & \text { SLD } & 1.3 \\ \text { Gabe } & \text { M } & 10 & 5 & \text { SLD } & 2.3 \\ \text { Patrick } & \text { M } & 10 & 5 & \text { SLD } & 1.8 \\ \text { GP } & \text { M } & 9 & 4 & \text { SLD } & 2.4\end{array}$

Note. *All participant names are pseudonyms. ** Grade Equivalent derived from the Woodcock-Johnson-III (WJ-III; Woodcock et al., 2002) and is based on the broad reading score. 


\section{Participant 2}

Gabe (pseudonym) was fifth grader who originally attended a public school from kindergarten through his third grade years. He had a public school evaluation that indicated that had a SLD. Upon enrolling at the private school, Gabe brought with him a copy of his IEP that indicated that his weaknesses in reading and writing as well. The private school also administered to Gabe a series of academic testing that corroborated with this documentation. According to the WJ-III (2002), Gabe was functioning at a 2.3 grade level in terms of reading and language arts. Gabe accesses his reading, language arts, and writing curriculum in a resource room where he and four peers received specialized instruction. He then returned to his homeroom class in order to receive the remainder of his subjects.

\section{Participant 3}

Patrick (pseudonym) was a fifth grade student who is Bob's older brother. He has struggled with reading and language arts since he began at the private suburban school in Kindergarten. He was referred 2 years ago by the school so the parents could obtain a private evaluation which indicated that he had an SLD in reading. Based upon the findings of the private evaluation, as well as the academic testing results from WJ-III (Woodcock et al., 2002); an individualized education plan created at the school has been in effect for the past 3 years. His WJ-III broad reading level, which is combination of literacy-based scores, was at the 1.8 grade equivalency. He received his instruction in a resource room in order to receive instruction with lower pupil-to-teacher ratio with the assistance of specialized instruction in reading and language arts. A special education teacher delivered his instruction in the resource room. 


\section{Participant 4}

GP was a fourth grade boy who received an IEP due to a private evaluation given to him by a private school psychologist, hired by the parents. GP had weakness in reading, writing, decoding, and vocabulary. He struggled to keep up with his peers for the past three years, until the school recommended for him to be evaluated. Upon the results of the private evaluation, GP was determined to have attention and focusing issues. He subsequently was diagnosed as having an SLD. He had been the administered the Woodcock Johnson Test of Academic Achievement (WJ-III; Woodcock et al., 2002) that indicated that he was performing at the 2.4 grade level in reading and literacy areas. GP was performing well below grade level. GP's goals on his IEP were also literacy based, focusing on reading and language arts. He received specialized instruction in a resource room with four other students every day for reading, language arts, as well as mathematics.

\section{Setting}

The study was conducted in a classroom with computers in a suburban private religious school in Southern Florida. The classroom was equipped with one personal computer and three laptops. Kidspiration 3.0 (2011), the software used in the study, was available on all of the computers. Only a teacher employed at the school (who for the purposes of this study is referred to as the "teacher research assistant") along with the participants, and the researcher was in the classroom during the research sessions. The sessions were held after school, 4 days a week for a total of 14 weeks. Due to a 2 -week holiday break, data were collected for 12 of these weeks. 


\section{Materials}

The following is a description of materials used in the study. Materials included consent forms, technology assessment forms, writing prompts, treatment fidelity procedure sheets, data logs, interobserver agreement (IOA) and treatment fidelity forms, and computer hardware and software.

\section{IRB Approval Form}

IRB approval from the university (see Appendix A) was obtained before the start of the study.

\section{Parental Consent Form}

A parental consent form was given to each parent (see Appendix B). The purpose of this form was to establish parental consent for this study. The form provided a concise study description along with its purpose, information regarding the length of the study, and the parental and student participation expectations. Researcher and university contact information were provided on the form. All forms were provided in English and in Spanish.

\section{Student Assent Form}

A student assent form was given to each student after the parent signed the parental consent form (see Appendix C). The student assent form explained the study to the participating student and the expectations for the student.

\section{Pencils and Paper}

Two mechanical pencils and two lined white sheets of paper were provided for each participant daily while the participant was in the baseline condition. The paper was 
available for the participants to use for their planning during baseline condition and for the writing of their final compositions daily.

\section{Writing Prompts}

Writing prompts were question posed to the participants, which served as a guide for the essay writing each session (see Appendix D for list of writing prompts). Writing prompts were generated from an urban school district pool of an available monthly narrative writing prompts. One elementary special education teacher and a general education teacher who represented each participant's grade level were asked to rate each prompt as easy or difficult. If either the special education teacher or the reading coach labeled a prompt as difficult it was discarded and easy prompts were included to be used in random order in the study.

\section{Treatment Fidelity Procedure Sheet and Checklist}

The treatment fidelity checklist included the procedures for each phase in the study and step-by-step daily instructions (see Appendix E). The researcher and the independent observer used the treatment fidelity checklist daily either as a guide to follow procedures. The researcher and the teacher research assistant also used this checklist when treatment fidelity data.

\section{Writing Samples Scoring Procedures Sheet}

A procedures sheet for scoring four dependent variables related to writing: common story elements, number of words written, time spent planning, and organization was used. As a part of this scoring sheet an analytical rubric that was being used to measure overall organization was also attached to the writing samples scoring sheet (see Appendix F). 


\section{Writing Sample Data Logs}

Writing logs were kept on each of the participants. Daily progress was charted on logs for each of the dependent variables: e.g., common story elements, number of words written, time spent planning and organization. This information was retrieved daily from the writing samples scoring sheet and analytical organizational rubric (see Appendix F).

\section{Interobserver Agreement (IOA) Form}

An interobserver agreement form was used to compare the writing samples scores obtained from the scoring guides by each rater (see Appendix $\mathrm{H}$ ).

\section{Computer Hardware}

One desktop computer and three laptop computers were used in this study. All computers were located in the same classroom. The three laptops were Dell notebooks. The desktop computer consisted of a DELL tower with a 16-inch monitor. The Dell notebooks were approximately 18 inches by 16 inches. Both the notebooks and the desktop had Kidspiration 3.0 (2011) software installed prior to the start of the study.

\section{Kidspiration 3.0 (2011)}

Kidspiration 3.0 (2011) is a commercially available graphic organizer program that is used to create different types of visual organizers that allows users to visualize ideas, concepts and relationships, and to expand on these ideas in an outline form. In this study, all features of the software were available, and students were prompted to use specific features.

\section{Kidspiration 3.0 (2011) Narrative Writing Graphic Organizer Template}

This template is available on Kidspiration 3.0 (2011). It helps users plan and organize their narrative essays (see Appendix I). 


\section{PNY 2.0 gigabyte USB Flash-drive}

A PNY 2.0 gigabyte USB Flash-drive was used as a portable memory storage device to transfer all of the participants' writings and graphic organizers from the individual computers to the researcher's computer.

\section{Dependent Variables}

At the end of each session, the writing samples as well as the planning materials were collected, or saved on a jump drive (when in intervention). The total number of words was counted per composition. Each participant's planning time, writing samples, as well as their planning material were reviewed. The number of common story elements (Beginning, Middle, End, Character, Setting, and Conflict) developed in planning and the number of common story elements found in the written composition were analyzed and compared. The overall organization was monitored and recorded as measured by a 6point rubric were logged per essay or composition. Detailed definitions follow.

\section{Number of Words Written}

Overall word count was counted per composition. In each participant's composition, the number of words were counted and logged. Number of words written was the primary dependent variable upon which decisions were made to move to intervention.

\section{Total Time Spent in Planning Stage}

The total number of minutes spent on the planning stage was recorded on the top of the printed essay of each participant. The maximum allowed planning time was 10 minutes. As the participant was ready to move into the writing stage, he raised his hand to inform the researcher. The researcher recorded the number of minutes spent planning on 
a piece of paper and then copied it onto the top of the participant's printed essay when he finished the essay.

\section{Common Story Elements}

The number of elements that were found both in the planning documents and its corresponding narrative writing compositions was counted. There were six total possible story elements per planning and writing session. For the element to be scored, it needed to appear in both the planning document and its corresponding narrative writing. Each element was given a score of one per document/writing. The measured common story elements were: (a) character, (b) setting, (c) story beginning, (d) story middle, (e) story ending, and (f) story conflict or turn. See Appendix G for the logs used to measure common story elements as well the writing sample scoring sheet (Appendix F) used also to record common story elements.

\section{Overall Organization}

Overall organization was measured using an analytical scoring guide. The analytical scoring guide used in this study (see Appendix F) was adapted from Monroe and Troia (2006) and Unzueta and Barbetta (2012). The analytical rubric focused on six areas in each of the essays: content, sentence fluency, organization, word choice, conventions, and presentation. These six areas were each scored from 1 through 6 , with 1 being poor and 6 being excellent. The average of these six areas gave the essay its score.

\section{Interobserver Agreement}

According to Cooper et al. (2007), interobserver agreement (IOA) is the degree to which two or more independent observers or raters agree after observing or scoring the same events. Depending on the dependent variable being measured, there were two 
methods of measuring IOA used in this study; 1) Total Count IOA and 2) Exact

Agreement IOA. When measuring total number of words, total planning time, and overall organization, total count IOA was employed. Total count IOA is calculated by comparing the total number of behaviors observed by the two independent raters (in this case the researcher and the teacher research assistant) and dividing the smaller number of the two by the larger number and multiplying that sum by 100 (Cooper et al., 2007). In terms of the common number of story elements dependent variable, exact agreement IOA was used. In this type of IOA, the observation of the exact same story elements and number of occurrences was noted for each observer. The smaller number was divided by the larger number and then multiplied by 100. A minimal interobserver agreement of $90 \%$ was obtained for each dependent variable in each writing sample. Throughout the study this threshold was achieved. The interobserver agreement scores were recorded on the Interobserver Agreement Form (see Appendix H).

In this study, the researcher served as the rater and collected interobserver agreement data on all dependent variables on approximately $25 \%$ of the sessions in each condition. The researcher served as the rater and the teacher research assistant served as the second independent rater. The teacher research assistant received training conducted by the researcher prior to the start of the study. During training, each of the dependent variables was clearly explained, and the independent rater received examples of each and examples of how to score each. Then the rater was given two sample narrative essays to score and rate using the scoring sheet (see Appendix F). The researcher and the teacher research assistant then compared their independent scores with each other. Training was 
completed when both the researcher and the independent rater had at least $90 \%$ agreement.

\section{Treatment Fidelity}

Treatment fidelity refers to the extent to which the independent measures are carried out as planned by the researcher (Cooper et al., 2007). In order to maintain treatment fidelity, a treatment fidelity checklist (see Appendix E) was used daily. This served as a measure to ensure that procedures were carried out as planned. Any deviation from the plan was noted. The researcher collected treatment fidelity data on $25 \%$ of the writing sessions during baseline and intervention using the procedural checklist. The researcher filled out the Treatment Fidelity Procedure Sheet and Checklist (see Appendix E) while observing the sessions led by the teacher research assistant. The Treatment Fidelity Procedure Sheet and Checklist (see Appendix E) was also used daily by the person leading the session, even if no Treatment Fidelity data were being collected, as a guide to clearly indicate to the session leader the necessary steps needed to follow throughout each session.

\section{Experimental Design}

A single subject, multiple baseline across subjects design was employed using four participants. In this design, the treatment variable is applied to the same behavior of two or more subjects (or groups) in the same setting in a staggered fashion. That is, this design begins with the concurrent measurement of behaviors in a baseline condition across subjects. This is followed by the application of an intervention treatment for one of the participants who has reached a stable performance on a particular variable while in baseline. In this study, total number of words was the dependent variable used to 
determine whether a participant moved to intervention. When the first participant moved to intervention, baseline conditions remained in effect for the other participants. Then each of the remaining participants moved to intervention, as determined by the data in a sequential fashion as dictated by this design.

The multiple baseline design was selected for several reasons. First, treatment does not have to be withdrawn in a multiple baseline design (Cooper et al., 2007). The treatment in this project makes it useful for behavior challenges that are not easily "unlearned" (Cooper et al., 2007). Another benefit of utilizing a multiple baseline design is that it allowed for prediction, replication and verification of behaviors both academically and socially (Cooper et al., 2007). Prediction is the assumption that without the intervention that baseline conditions will remain the same. As each participant was moved into intervention, the remaining participants who remained in baseline verified this prediction. Replication was determined by continuously comparing results of the participant who received the intervention to those participants who had also been moved to intervention.

This study also set out to replicate the results of previous studies that also utilized technology and writing. By repeating whole experiments, the generality of findings can be extended to other subjects, settings, and/or behaviors. Secondly, this study has replication because repeating conditions within an experiment across subjects is what determines the reliability of effects and increases internal validity (Cooper et al., 2007). Another important benefit of a multiple baseline across subject design is that the design is relatively easy to conceptualize and implement (Cooper et al., 2007). 


\section{Pre-Study Procedure}

The pre-study procedures are those that were conducted and put into place in order to begin the study. The following is an explanation of how participants were selected and how the required consent forms were obtained. This is followed by an explanation of who the teacher research assistant was and how she received training, and an explanation of the technology assessment and the how the narrative writing genre was taught to the participants. Finally, procedures for the training of the independent raters were then explained.

\section{Selection of Participants and Consent and Assent Forms}

Four participants were selected from the available pool of six students who were diagnosed as having an SLD. Letters were sent home inviting parents of potential participants to individually meet with the researcher. The researcher explained the purpose, requirements, and time commitments of the study. Each parent was asked to sign a consent form if he or she agreed to have his or her child participate in the study (see Appendix B). Additionally, each student was required to sign an assent form consenting to being part of the study (see Appendix C).

\section{Training of Teacher Research Assistant}

The teacher research assistant assisted the researcher and was involved in many of the daily presentations of writing prompts, instruction of narrative writing, and collection of data. She was trained on all dependent variable definitions and was trained to lead sessions by following the Treatment Fidelity Checklist. The teacher research assistant has a doctorate in Exceptional Student Education, is a teacher at the site of the study, and has conducted previous research on graphic organizers. 
During the training, an overview of the dependent variables involved in the study was provided including a review of (a) word count; (b) total planning time; (c) story elements; and (d) overall organization. The researcher then scored two narrative writing examples simultaneously with the teacher research assistant, using the scoring sheet which included the organizational rubric, and then compared the rubrics of each to ensure that the researcher and teacher research assistant were within a 90\% agreement.

\section{Selection of Writing Prompts}

Writing prompts were adapted from a readily available pool of narrative prompts provided by an urban public school system. An elementary school reading coach and a special education teacher were asked to rate each prompt as either easy or difficult. Only the prompts rated as easy were maintained in this study. Selection of prompts was randomly pulled from a file. Each chosen prompt was typed and numbered before the study began (see Appendix D).

\section{Teaching of Narrative Writing}

For three, half-hour sessions, all participants received direct instruction in the writing process. More specifically, the participants were taught the tenets of the narrative writing genre. This was primarily done by the introduction of a mnemonic device $3 \mathrm{Ws}+2 \mathrm{Hs}$ along with the assistance of worksheets and handouts. The mnemonic device $3 \mathrm{Ws}+2 \mathrm{Hs}$ is a tool to help the participants remember to ask for the three main questions in order elicit story elements and refers specifically to the who, what, and where of the story along with how things happened in the story and how the story ended. This was explained in detail using examples and non-examples. 
The researcher taught narrative writing during three sessions. The researcher conducted the instruction using researcher-created handouts and examples. Throughout the three sessions, the researcher highlighted many examples of narrative writing and of non-examples as well. As a culminating activity, the researcher presented two examples of narrative compositions. The students were asked to identify the parts of a narrative writing using the sample compositions. Utilizing the 3 W's $+2 \mathrm{H}$ 's method, the students had to identify story elements in the example compositions. This was used as an assessment of narrative writing (see Appendix K). This assessment was scored to ascertain that the participants understood the components of narrative compositions. Being able to locate the story elements of a sample narrative writing composition was considered sufficient criteria for understanding the basics of the narrative genre. Finally, the participants were given a sample prompt in which they were required to plan and write a narrative essay on a pre-determined topic. Being able to develop some form of plan and write at least three sentences from this plan was the criteria used to determine that the students could move into baseline.

\section{Study Procedures}

The study procedures are those that were conducted once the study began. The following is an explanation of what procedures were followed throughout the study on a daily basis. This is followed by an explanation as to the procedures that differed from baseline, intervention training, and intervention conditions.

\section{General Session Procedures}

The general session procedures occurred in baseline and intervention study sessions. During the study sessions, the participants arrived either on their own or they 
were picked up either by the researcher or the teacher research assistant. Each of the participants was offered a snack and asked to sit down. A printed copy of a randomlyselected writing prompt was placed at each seat, along with two mechanical pencils, and two blank sheets of lined paper. Each session's prompt was identical for each participant. Either the researcher or the teacher research assistant was available during each session, provided the daily instruction to the participants, and collected the writing samples as both led sessions and collected data independently. For $25 \%$ of the sessions, both the researcher and the teacher research assistant were present as the researcher collected treatment fidelity data. IOA and treatment fidelity were collected during the sessions. The researcher served as the instructor during 17 of the sessions and the teacher research assistant served as instructor for the other 22 sessions. (Note: The individual conducting the session during any particular session is referred to as the instructor.)

After the participants finished with their snacks, the instructor read aloud the scripted directions to the participants. The directions were read from the Treatment Fidelity Procedure Sheet and Checklist (see Appendix E). The instructor then read the writing prompt for the session. The participants were reminded of the tenets of narrative writing and were reminded of the common story elements. The instructor then informed them that they had 10 minutes for planning, 15 minutes for writing, and 5 minutes for editing. The instructor verbally cued transition between stages during the writing session. These time constraints were selected to adhere to the general format of most standardized tests, as well as to mimic the typical class allotment for writing in an elementary setting. If the participant did not need all of the time allotted, he could move onto the next stage 
by raising his hand and letting the instructor know that he was moving to the next stage. The writing of the compositions was done with paper and pencil.

Upon completion of the compositions, the participant handed in his copy of the prompt, planning sheet, and composition and this was all stapled to a Scoring Sheet and Organizational Rubric (see Appendix F).

\section{Baseline Procedures}

All general session procedures were followed. Specifically, with baseline, the participants did their planning using paper and pencil. Two number 2 pencils and two sheets of white lined paper were placed on the table where each of the participants was directed to sit. They were directed to plan with the pencils and paper. As was described in the general procedures, the writing and editing of the compositions also was done with paper and pencil.

\section{Kidspiration 3.0 Intervention Training}

The determination as to whether intervention would be introduced was based on daily analysis of each participant's writing, specifically the dependent variable of total word count. Prior to being moved to intervention, each participant received an individualized Kidspiration 3.0 (2011) training session conducted by the researcher in a resource room during that participant's free time or during a session while the participants was participating in baseline.

The training involved the researcher instructing the participant on the basic use of the graphic organizer software Kidspiration 3.0 (2011), and the Kidspiration 3.0 (2011) narrative writing graphic organizer template that was designed by the researcher (see Appendix I). This template consisted of different clusters for the participants to plan their 
narrative essays. The researcher conducted the training either during one of the sessions or during free time. The student was trained in the resource room with a laptop computer, as well as handouts and sample writing prompts. First, the narrative writing tenets were explained using examples and non-examples that were originally introduced during the first three sessions of the study when narrative writing was originally taught to the participants. Then the participants were introduced to the Kidspiration 3.0 (2011) template. Next, the outline program in Kidspiration 3.0 (2011) was taught to the participants, and they learned how to transfer their organizers to an outline form while on the computer. This outline form could be used to assist the participants in writing a final composition with paper and pencils on a separate piece of paper. Once the participant became familiar and demonstrated that he could access the program and utilize it appropriately, he was given a writing prompt and asked to use the program to plan and begin writing the essay using Kidspiration 3.0. A participant was deemed ready to use the program after he was successfully able to fill out the graphic organizer on the computer, transfer the information to outline form on the computer and immediately afterwards write a composition from the outline while being observed by the researcher. The researcher then reviewed the planning, the outline, and the composition and judged whether the participant competently was able to maneuver the software.

\section{Kidspiration 3.0 Intervention}

During intervention, all of the general procedures were used as was done in baseline with the exception of how planning was done. Unlike baseline in which planning was done using paper and pencil, planning during intervention was done using the template developed from Kidspiration 3.0 (2011) on a laptop or desktop. For 
participants in intervention, the Kidspiration 3.0 software was opened on their computer screens when they arrived to the study setting. Once they developed their planning diagram using Kidspiration 3.0, they converted the diagram to an outline form. Each participant could then choose to view his planning either in the Kidspiration 3.0 outline form or as a graphic organizer on the computer as he composed his narrative writing using pencil and paper.

\section{Summary}

This study examined the effects of computer graphic organizers on the written narrative essays of elementary students with SLD who have difficulties in writing. The study participants were elementary school students, Grades 4 through 5, enrolled in a suburban religious-based private school located in the Southern Florida. The teacher nominated these participants as having a deficiency in written expression as identified by performance on standardized, norm referenced achievement exams. The setting was a classroom equipped with one desktop computer and three laptop computers. The computers had available Kidspiration 3.0 (2011) and paper and pencil was available.

The dependent variables were the total amount of total number of written words, planning time, total number of story elements written, and the overall organization of the essay. Interobserver agreement and treatment fidelity data were collected and reported as well.

A single subject, multiple baseline design across subjects was used in this investigation. Multiple baseline designs allow for replication and verification, they are naturalistic in their implementation, and there is no withdrawal of the intervention (Cooper et al., 2007). 
Prior to baseline data being collected, all four participants received direct instruction in $3 \mathrm{~W}$ 's and $2 \mathrm{H}$ 's method for creating narrative compositions. The $3 \mathrm{Ws}$ and $2 \mathrm{Hs}$ method is a mnemonic device created to help elementary-aged students to produce narrative compositions and comprehend narrative text. The $3 \mathrm{Ws}$ and $2 \mathrm{Hs}$ stands for Who, Where, What happened, as well as How did it get solved and How does it end? This mnemonic device was used as it is a common tool for teaching elementary-level students about narrative writing.

After instruction in narrative writing, all participants moved to baseline. In baseline, the participants were asked to plan using paper and pencil for a maximum time limit of ten minutes per session. The participants could move to writing before the ten minutes were up as long as they indicated they were moving on by raising their hands. The participants then had 15 minutes in order to write a narrative composition from the planning generated, also using paper and pencil. Just prior to being moved to intervention, participants were trained one at a time on how to use Kidspiration 3.0 (2011) for planning their writing. The participants were moved to intervention one at a time in a staggered fashion based on the dependent variable, total number of words written. Procedures used in intervention were identical to those in baseline with the exception that planning was done using a Kidspiration 3.0 (2011) template on a computer instead of paper and pencil. Data were analyzed and plotted daily in order to determine when the participants should move to the intervention. 


\section{CHAPTER IV}

\section{RESULTS}

This chapter describes the findings of a study which used a multiple baseline

design to examine the effects of the use of a graphic organizer program, Kidspiration 3.0 (2011), on the narrative writing of elementary students with Specific Learning

Disabilities (SLD). The narrative writing compositions were measured for total number of words written, total minutes spent planning, common story elements transferred from planning to composition, and overall organization across baseline and intervention conditions.

During baseline, the participants were given narrative writing prompt and were asked to plan for 10 minutes using traditional paper and pencil. After ten minutes of planning, participants were given 15 minutes for narrative story writing using paper and pencil, followed by five minutes for editing. Each of the participants' compositions and planning sheets were collected and evaluated using a scoring sheet that measured total number of words, total time spent planning, common story elements transferred, from planning to composition, and overall organization. Overall organization was measured using a rubric that examined the student's word choice, grammar, sentence usage, and voice.

Prior to moving from baseline to intervention, each participant individually received a short training on how to use the graphic organizer program Kidspiration 3.0 (2011) for planning. Once in intervention, each participant was given a narrative writing prompt, as in baseline, but instead of planning using paper and pencil, he used the 
Kidspiration 3.0 graphic organizer computer program. Then each participant had up to ten minutes to plan. Once the participant completed his planning, he converted the Kidspiration 3.0 diagram to an outline. He could then use the outline or diagram on the computer to guide his 15 minutes of narrative composition writing using paper and pencil.

The following sections present the treatment fidelity and interobserver agreement data first. Then, the results of each participant's and the group's performances on the dependent variables is presented. In all figures, the data points to the left of the condition change lines represent performances during baseline, and those to the right of the condition change lines represent data collected during the intervention. Finally, this chapter concludes with a summary of the results.

\section{Treatment Fidelity}

In order to confirm that procedures were followed as specified, the researcher or the trained independent teacher research assistant collected treatment fidelity data. The teacher research assistant led 22 of the 38 (56\%) study sessions, and the researcher conducted the remaining 17 sessions. While the researcher or the teacher research assistant served as the session instructor, each collected treatment implementation data during each session (100\%) for all participants and across both baseline and intervention phases accordingly. These data indicated that procedures were being followed an average of $99.73 \%$ of the time (range $95.75-100$ ) throughout all of the sessions conducted by the teacher research assistant and $99.96 \%$ of the time (range 99-100) on sessions conducted by the researcher. Additionally, the researcher was available to serve as an independent observer and collected treatment fidelity data on $25 \%$ of the sessions taught by the 
teacher research assistant for all participants across all conditions

\section{Interobserver Agreement}

Interobserver agreement data were collected overall for $25 \%$ of all sessions across all dependent variables by the researcher. The total count IOA data for number of total words was $97.67 \%$ (range $92.75-100$ ); planning time was $100 \%$ total overall organization answered correctly was $94.65 \%$ (range $90-100$ ). The exact count IOA for common story elements transferred was 98.25\% (range 96.45-100).

\section{Total Number of Words Written}

This study was conducted, in part, to examine the effects of a computer graphic organizer on the number of words written by elementary students SLD. Total number of words written was measured by counting the total number of legible words within each narrative writing composition written by the participants during baseline and intervention. Each participant's total number of words written per session is presented in Figure 1. Data points to the left of the condition change line represents baseline in which the participants planned their writing using traditional paper and pencil for up to 10 minutes. Data points to the right of the condition line represent the total number of words written per session using Kidspiration 3.0 (2011) during planning. A summary of the individual and group performance data across baseline and intervention conditions is presented in Table 2 .

\section{Bob}

Bob's data are displayed in the first tier of Figure 1. During baseline, there was little performance variability and performances were at the low level. Once Bob was moved to intervention (based on words per minute data), there was increased variability 
Figure 1

Total Words Written

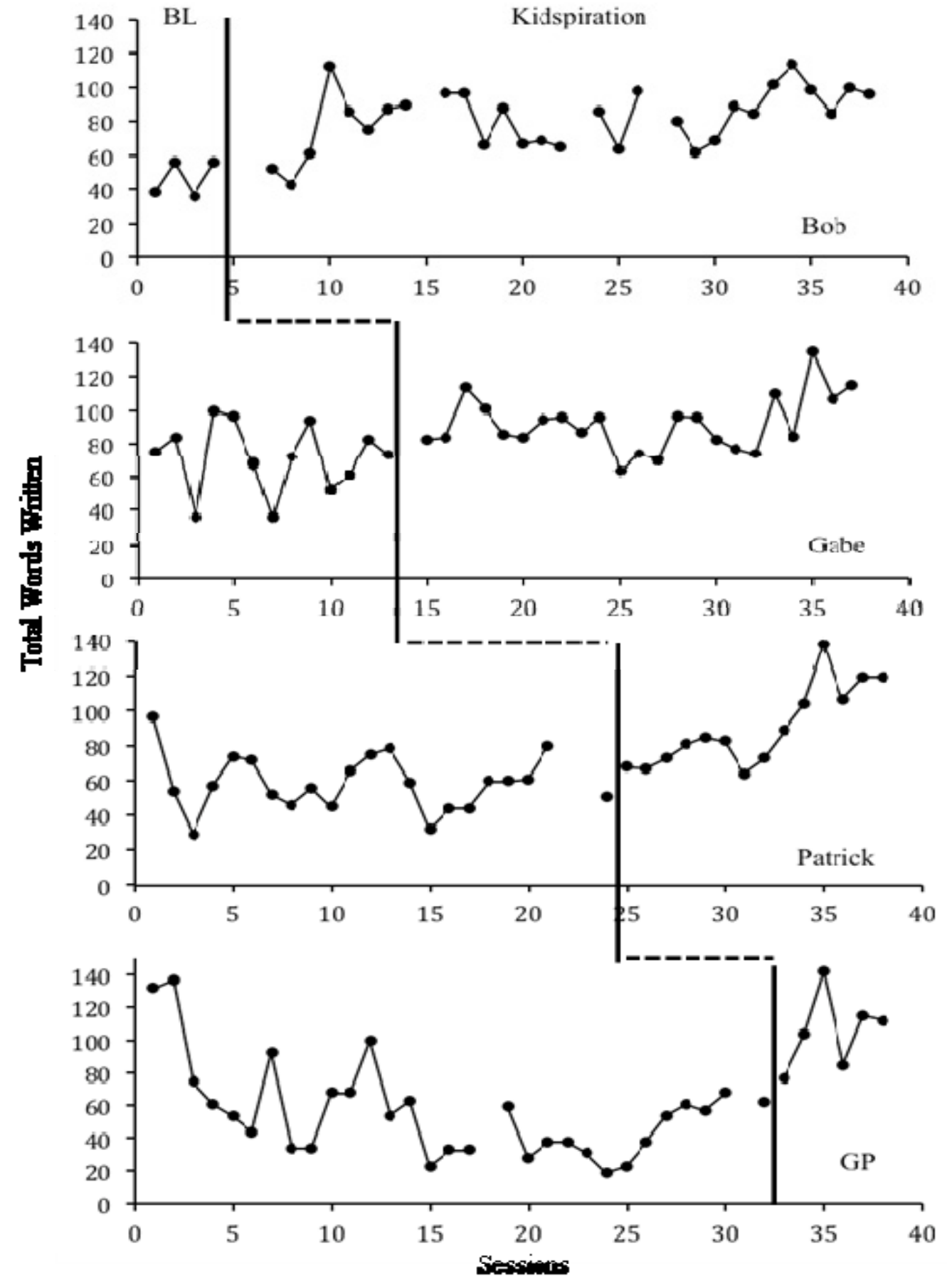

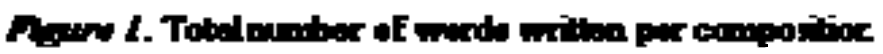


Table 2

Individual and Group Means for Total Words Written

\begin{tabular}{ccc}
\hline Participant & Baseline & Intervention \\
& & 82.00 \\
Bob & $(46.00-56.00)$ & $(43.00-114.00)$ \\
& 71.61 & 91.86 \\
Gabe & $(36.00-100.00)$ & $(54.00-135.00)$ \\
& 58.10 & 85.50 \\
Patrick & $(32.00-79.00)$ & $(51.00-138.00)$ \\
& 54.74 & 96.60 \\
GP & $(19.00-137.00)$ & $(62.00-142.00)$ \\
& 58.70 & 88.76 \\
Group & $(19.00-137.00)$ & $(43.00-135.00)$ \\
\hline
\end{tabular}

Note. The top numbers indicate individual mean number of words written. The bottom numbers represent the range of scores.

of performance with ascending and descending trend lines observed throughout.

A variable ascending trend line towards the end of intervention was observed. As can be seen in Table 2, during baseline, Bob's mean number of words was 46.5 (range 46.0-56.0). His mean number of words during intervention was 82.0 (range 43.0-114). This represents a mean increase of 35.5 more words written per composition during intervention than baseline.

\section{Gabe}

Gabe's data of total number of words written per narrative composition are displayed in the second tier in Figure 1. During baseline, there was considerable variability at the low to middle performance levels. Once Gabe was moved to 
intervention (based on words per minute data), there was a slight increase in stability at a middle level, followed by a variable ascending trend line towards the end of intervention.

As can be seen in Table 2, during baseline, Gabe's mean number of words was 71.61 (range 36.0-100). His mean number of words during intervention was 91.86 (range 54.0-135). This represents a mean increase of 20.25 words written per composition when comparing baseline to intervention.

\section{Patrick}

Patrick's data of total number of words written per narrative composition are displayed in the second tier in Figure 1. During baseline, there was some variability within a few ascending trend lines. Once Patrick was moved to intervention (based on words per minute data), data were initially stable data at the middle level, followed by an ascending trend line toward the later part of intervention.

As can be seen in Table 2, during baseline, Patrick's mean number of words was 58.1 (range 32.0-79.0). His mean number of words during intervention was 85.5 (range 51.0-138). This represents a mean increase of 27.4 words written per composition.

\section{GP}

GP's data of total number of words written per narrative composition are displayed in the fourth tier of Figure 1. During baseline, there was a descending trend followed by relative stability and an ascending trend line. (Note: It was not ideal to move GP to intervention when it was done, due to the ascending trend line at the end of baseline. However, there were limited days remaining in which intervention data could be collected. Once GP was moved to intervention (based on limited number of sessions remaining), the ascending trend line continued. 
As can be seen in Table 2, GP's mean number of words was 54.7 (range 19.0137). His mean number of words written during intervention conditions was 96.6 (range 62.0-142). This represents a mean increase of 41.86 words written per composition when comparing baseline to intervention.

\section{Group Means for Total Words Written}

Table 2 displays the group mean of total words written during baseline and intervention conditions. During baseline the group mean of total words written was 58.70 (range 19.0-137). During intervention the group mean increased to 88.76 (range 43.00-135.0) total words. This represents a mean increase of 30.06 words written per composition when comparing baseline to intervention.

\section{Total Planning Time}

This study was conducted, in part, to examine the effects of a technology-based computer graphic organizer on planning time for narrative compositions. Participants were given up to 10 minutes of a 30-minute session to plan for each of the writing prompts. Timing started once the prompt was read aloud. If participants chose to spend less than 10 minutes on planning, they raised their hands to let the instructor know and were given permission to move to writing. If the 10 minutes were up before the students were done planning, they were asked to stop planning and to move to composition writing.

\section{Bob}

Bob's total planning time during baseline and intervention is displayed in the first tier in Figure 2. During baseline, there was an observable descending trend line in the 
Figure 2.

Total Planning Time

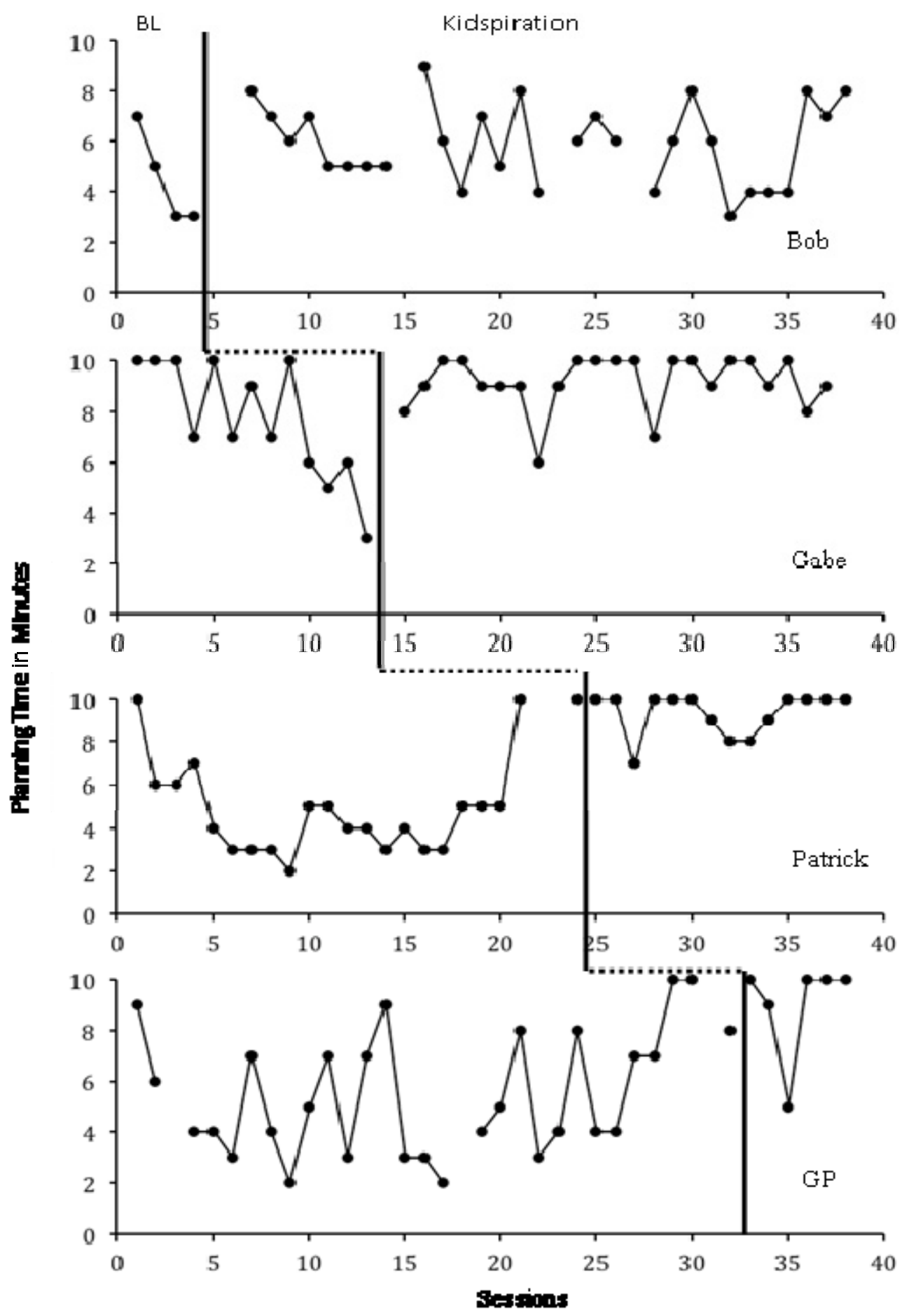

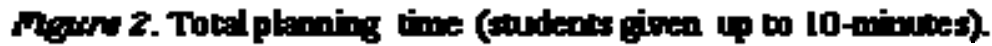


Table 3

Individual and Group Means of Total Planning Time

\begin{tabular}{ccc}
\hline Participant & Baseline & Intervention \\
\hline Bob & 4.50 & 5.50 \\
& $(3.00-5.00)$ & $(3.00-9.00)$ \\
Gabe & 7.70 & 9.60 \\
& $(3.00-10.00)$ & $(6.00-10.00)$ \\
Patrick & 4.50 & 9.50 \\
& $(2.00-7.00)$ & $(7.00-10.00)$ \\
GP & 4.95 & 8.30 \\
& $(2.00-9.00)$ & $(4.00-10.00)$ \\
Group & 5.40 & $(4.00-10.00)$ \\
\hline
\end{tabular}

Note. The top numbers indicate individual mean number of words written. The bottom numbers represent the range of scores.

number of minutes spent planning. Once Bob was moved to intervention (based on words per minute data), there was considerable variability of performance and overlap between baseline and intervention data points.

As can be seen in Table 3, during baseline Bob planned for a mean time of 4.50 (range 3.00-5.00) minutes. His mean planning time during intervention was 5.50 (range 3.00-9.00). This demonstrates a mean increase of one minute of time spent planning during intervention when compared to baseline.

\section{Gabe}

Gabe's total planning time performances during baseline and intervention conditions is displayed in the second tier in Figure 2. During baseline, initially there was 
relative stability in Gabe's performance followed by was an observable descending trend line during the last half of the baseline condition. Once Gabe was moved to intervention (based on words per minute data), there was an immediate increase in performance with relative stability in the data. There was considerable overlap in the data points between baseline and intervention conditions.

As can be seen in Table 3, during baseline Gabe's mean time spent planning was 7.70 minutes (range 3.00-10.0). During intervention Gabe's total mean time spent planning was 9.60 (range 6.00-10.0). This represents an increase of 1.90 minute of planning time when comparing baseline to intervention.

\section{Patrick}

Patrick's total planning time performances during baseline and intervention conditions are displayed in the third tier in Figure 2. During baseline, there was an immediate descending trend in minutes planning. This is followed by some stability in Patrick's performance and a substantial increase to a high level of performance with the final baseline data point. Once Patrick was moved to intervention (based on words per minute data), he maintained that high level of performance and there was relative stability in the data. Although there was overlap in the data points between baseline and intervention conditions, there were only two data points in baseline as high as intervention levels.

As can be seen in Table 3, during baseline, Patrick's mean time spent planning was 4.50 minutes (range 2.00-7.00). During intervention Patrick's total mean time spent planning was 9.50 minutes (range 7.00-10.00), representing an increase of 5.00 minutes. 
GP

Figure 2 displays GP's total planning time performances during baseline and intervention conditions. During baseline, there was variability throughout GP's performance. Once GP was moved to intervention (based on words per minute data), there was relative stability in his performance with the exception of one data point. As can be seen in Table 3, during baseline, GP's mean time spent planning was 4.95 minutes (range 2.00-9.00). During intervention, Gabe's mean time spent planning spent planning was 8.30 minutes (range 4.00-10.00). This represents an increase of 3.35 minutes of planning time.

\section{Group Means for Total Planning Time}

Table 3 displays the group mean of total minutes planning during baseline and intervention. During baseline the group's mean minutes planning was 5.40 (range 2.0010.0). During intervention the group mean increased to 7.96 (range 4.00-10.00) minutes of planning time. This represents a mean increase of 2.56 minutes spent planning as a group when comparing baseline to intervention.

\section{Story Elements Found in Final Compositions}

This study was conducted, in part, to examine the number of common story elements that were transferred from planning to narrative writing compositions. Common story elements were measured using a scoring sheet. There was a 6.00 total possible story elements that could be counted per session, with one point per each of the six story elements (i.e., character, setting, beginning, middle, end, and conflict/problem). The story elements measured daily and to be counted they had to be found both in planning and its corresponding composition. For example, if a composition had a 
character and the character was evident in planning as well as in the composition then that counted as one story element. The same logic followed for the remaining five story elements measured. Each participant's individual performance is discussed and is presented in Figure 3. Table 4 displays the individual mean and range performances as well as group performances in baseline and intervention conditions.

\section{Bob}

Bob's performance data of number of common story elements found in his daily narrative writings that were transferred from his planning are represented in the first tier in Figure 3. During baseline, there was stability at a low level. Once Bob was moved to intervention (based on words per minute data), there was a small, immediate increase followed by an ascending trend line, followed by stability.

As can be seen in Table 4, during baseline, Bob's mean number of common story elements was 3.60 (range 2.00-5.00) out of a possible 6.00 points. During intervention, Bob's mean number of common story elements was 4.40 (range 2.00-6.00). This represents an increase of .80 common story elements out of a possible 6.00 points when comparing baseline to intervention.

\section{Gabe}

Gabe's performance data of number of common story elements found in his daily narrative writings that were transferred from his planning are represented in the Figure 3. During baseline, there was variability followed by relative stability of performance at the middle performance level. Once Gabe was moved to intervention, there was an immediate increase in performance with a relative stability in the data at mid levels. 
Figure 3.

Common Story Elements

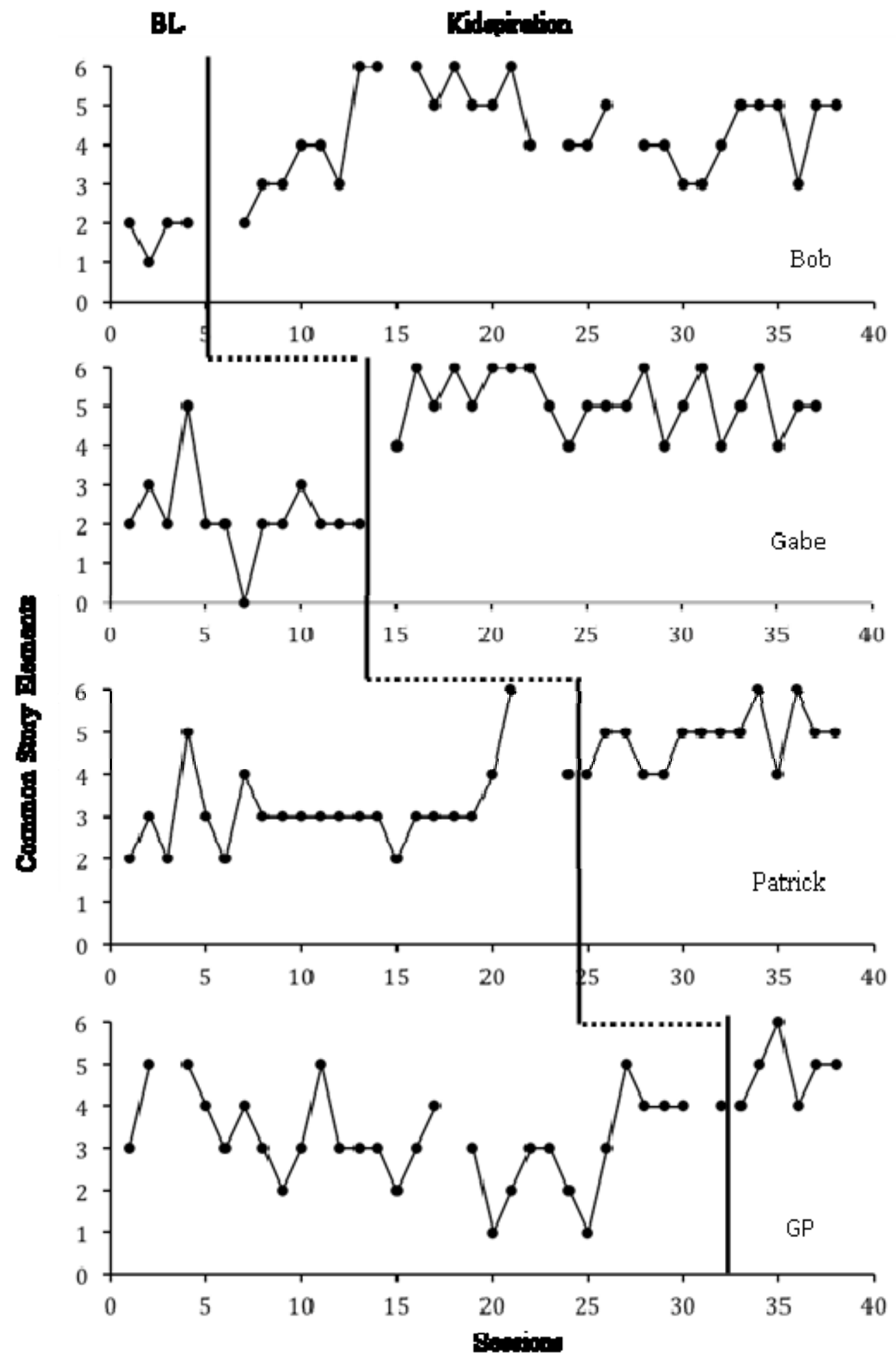

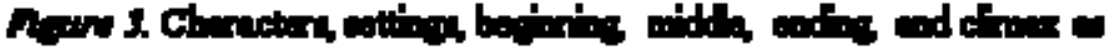

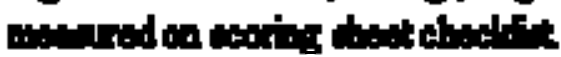


Table 4

Individual and Group Means for Common Story Elements

\begin{tabular}{|c|c|c|}
\hline Participant & Baseline & Intervention \\
\hline Bob & $\begin{array}{c}3.60 \\
(1.00-2.00)\end{array}$ & $\begin{array}{c}4.40 \\
(2.00-6.00)\end{array}$ \\
\hline Gabe & $\begin{array}{c}2.00 \\
(0.00-5.00)\end{array}$ & $\begin{array}{c}5.10 \\
(4.00-6.00)\end{array}$ \\
\hline Patrick & $\begin{array}{c}3.00 \\
(2.00-5.00)\end{array}$ & $\begin{array}{c}5.00 \\
(4.00-6.00)\end{array}$ \\
\hline GP & $\begin{array}{c}3.00 \\
(1.00-5.00)\end{array}$ & $\begin{array}{c}4.50 \\
(4.00-6.00)\end{array}$ \\
\hline Group & $\begin{array}{c}4.00 \\
(0.00-6.00)\end{array}$ & $\begin{array}{c}5.33 \\
(3.00-6.00)\end{array}$ \\
\hline
\end{tabular}

Note. The top numbers indicate individual mean number of common story elements found in the narrative writing samples that were also found in planning. The bottom numbers represent the range of scores

As can be seen in Table 4, during baseline Gabe's mean number of common story elements was 2.00 (range $0.00-5.00$ ) out of a possible 6.00 points. During intervention, his mean number of common story elements was 5.10 (range 4.00-6.00) out of a possible 6.00 points. This represents a mean increase of 3.10 common story elements transferred from planning to compositions when comparing baseline to intervention.

\section{Patrick}

Patrick's performance data of number of common story elements found in his daily narrative writings that were transferred from his planning are represented in Figure 
3. During baseline, initially there was variability followed by middle-level stable performances. This was followed by a short ascending trend and ended with a decrease in elements transferred. Once Patrick was moved to intervention (based on words per minute data), there was an immediate slight increase in performance from the last two baseline data points with a relative stability in the data at mid-level, followed by variability in performance at the higher level.

As can be seen in Table 4, during the baseline, Patrick's mean number of common story elements was 3.00 (range 2.00-5.00) out of a possible 6.00 points. During intervention, Patrick's mean number of common story elements was 5.00 (range 4.006.00) out of a possible 6.00 points. This represents an increase of 2.00 common story elements out of a possible 6.00 points transferred from planning to compositions when

\section{GP}

GPs performance data of number of common story elements found in his daily narrative writings that were transferred from his planning are represented in Figure 3. There was variability found throughout baseline. After GP moved to intervention (based on total number of words written), minimal stability was established. There was a considerable amount of data point overlap between baseline and intervention.

As can be seen in Table 4, during the baseline, GP's mean number of common story elements was 3.00 (range 1.00-5.00) out of a possible 6 points. During intervention, GP's mean number of common story elements was 4.50 (range 4.00-6.00) out of a possible 6.00 points. This represents a 1.50 mean increase in common story elements out of a possible 6 points transferred when comparing baseline to intervention. 


\section{Group Means for Common Story Elements}

Table 4 displays the group means for common story elements during baseline and intervention. During baseline the group mean of common story elements was 4.00 (range 0.00-6.00) out of a possible 6.00 points. During intervention the group mean increased to 5.33 (range 3.00-6.00) common story elements out of a possible 6.00 points found transferred to the compositions. This represents a 1.33 mean increase of common story elements out of a possible 6.00 points transferred from planning to narrative writing compositions by the group when comparing baseline to intervention.

\section{Overall Organization}

This study was conducted, in part, to examine the effects of a computer graphic organizer on the overall organization of narrative writing essays. Overall organization was measured using an analytic scoring rubric that evaluated five areas in each of the narrative compositions: content, sentence fluency, organization, word choice, and conventions. These five areas were scored on a 6-point scale, with a score of one rating "poor" and a six rating of "excellent." The mean of these six areas constitutes the composition's overall organization score. Each participant's overall organization score per session is presented visually in Figure 4. This is followed by Table 5, which displays each participant's mean performance in overall organization in baseline and in intervention. A group comparison is also included.

\section{Bob}

Bob's performance on overall organization of writing narrative writing during baseline and intervention is displayed in the first tier of Figure 4. During baseline, there was stability at a low level of performance. Once Bob was moved to intervention (based 
on words per minute data), there was a slight increase in performance followed by relative stability at low levels with the exception of two data points.

A can be seen in Table 5, during baseline, Bob's mean overall organization score was 1.00 (range 1.00-1.00) out of a possible 6.00. During intervention, Bob's mean overall organization score was 1.50 (range $0.00-1.80$ ) out of a possible 6.00 . This represents a mean increase of .50 out of a possible 6.00 in overall organization between baseline and intervention.

\section{Gabe}

Gabe's performance on overall organization of writing narrative writing during baseline and intervention is displayed in the second tier in Figure 4. During baseline, there was stability at low to middle levels of performance. Once Gabe was moved to intervention (based on words per minute data), there continued to be stable performances in the low to middle levels.

As can be seen in Table 5, during baseline conditions, Gabe's mean overall organization score was 2.30 (range 1.80-3.00) out of a possible 6.00. During intervention conditions, Gabe's mean overall organization score was 2.30 (range 1.40-3.20) out of a possible 6.00. Gabe maintained his mean performances in overall organization from baseline.

\section{Patrick}

Patrick's performance on overall organization of writing narrative writing during baseline and intervention is displayed in the third tier in Figure 4. During baseline, there was stability at a low level of performance. Once Patrick was moved to intervention, there continued to be stable performances in lower levels. 
Figure 4. Overall Organization

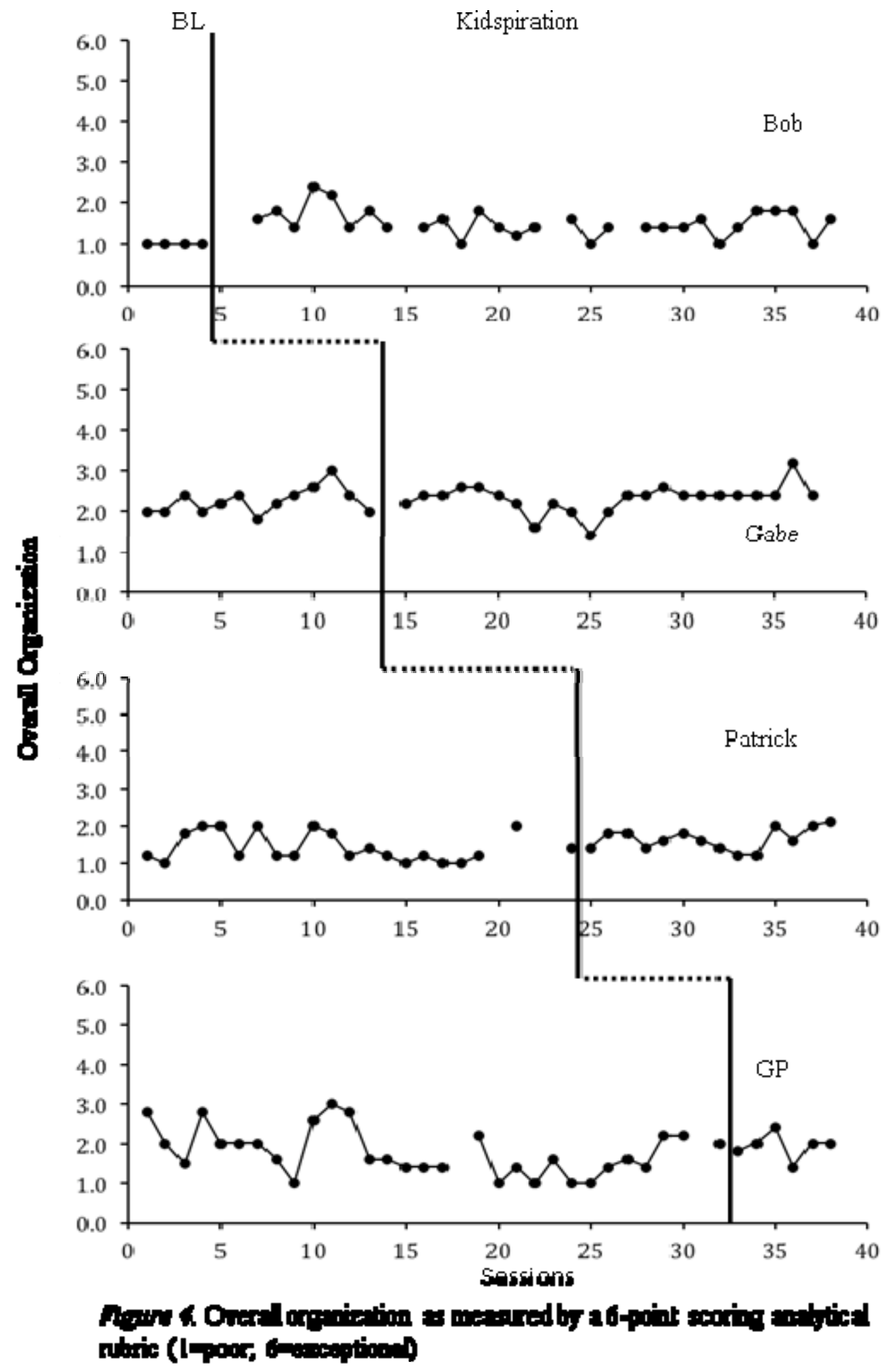


Table 5

Individual and Group Means for Overall Organization

\begin{tabular}{ccc}
\hline Participant & Baseline & Intervention \\
\hline Bob & 1.00 & 1.50 \\
& $(1.00-1.00)$ & $(0.00-1.80)$ \\
Gabe & 2.30 & 2.30 \\
& $(1.80-3.00)$ & $(1.40-3.20)$ \\
Patrick & 1.40 & 1.60 \\
& $(0.00-2.00)$ & $(1.20-2.00)$ \\
GP & 1.80 & $(1.80-2.00)$ \\
& $(1.00-2.20)$ & 1.83 \\
Group & 1.70 & $(1.00-2.60)$ \\
\hline
\end{tabular}

Note. The top numbers indicate individual mean number of words written. The bottom numbers represent the range of scores.

As can be seen in Table 5, during baseline, Patrick's mean overall organization score was 1.40 (range $0.00-2.00$ ) out of a possible 6.00. During intervention conditions, Patrick's mean overall organization score was 1.60 (range 1.20-2.00) out of a possible 6.00. This represents only a minimal mean increase of .20 when comparing overall organization from baseline to intervention.

\section{GP}

GP's performance on overall organization of writing narrative writing during baseline and intervention is displayed in the fourth tier in Figure 4. During baseline, there was some variability seen at a low to middle levels of performance. Once GP was moved 
to intervention (based on words per minute data), there continued to be variable performances at low levels of performance.

A can be seen in Table 5, during baseline, GP's mean overall organization score was 1.80 (range 1.00-2.20) out of a possible 6.00. During intervention conditions, GP's mean overall organization score was 1.97 (range 1.80-2.00) out of a possible 6.00. This represents a nominal mean increase of .17 when comparing overall organization performances in baseline to intervention.

\section{Group Means for Overall Organization}

Table 5 displays the group's mean for overall organization during baseline and intervention. During baseline, the group's mean of overall organization was 1.70 (range 1.00-2.20) out of a possible 6.00. During intervention the group means increased to 1.83 (range 1.00-2.60) out of a possible 6.00. This was a nominal .13 group mean overall increase out of a possible 6.00 when comparing baseline to intervention.

\section{Summary}

The study sought to examine the effects of a computer graphic organizer software program for planning in the narrative writing of elementary aged students who have SLD. The results of this study demonstrated that the use of computer based graphic organizer programs increased the total words written substantially. There were recognizable increases in total time spent planning. More moderate increases could be found in common story elements. Nominal to no improvements were seen in overall organization.

More specifically, with regards to the total number of words written, all participants had increases to varying degrees from baseline to intervention with increases in word count by 20.25 words to 41.85 words. In examining the data provided regarding 
minutes spent planning, all four participants increased their mean number of minutes spent planning after moving to intervention. The mean increases ranged from 1.00 minutes to 5.00 minutes. Patrick spent the most time planning, averaging 5.00 minutes per session planning after being moved to intervention. GP also increased his planning time by 3.35 minutes after being moved to intervention.

In examining the number of common story elements found in the narrative writing compositions when compared to planning, there was an increase to varying degrees for all participants. Increases out of total possible score of 6.00 mean increases in common story elements were from 1.50 to 3.10 .

In regards to overall organization, which was rated on a one-to-six point scale, the results were mixed results with minimal, with increases for three of participants and one participant whose score remained the same between baseline and intervention. The range of changes was from 00 to .50 . 


\section{CHAPTER V}

\section{DISCUSSION}

This chapter presents a discussion of the results of this study. First presented is a brief overview of the study followed by a summary of the results with respect to literature of graphic organizers. Lastly, the study's limitations, implications for practice, and suggestions for future research are presented.

This study examined the effects of a computer graphic organizer on the narrative writing of elementary school students with SLD. In particular, the study sought to answer the research questions by measuring multiple dependent variables including: (a) number total words written; (b) amount of time spent on planning; (c) number of common story elements transferred; and (d) overall organization. Data were collected and analyzed on a total of 146 narrative writing compositions, on 39 session dates, with four participants, across the dependent variables.

In several cases the intervention did not result in immediate increase or improvements in performance. However, overall the results of this study demonstrated to varying degrees that the use of the computer graphic organizer had positive effects on the participants' compositions as measured by three of four of the dependent variables. Increases to varying degrees in the mean scores across the following dependent variables were observed: (a) number total words written; (b) amount of time spent on planning; and (c) number of common story elements. Insignificant differences were noted across all participants in overall organization. The following is an examination of the results for each dependent variable. 


\section{Total Words Written}

Data were collected on the total words written by each participant and the group across baseline and intervention conditions. Overall, the results of this study demonstrated an increase in varying degrees for all participants when comparing total words written from baseline to intervention. During baseline, GP, the last participant to move to intervention had the most substantial increase from baseline to intervention in the mean total words written, with a mean increase of 41.86 . This is a $43 \%$ increase of total words written. This was followed by Bob with a mean increase of 35.5 words, representing a $43 \%$ increase, Patrick with a mean increase in total words of 27.40 , representing a $32 \%$ increase in the total number of words, and finally Gabe with a mean increase of 20.25 total words, representing a $22 \%$ increase in total words written. For all four participants these observed increases were not immediate upon implementation of the intervention. Instead, however towards the end of the study all four of the participants had an ascending trend line suggesting that additional practice was necessary in order for the intervention to be more effective.

Students with SLD show moderate to severe academic skill deficits, particularly in the areas of literacy, language, and writing (Mattison et al., 1998; Nelson et al., 2006). These students displayed deficits with written expression skills, ultimately having difficulty composing complete, grammatical sentences, and tend to have poor writing fluency (Chalk et al., 2005). Also, some students with SLD have difficulty organizing written information and struggle with poor handwriting and extremely poor alignment (Saddler, 2006). This leads to written compositions that lack length and are typically short in words. Deficits in these areas were observed in the writing performances of the 
participants of this study. Other also demonstrated similar results on the quality of composition writing (e.g., Blair et al., 2002; Lin et al., 2002; Sturm \& Rankin-Erickson, 2002; Unzueta \& Barbetta, 2012). The quantity of writing in these previously mentioned studies, as well as the current study, was measured by counting the total number of words. These results support the notion that using a computer graphic organizer can assist elementary-level students with SLD in writing compositions that have more words, ultimately increasing their compositions in length and quantity.

The results of this study support and strengthen the results of Unzueta and Barbetta (2012) in that both studies found increases in total number of words written per composition with the use of a computer graphic organizer. Across participants, Unzueta and Barbetta found substantial increases, often immediately following the introduction to the intervention. In fact, the participants in Unzueta and Barbetta study saw overall mean increases of words written by $125.7,233,104$, and 177.9 across the 40 -minute writing sessions. The groups mean increase in total words written in was 138.1 which represented a $32 \%$ mean increase, while the current study had a $22 \%$ overall increases in the number of words written.

The aforementioned immediate and more substantial increases of the participants in the Unzueta and Barbetta (2012) study in comparison to the current study's results in total words could be attributed to the fact that the participants in the Unzueta and Barbetta study were middle school students, and they were at a higher academic level than the elementary level students involved in the current study.

The results of this study supports the findings of Blair et al. (2002), who noted an increase in the length of each of the compositions after the introduction of a computer 
graphic organizer with middle school students with SLD. It also supports in part, the results of Sturm and Rankin-Erickson (2002) who observed substantial increases in total number of words written with the use of graphic organizers. Sturm and Rankin-Erickson had increases in the total number of words written across three interventions: (a) writing without graphic organizers, (b) handwritten graphic organizers, and (c) computer graphic organizer. However, Sturm and Rankin-Erickson were unable to determine which intervention was more effective due to the fact that there was a component of their methodology that incorporated an explicit teaching of expository writing after baseline was collected. This current study reduces the confounding effects of Sturm and RankinErickson's study by mirroring methodology employed by Unzueta and Barbetta (2012).

In Unzueta and Barbetta (2012), the researchers chose to teach persuasive writing before collecting baseline data. This was done to increase the likelihood that it was the intervention that affected the dependent variables and not additional explicit instruction in persuasive writing. In the current study, the same methodology was utilized; in that teaching the participant the tenets of narrative writing was done prior to collecting baseline data which increased the likelihood that any changes in the dependent variables were due to the graphic organizer intervention, not additional explicit instruction. Ultimately, the use of computer graphic organizers increased the number of words written in the narrative writing compositions across all participants in the current study.

In summary, this study's results demonstrated that using computer graphic organizers with elementary students with SLD had positive increases in the results for the total words written which supports the results of previous research (e.g., Blair et al., 2002; Sturm \& Rankin-Erickson, 2002; Unzueta \& Barbetta, 2012). Although the results 
weren't immediate, they were substantial and ascending trend lines were seen at the end of intervention for all 4 participants. This suggests that perhaps with further practice with graphic organizers further improvements would be observed.

The current study extends the research base by incorporating the use of Kidspiration 3.0 (2011), which has not been utilized in the previous studies. Instead those studies used different versions of Inspiration. Also, this research investigated elementary-level participants which have only been researched in two other studies (e.g., Capretz et al.; Zollman. 2009), however it is important to note that these studies were both handwritten graphic organizers. The remaining existing research on graphic organizers and writing (e.g., Blair et al., 2002; DiCecco \& Gleason, 2002; Lin et al., 2004; Lorber, 2004; Sturm \& Rankin-Erickson, 2002; Unzueta \& Barbetta, 2012) used participants at the middle and high school-level. Finally, the current study extends the research base by focusing on the narrative writing genre, which has only been researched in conjunction with graphic organizers in two other studies (e.g., Capretz et al., 2003; Blair et al., 2002).

\section{Planning Time}

Upon examination of the time spent on planning each composition, overall all four participants increased their mean planning time per writing session. From baseline to intervention, Patrick had the largest increase of time spent planning with an increase of 5.00 minutes of planning time when comparing baseline to intervention which represents a $53 \%$ increase from baseline to intervention in minutes spent planning. This is followed by GP who saw an increase of 3.35 minutes of planning time representing a $40 \%$ increase. Both Gabe and Bob experienced less substantial increases of 1.90 and 1.0 
minutes, exhibiting $21 \%$ and $17 \%$ increases in minutes planning, respectively. It is important to note that although there were increases in planning time, the results indicated that at times they were not immediate and with the exception to Patrick, not very substantial in terms of minutes planning.

Time spent planning in writing may play an important role in the final product of writing compositions (Englert et al., 2007; Wong, 2000). According to De la Paz and Graham (2002), considerable amounts of time are spent planning by skilled writers in order to produce quality compositions. Unfortunately, however, many students with SLD have multiple challenges that affect their ability to plan writing effectively. Mayer et al., (2005) found that as many as to $40 \%$ of students with SLD also have poor attention skills and that many of these students lack focus, increasing the difficulty of all academic areas. Furthermore, students with SLD consistently show difficulties with their regulating strategies (e.g., Englert et al., 2007; Graham et al., 2005; Saddler et al., 2004; Wong, 2000). Moreover, Graham et al. found that students with SLD have difficulty ultimately planning their writing as a process.

The results of this study support the findings of several other studies that investigated the time spent planning and use of graphic organizers. Previous studies have noted increases in planning time when utilizing a graphic organizer (e.g., Blair et al., 2004; Lin et al., 2004; Unzueta \& Barbetta, 2012). It is important to note that although there was an increase in planning, the current study did not manipulate planning time as dependent variable; therefore the only result that can be discussed is the amount of time spent planning and not whether that played a role in the changes in the quantity and quality of the writing. This study further strengthens the results found in the Unzueta and 
Barbetta study which demonstrated that Hispanic students with SLD who used a computer graphic organizer doubled and tripled their planning time. Of the four participants who participated in the Unzueta and Barbetta study, all increased their planning time by at least 8.00 minutes. In comparison, the current study did not show as dramatic increases as previous studies. Perhaps this could be due to the fact that the participants involved in the current study were at the elementary level, therefore lacking some of the academic skills needed to plan effectively, while the participants in previous studies were either middle school or high school levels.

The current study also strengthens the study conducted by Lin et al. (2004). Lin et al. compared handwritten graphic organizers to computer graphic organizers. Both groups, handwritten and computer graphic organizers, increased the amount of time spent planning, ultimately finding that out of a dedicated 90 minutes writing block the participants planned for 21.5 and 25.7 minutes. The authors did not offer data as to the planning time per participants' pre-graphic organizer. However, they noted that this was a considerable increase compared to pre-assessment conditions as referenced by the authors. In fact, the authors made the distinction that the group performance with use of a computer graphic organizer increased planning time by 2.56 minutes comparing baseline to intervention.

The current study also corroborates with the qualitative findings of Blair et al. (2002). In Blair et al., a limited number of students spent any time planning their work before writing a narrative composition. Similarly, to the current study, in Blair et al., one student increased his planning time with the use of a computer graphic organizer from 0 minutes to four minutes. It is important to mention that the Blair et al. study lacks other 
concrete quantitative data and the researcher was unable to compare the current study further as there is limited data available for comparison in that study.

In summary, the results demonstrated that using computer graphic organizers with elementary-level students with SLD increased the amount of time spent on planning. This study adds to the existing literature base by adding quantitative results of the effects of computer graphic organizers on the planning time spent by students. It also adds to the research base by utilizing the Kidspiration 3.0 (2011) software which has not previously been utilized. The current study's focus on narrative writing is a departure from previous studies that focused on persuasive or expository writing. Finally, as noted previously, the current study had elementary-level participants as opposed to previous studies that had participants in the middle school and high school levels.

\section{Common Story Elements}

Upon analysis of the participants' number of common story elements, all participants increased the mean number of number of common story elements found per composition per session. Gabe demonstrated the largest increase in common story elements from baseline to intervention, at 3.10 elements out of a possible 6.00. From baseline to intervention, Bob, Patrick and GP increased their number of common story elements written by $.80,2.00$, and 1.50 out of a possible 6.00 . It is important to note that although there were some increases in regards to the total number of common story elements, all participants had considerable overlap of data points when comparing the baseline to intervention.

The focus of this study was the narrative writing genre. Mastering this genre of writing is critical in elementary school as it is the most utilized across subject areas 
(Wong, 2000). With narrative writing, the writer tells a story to the reader and, as such, can be described as story-telling writing. The focus of the writing in this current study strictly examined the creative narrative writing genre in which the writing has a plot, a setting (where and when the story happens), and characters who have motives (reasons) for what they do. These compositions should follow a conventional story arc (typically beginning, middle, and end), and should have characters, and a setting as well as a natural flow of events.

The current study is the only one of the previously mentioned studies (e.g., Blair et al., 2004; Capretz et al., 2003; 2002; DiCecco \& Gleason, 2002; Lin et al., 2004; Lorber, 2004; Sturm \& Rankin-Erickson, 2002; Unzueta \& Barbetta, 2012; Zollman. 2009), however it is important to note that these studies were both handwritten graphic organizers. The remaining existing research on graphic organizers and writing that focused on common story elements. However, some of the previous studies mentioned did measure components relevant to the writing genres being investigated such ideas in expository writing or supporting arguments in persuasive writing (e.g., Lorber, 2004; Unzueta \& Barbetta, 2012). In Lorber's study, there was a perception by teachers that planning increased the number of ideas that the students were writing which is supported by the findings of the current study in which a computer graphic organizer increased the total number of common story elements. This study examined the total number of common story elements in a quantitative manner which supports Lorber's qualitative approach to measuring perceived ideas. In Unzueta and Barbetta's study, a quantitative measure was derived for the number of arguments and supportive details in persuasive writing. The results indicated that middle school level Hispanic students with SLD were 
able to produce substantially more supporting details using the computer graphic organizer. In the current study, elementary-level student with SLD had increases in their total number of common story elements with the use of computer graphic organizers, thereby extending the work of Unzueta and Barbetta. Also, the current study extends the studies previously conducted because it is the first study that measured common story elements as a part of the narrative writing genre at the elementary level.

\section{Overall Organization}

The results of this study on the overall organization of the written compositions, demonstrates negligible increases to varying degrees for three participants and none for the fourth participant. The second participant, Gabe, who performed the best in this area, maintained the mean performance between baseline and intervention at 2.30 . On a 6point scale, Bob, Patrick, and GP increased by a mean of $.50, .20$, and .17, respectively. There was considerable variability among the data points for all of the participants.

Organization in writing is critical as it is the process that ensures that thoughts become organized into written form. Students with SLD have difficulties putting together thoughts in written form and often put together their writing in an associative manner, creating compositions that are unclear (Saddler et al., 2004). Englert et al. (2007) indicated that students with SLD lack knowledge of text structure. Students with SLD have problems logically organizing a paragraph in a sequential manner (Englert et al. 2007; Graham et al., 2001; Wong, 2000). Many of these students do not look for ways to improve their compositions (De la Paz and Graham, 2002; Graham et al., 2001; Wong, 2000). 
As a systematic replication of Unzueta and Barbetta's (2012) study, the current study also utilized an analytical scoring guide. In Unzueta and Barbetta's study, the authors found that using graphic organizers did increase overall organization as measured by an analytical scoring guide. Mirroring the methodology utilized by Unzueta and Barbetta, this study also utilized an analytical scoring guide, however, the current study offered minimal to no support to their findings that using computer graphic organizers with Hispanic students with SLD increases the organization of the written compositions. On the same note, the current study fails to offer support or strengthen the finding of Sturm and Rankin-Erickson (2002) in that the score of students' compositions created with a computer graphic organizer were higher than the students' baseline compositions in that study. This study also offers minimal to no support to the study by Lorber (2004) who found that general-education students using the computer graphic organizer did perform significantly better on holistic scoring of their compositions $F(4,79)=2.49, p=$ .05 .

In summary, three studies (i.e., Lorber, 2004; Sturm \& Rankin-Erickson, 2002; Unzueta \& Barbetta, 2012) all utilized a form of evaluation to measure organization of writing. All three studies saw some increases to varying degrees. This suggests that computer graphic organizers may in fact improve the overall organization of compositions. However, the current study saw negligible increases in three participants and one participant maintained his performance across baseline through intervention. This could be due to the fact the current studies' participants had academic gaps related to overall composition that were too substantial to overcome with a graphic organizer only. Perhaps, the addition of some remedial instruction along with the use of the 
graphic organizer may have positively influenced the results in overall organization. Also, the design of the graphic organizer used in the study, focused on common story elements as opposed to overall organization which may have directly impacted the results of this dependent variable.

Finally, Kidspiration 3.0 (2011) has the ability to type additional sentences under the key points while in outline form. However, the participants of the current study had difficulty with typing and therefore, it was decided that the participants would write their compositions using paper and pencil. As a consequence this prevented the participants from taking advantage of the software function that allows students to add sentences directly under the key points on the outline. If they had been able to type, this may have supported them in their writing.

\section{Summary of Results of All Dependent Variables}

This study examined the effects of computer graphic organizers on narrative writing compositions of elementary aged students with SLD. The following dependent variables were studied: (a) total number of words; (b) total planning time; (c) common story elements; and (d) overall organization. Five studies were found that used computer graphic organizers as a writing strategy to improve student compositions (e.g.; Blair et al., 2002; Lin et al., 2004; Lorber, 2004; Sturm \& Rankin-Erickson, 2002; Unzueta \& Barbetta, 2012). Other studies employed the use of handwritten graphic organizers in writing as a component of their research (i.e., Capretz et al., 2003; DiCecco \& Gleason, 2002; Zollman, 2009). Of these, only three were used with students with disabilities (i.e., Blair et al., 2002; Sturm \& Rankin-Erickson, 2002; Unzueta \& Barbetta, 2012). None of the five studies that utilized computer graphic organizers specifically focused on 
elementary-level student with SLD and only two that utilized hand written graphic organizers focused on this population (i.e., Capretz et al., 2003; Zollman, 2009). Only one other study found (i.e., Blair et al., 2002) investigated narrative writing.

Of the dependent variables investigated in this study, when computer graphic organizers were introduced as the intervention, improvements to varying degrees were demonstrated in three of the four dependent variables. There were increases for all four participants in the total number of words written, total time spent planning, and common story elements. Minimal to no increases were found with the overall organization. This could be due to the fact that the design of the graphic organizer focused on the number of common story elements as opposed to overall organization. It could also be due to the already significant gaps in knowledge base that the participants had in writing.

When comparing the results with substantial improvements in the dependent variables (i.e., total number of words, total planning time, planning time, overall organization), the current study supports and strengthens the results of the previouslymentioned studies (e.g., Blair et al., 2002; Lin et al., 2004; Lorber, 2004; Sturm \& Rankin-Erickson, 2002; Unzueta \& Barbetta, 2012). The current study supports and strengthens the research done by Sturm and Rankin-Erickson, Blair et al., and Unzueta and Barbetta in which total number of words was measured and found that computer graphic organizer dramatically increases the number of words written in final compositions. The results also extend the research conducted by Lin et al., Lorber, and Unzueta and Barbetta in which increases were found with the total number of common story elements after using computer graphic organizer, as was found in this study. Furthermore, the current study supports the studies of Blair et al., Lin et al., and Unzueta 
and Barbetta which all saw increases in planning time. Finally, the data of overall organization offered little to no support to the findings of Sturm and Rankin-Erickson, Lorber, and Unzueta and Barbetta.

In regards to overall organization, the current study found only nominal to negligible increases and were dissimilar to the results found by Unzueta and Barbetta (2012). Given the current study's negligible results in this area, they do not support the findings in the existing literature. Simultaneously, they do not contradict the results found in previous studies, as there was not a decrease in overall organization. The current study's findings do contribute to the literature in that although there were minimal to no increases, it perhaps indicates that this intervention was not robust enough for this population in terms of overall organization.

This study represents a systematic replication and an extension of the Unzueta and Barbetta (2012) study. Even though improvements were found across several of the dependent variables in this study, the current study found less substantial increases than those observed in the Unzueta and Barbetta. This perhaps could be due to the academic and grade levels of the participants of the current study being much lower than those who participated in the Unzueta and Barbetta study. Another possibility could be that the narrative genre of writing may be more difficult to grasp in comparison to persuasive writing which has a more concrete model to follow. Finally, it is important to note that there were ascending trend lines found at the end of the study during intervention for many of the dependent variables. For example, Bob had observable ascending trend lines in planning time, common story elements, and overall organization. Gabe continued to exhibit an ascending trend line in total planning time. Patrick continued to increase his 
total number of words. Finally, GP the last participant to enter intervention had ascending trend lines in planning, common story elements, and organization. This suggests that if the study had continued there may have been more substantial gains.

\section{Implications for Practice}

The results of this study have important implications for classroom practice. The current study found that the use of a computer graphic organizer overall had positive effects on improving the narrative writings of elementary aged students with SLD. Due to this success, educators should consider the introduction of computer graphic organizers as early as elementary school. Kidspiration 3.0 (2011) was a successfully utilized tool that could be introduced during the writing block at many schools easily by uploading the software in a computer lab or classroom set of computers.

Another recommendation would be to introduce the use of Kidspiration 3.0 (2011) in conjunction with remedial instruction in writing. Utilizing strategies that help fill the academic gaps such as peer tutoring, small group instruction, or perhaps direct instruction could be beneficial. Upon completion of the current study it has become evident that the participants had more obvious academic gaps. Therefore the combination of the use of this computer graphic organizer in conjunction with intensive remedial instruction in writing might be beneficial. For example utilizing the approach known as Strategy Instruction could be beneficial (Luke, 2006). Strategy instruction is a teaching strategy that has hallmarks of providing continued guidance and ample opportunities for practice, students learn to integrate new information. This is especially helpful for students with SLD because typically these students require extensive supports in writing. 
Another successful remedial instructional strategy is known as Peer-Assisted Learning Strategies (PALS; Council for Exceptional Children, 2012). PALS involve an approach in where two students are paired and they perform certain academic tasks together (Saenz, McMaster, Fuchs, \& Fuchs, 2007.) PALS could be useful in that specific skills in writing could be targeted. The working collaborative aspect of this approach is also less threatening, perhaps increasing the likeliness of more ideas in planning. Finally, incorporating a computer graphic organizer could be included easily. Using the PALS approach in conjunction with a computer graphic organizer may increase positive results. Using the PALS approach in conjunction with a computer graphic organizer may increase positive results.

\section{Limitations}

There were some delimitations that were imbedded in the study that should be noted. Firstly, the current study also took place in a private school where the academic focus and school vision could be different than that of public urban school environment. All of the participants had a SLD and were at the elementary-level contributing the aforementioned academic gaps.

There were also several unplanned limitations to the study. First, all of the participants were male. Future studies could include female participants. Another limitation was the larger than expected academic gaps found in the participants. Perhaps the academic gaps found with these students with SLD contributed to smaller increases than found in previous studies. This phenomenon could also be attributed to the fact that the participants of the current study, were at the elementary level, and were functioning at lower levels academically then the participants from the previous studies who were 
predominantly in the middle or high school levels. The grade levels of the participants could have also played a role in the lack of technological repertoire found in the participants.

This lack of technological repertoire also may have affected the outcome of the study as the participants could not fully utilize the Kidspiration 3.0 (2011). A beneficial function of the Kidspiration 3.0 software program is that outline that is converted from the graphic organizer template can be manipulated and added to by the user. Sentences and elaboration can be added directly to the outlines. Due to the participants' limited abilities in typing, participants were required to handwrite their compositions from the outline converted from their planning, instead of typing. Therefore, the participants were unable to elaborate and add to their outlines that were converted from their planning.

Another limitation of this study is that the last participant entered intervention perhaps a bit prematurely due to time constraints in the study. As the participants were entering the last few weeks of the study it was brought to the researcher's attention that three out of four of the participants had previous commitments afterschool that were about to begin. GP was moved into intervention quickly in order to collect some intervention data before the study would draw to a close. Had time not been a factor, intervention should have been withheld until GP displayed more of a steady state of responding in total word written.

On a similar note, given that the total words written was the dependent variable chosen in order to move participants into intervention, other dependent variables often had ascending trend lines when the participant was being moved into intervention, causing one to question whether the intervention was the cause in the continued upward 
data trend or would the ascending trend line have continued without the intervention. Finally, on the same vain, having the sessions after school could have been particularly challenging for the participants. Other outcomes may have occurred had the study sessions occurred during the school day.

\section{Future Research}

There are several recommendations for areas for future research. The characteristics of the participants used for this study were limited to male elementarylevel students with SLD, solely. Participants of other demographics should be considered in future research such as females, Culturally or Linguistically Diverse Learners (CLD), English Language Learners (ELLs), and students in middle school or high school. Additionally, in this current study, the participants were expected to write individually. Further research could be done with collaborate writing in pairs or small groups.

In the current study, the software program Kidspiration 3.0 (2011) was used for the planning and organizational stage of writing. In terms of Kidspiration 3.0, future research may use more components of the software program that incorporate the word prediction utility along with a text-to-speech option and images. Consideration in allowing participants to create their own graphic organizer template and/or use other templates on Kidspiration 3.0 should be investigated. Also, the use of another computer graphic organizer program could be utilized such as Inspiration 9.0 which also allows for a word prediction utility along with a text-to-speech option.

Future research might allow the participants to spend more than one day writing and editing their compositions. Being able to revisit these same compositions and at the same time utilize the Kidspiration 3.0 (2011) graphic organizer over the course of a few 
days could provide increased opportunities for effective revising and editing.

This study focused on one particular genre, narrative writing. Future research should include the different writing genres with computer graphic organizers such expository writing and persuasive writing. Furthermore, only one type of narrative writing was investigated; the story telling form of narrative writing, Future research is warranted in regards to other forms of narrative writing such as personal narratives or biographical narrative writing. Other investigations in tone, voice, and figurative language would also be beneficial in future research.

Finally, future research could be dedicated to clearly observe behaviors being exhibited during planning. Motivational factors in the participants could also be investigated as a component in planning. Research in which the study sessions are held during the school day rather than afterschool should also be considered.

\section{Summary}

The results of this study demonstrated that overall the use of computer graphic organizers had positive effects to varying degrees on the written narrative compositions of elementary-level students with SLD. Increases were noted in the number of words written, planning time, writing fluency, and number of common story elements. There was nominal to no improvements in overall organization for the participants.

Participants were taught narrative writing prior to the collection of baseline data. During baseline, participants were asked to use paper and pencil during the planning of narrative compositions on a given prompt and then to write a composition using paper and pencil. The intervention required the participants to use Kidspiration 3.0 (2011) to plan their writing composition in a diagram and then to convert it to an outline form and 
then to write a composition using paper and pencil. The planning sheets and written compositions were collected and analyzed daily. Data were collected across baseline and intervention on total words written, total planning time, total number of common story elements, and overall organization. There were varied increases in regards to total words written, total planning time, and total number of common story elements. There were negligible to no improvements observed in overall organization.

With regards to total words written there was an overall mean increase in the group of 30 words per composition. This was the dependent variable chosen as an indicator to move each participant to intervention. Due to this decision, not all dependent variables saw a consistent rate of steady response when each of the participants was moved into intervention. Results of the other dependent variables had mixed results.

In regards to total planning time the group overall saw an increase of 2.56 minute of planning time overall from baseline to intervention. Although, this is not an admittedly substantial increase, there is a positive correlation of extended planning time across all participants. In regards to total number of common story elements, there was a more modest increase of 1.33. Finally, the results of the overall organization of the group showed negligible increases to no growth at all for at least one participant. The group increase for overall organization was a nominal .13 from baseline to intervention.

This study does provide positive evidence that using the computer graphic organizer Kidspiration 3.0 (2011) can be a successful strategy for elementary-level student with SLD. However, because this study only focused on male elementary-level students with SLD, these findings cannot be generalized across any populations. Further 
research could be warranted in regards to the use of females and other grade levels as well as replica studies with the current population.

As this was an extension of the research conducted by Barbetta and Unzueta (2012), an analysis of the different variables was investigated than they had researched. In doing so this current study extends and adds to the limited research on computer graphic organizers and writing in general, and more specifically it adds to the research on their use with students with disabilities. This study enriches the computer graphic organizer and writing literature by focusing on elementary-level students, a population that has not been researched previously. Furthermore, the current study extends the existing literature by adding quantitative results to what is known about the effects of computer graphic organizers on the total number of words written, the amount of time these students spend planning, the total common story elements.

Future research should investigate the effects of computer graphic organizers on the writing compositions of different populations of learners, including different age groups, genders, school enrollment, as well as different cultural backgrounds. Furthermore, future research should consider investigating the use of graphic organizer programs and different writing genres. 


\section{REFERENCES}

Ayres, K., Boon, R. T., Fore, C., \& Spencer, V. G. (2005). The effects of cognitive organizers to facilitate content-area learning for students with mild disabilities: A pilot study. Journal of Instructional Psychology, 32(2), 101-117. Retrieved from http://www.questia.com/PM.qst?a=o\&d=5009985206

Baker, S., Gersten, R., \& Graham, S. (2003). Teaching expressive writing to students with learning disabilities: Research-based applications and examples. Journal of Learning Disabilities 36, 109-123.

Barry, T. D., Lyman, R. D., \& Klinger, L. G. (2002). Academic underachievement and attention-deficit/hyperactivity disorder: The negative impact of symptom severity on school performance. Journal of School Psychology, 40, 259-283.

Birbili, M. (2006). Mapping knowledge: Concept maps in early childhood education. Early Childhood Research \& Practice, 8(2). Retrieved from http://ecrp.uiuc.edu/v8n2/birbili.html

Blair, R. B., Ormsbee, C., \& Brandes, J. (2002, March). Using writing strategies and visual thinking software to enhance the written performance of students with mild disabilities. In No child left behind: The vital role of rural schools, $22^{\text {nd }}$ Annual National Conference Proceedings of the American Council on Rural Special Education (ACRES). Reno, NV: ERIC Clearinghouse on Disabilities and Gifted Education. (ERIC Document Reproduction Service No. ED463125)

Boon, R. T., Fore, C. I., \& Spencer, V. G. (2007). Teachers' attitudes and perceptions toward the use of Inspiration 6 software in inclusive world history classes at the secondary level. Journal of Instructional Psychology, 34(3), 166-176. Retrieved from http://www.questia.com/PM.qst?a $=$ o\&d $=5023531070$

Capretz, K., Ricker, B., \& Sasak, A. (2003). Improving organizational skills through the use of graphic organizers (M.A. Research Project, Saint Xavier University and Skylight Professional Development, City, IL). (ERIC Document Reproduction Service No. ED473056)

Chalk, J. C., Hagan-Burke, S., \& Burke, M. D. (2005). Self-regulated strategy development and the writing process for high school students with learning disabilities. Learning Disabilities Quarterly, 28, 75-87.

Cooper, J. O., Heron, T. E., \& Heward, W. L. (2007). Applied behavior analysis (2nd ed.). Upper Saddle River, NJ: Pearson.

Council for Exceptional Children. (2012). Peer-assisted learning strategies. Retrieved from http://www.cec.sped.org/AM/Template.cfm?Section=Home\&TEMPLATE $=/ \mathrm{CM} /$ ContentDisplay.cfm $\&$ CONTENTID $=5445 \& \mathrm{CAT}=$ none 
De la Paz, S., \& Graham, S. (2002). Explicitly teaching strategies, skills and knowledge: Writing instruction in middle school classrooms. Journal of Educational Psychology, 94(4), 687-698.

Deatline-Buchman, A., \& Jitendra, A. K. (2006). Enhancing argumentative essay writing by fourth grade students with learning disabilities. Learning Disability Quarterly, 29(1), 39-54.

DiCecco, V. M., \& Gleason, M. M. (2002). Using graphic organizers to attain relational knowledge from expository text. Journal of Learning Disabilities, 35(4), 306-320.

Dockrell, J., Lindsay, G., Connelly, V., \& Mackie, C. (2007). Constraints in the development of writing skills in children with specific language impairments. Exceptional Children, 73(2), 147-164.

Ellis, E., \& Howard, P.W. (2007). Graphic organizers: Power tools for teaching students with learning disabilities. Current Practice Alerts, 13, 1-4.

Englert, C. S., Zhao, Y., Dunsmore, K., Collings, N. Y., \& Wolbers, K. (2007). Scaffolding the writing of students with disabilities through procedural facilitation: Using an Internet-based technology to improve performance. Learning Disability Quarterly, 30(1), 9-29.

Graham, S. (2008). Effective writing instruction for all students. Retrieved from Renaissance Learning website: http://doc.renlearn.com/KMNet/R004250923GJCF33.pdf

Graham, S., Harris, K. R., \& Larsen, L. (2001). Prevention and intervention of writing difficulties for students with learning disabilities. Learning Disabilities Research \& Practice 16(2), 74-84.

Graham, S., Harris, K. R., \& Mason, L. (2005). Improving the writing performance, knowledge, and self-efficacy of struggling writers: The effects of self-regulated strategy development. Contemporary Educational Psychology, 30(2), 207-241.

Hammond, J., \& Gibbons, P. (2001). What is scaffolding? In J. Hammond (Ed.), Scaffolding: Teaching and learning in language and literacy education (pp. 1-14). Newtown, NSW: PETA.

Harris, K. R., Graham, S., \& Mason, L. H. (2006). Self-regulated strategy development for 2nd-grade students who struggle with writing. American Educational Research Journal, 43, 295-340. 
Horner, R. H., Carr, E. G., Halle, J., McGee, G., Odom, S., \& Wolery, M. (2005). The use of single-subject research design to identify evidence-based practice in special education. Exceptional Children, 71, 165-179.

Inspiration (Version 8.0). (2008). [Computer software]. Beaverton, OR: Kidspiration 3.0 Software.

Kamps, D., \& Greenwood, C. (2005). Formulating secondary level reading interventions. Journal of Learning Disabilities, 38(6), 500-509.

Kidspiration 3.0 (Version 3.0). (2011). [Computer software]. Beaverton, OR: Author.

Kim, A., Vaughn, S., Wanzek, J., \& Wei, S. (2004). Graphic organizers and their effects on the reading comprehension of students with LD: A synthesis of research. Journal of Learning Disabilities, 37(2), 105-118.

Kirk, S. A., Gallagher, J. J., \& Anastasiow, N. J. (2000). Educating exceptional children (9th ed.). New York, NY: Houghton Mifflin.

Kuder, J. (2002). Teaching students with language and communication disabilities (3rd ed.). Upper Saddle River, NJ: Allyn \& Bacon.

Kunka, J. L., Harris, M., Bishop, K., Kopp, B., Mooney, M., Neyhart D., et al. (2007). The writing process presentation. The Owl at Purdue [On-line Writing Lab]. Retrieved from http://owl.english.purdue.edu/owl/resource/701/01/

Lane, K. L., Graham, S., Harris, K. R., \& Weisenbach, J. L. (2006). Teaching writing strategies to young students struggling with writing and at risk for behavioral disorders: Self-regulated strategy development. Teaching Exceptional Children, 39, 60-73. Retrieved from http://www.questia.com/PM.qst?a=o\&d=5035135563

Lane, K. L., Harris, K. R., Graham, S., Weisenbach, J. L., Brindle, M., \& Morphy, P. (2008). The effects of self-regulated strategy development on the writing performance of second-grade students with behavioral and writing difficulties. Journal of Special Education, 41(4), 234-252. Retrieved from http://www.questia.com/PM.qst?a=o\&d=5025386378

Learning Disabilities Association of America. (2012). Successful strategies for teaching students with learning disabilities. Retrieved from http://www.ldanatl.org/aboutld/teachers/understanding/strategies.asp

Lenz, B. K., Adams, G. L., Bulgren, J. A., Pouliot, N., \& Laraux, M. (2007). Effects of curriculum maps and guiding questions on the test performance of adolescents with learning disabilities. Learning Disability Quarterly, 30(4), 235-244. Retrieved from: http://www.questia.com/PM.qst?a $=$ o\&d=5024823153 
Lin, S. Strickland, J., Ray, B., \& Denner, P. (2004). Computer-based concept mapping as a prewriting strategy for middle school students. Meridian Middle School Computer Technologies Journal. Retrieved from http://www.ncsu.edu/meridian/sum2004/cbconceptmapping/

Lorber, M. (2004). Instructional computer technology and student learning: An investigation into using inspiration(TM) software to improve eighth grade students' ability to write. Ann Arbor, MI: ProQuest Information and Learning Company. (UMI 3158289)

Luke, S. D. (2006). The power of strategy instruction. Evidence for Education, 1(1) 1-12. Retrieved from http://nichcy.org/wp-content/uploads/docs/eestrategy.pdf

MacArthur, C., \& Cavalier, A. (2004). Dictation and speech recognition as test accommodations. Exceptional Children, 71, 43-58.

Martin, D., Martin, M., \& Carvalho, K. (2008). Reading and learning-disabled children: understanding the problem. The Clearing House, 81(3), 113-117. Retrieved from ProQuest Education Journals database. (Document No. 1428819441)

Mastropieri, M. A., Scruggs, T. E., Abdulrahman, N., \& Gardizi, W. (2002). Computerassisted instruction in spatial organization strategies to facilitate high school content-area learning. Fairfax, VA: George Mason University, Graduate School of Education.

Mattison, R. E., Spitznagel, E. L., \& Felix, B. C. (1998). Enrollment predictors of the special education outcome for students with SED. Behavioral Disorders, 23, 243256.

Mayes, S. D., \& Calhoun, S. L. (2005). Frequency of reading, math, and writing disabilities in children with clinical disorders. Learning and Individual Differences, 16(2), 145-157.

McCormick, C. B. (2003). Metacognition and learning. In I. B. Weiner (Series Ed.), W. M. Reynolds \& G. E. Miller (Eds.), Handbook of psychology: Vol. 7. Educational Psychology (pp. 125-148). Hoboken, NJ: John Wiley \& Sons.

Mayer, S., Calhoun, S., \& Crowell, E. (2005). Effect of acquisition rates on off-task behavior with children identified as having learning disabilities. Journal of Learning Disabilities, 22, 417-424.

Monroe, B. W., \& Troia, G. A. (2006). Teaching writing strategies to middle school students with disabilities. The Journal of Educational Research, 100(1), 21-33. 
Montgomery, J .K. \& Moreau, M. R. (2004). East meets west: Using children's books $\underline{\text { as }}$ clinical intervention for language and reading disabilities. Vol. $1 \& 2$. Springfield, M.A.: Mindwing Concepts.

National Joint Committee on Learning Disabilities. (2006, October). Learning disabilities and young children: Identification and Intervention. Retrieved from http://www.ldonline.org/article/11511/

National Writing Project. (2003). National Writing Project Statement on the 2002 NAEP Writing Report Card. Berkeley, CA: University of California.

Nelson, J. R., Benner, G. J., Neill, S., \& Stage, S. A. (2006). The interrelationships among language skills, externalizing behavior, and academic fluency and their impact on the academic skills of students with emotional disturbance. Journal of Emotional and Behavioral Disorders, 14, 209-216.

Nesbit, J. C., \& Adescope, O. O. (2006). Learning with concept and knowledge maps: A meta-analysis. Review of Educational Research, 76, 413-448.

Olson, J.L., \& Platt, J.M. (2004). Teaching children and adolescents with special needs (4th ed.). New York, NY: Houghton Mifflin.

Persky, H. R., Daane, M. S., \& Jin, Y. (2003). The nation's report card: Writing 2002 (NCES 2003-529). Washington, DC: U.S. Government Printing Office.

Raymond, E. B. (2004). Learners with mild disabilities: A characteristics approach (2nd ed.). Boston: Allyn and Bacon.

Saddler, B. (2006). Increasing story-writing ability through self-regulated strategy development: Effects on young writers with learning disabilities. Learning Disability Quarterly, 29(4), 291-305. Retrieved from http://www.questia.com/PM.qst?a $=$ o\&d=5018562215

Saddler, B., Moran, S., Graham, S., \& Harris, K. R. (2004). Preventing writing difficulties: The effects of planning strategy instruction on the writing performance of struggling writers. Exceptionality, 12, 13-17.

Saenz, L., McMaster, K., Fuchs, D., \& Fuchs, L.S. (2007). Peer-assisted learning strategies in reading for students with different learning needs. Journal of Cognitive Education and Psychology, 6(3), 395-410.

Salahu-Din, D., Persky, H., and Miller, J. (2008). The nation's report card: Writing 2007 (NCES 2008-468). National Center for Education Statistics, Institute of Educational Sciences. 
Scott, B. J., \& Vitale, M. R. (2003) Teaching the writing process to students with LD Intervention in School \& Clinic, 38, 220-224.

Sitko, M. C., Laine, C. J., \& Sitko, C. (2005). Writing tools: Technology and strategies for struggling writers. In D. Edyburn, K. Higgins, \& R. Boone (Eds.), Handbook of special education technology research and practice (pp. 355-377). Whitefish Bay, WI: Knowledge by Design.

Slavin, R.E., \& Madden, N.A. (2001). Success for All: Research and reform in elementary education. Mahwah, NJ: Erlbaum.

Strangman, N., Hall, T., \& Meyer, A. (2003). Graphic organizers with UDL. Wakefield, MA: National Center on Accessing the General Curriculum. Retrieved from http://aim.cast.org/learn/historyarchive/backgroundpapers/graphic_organizers_udl

Sturm, J. M., \& Rankin-Erickson, J. L. (2002). Effects of hand-drawn and computergenerated concept mapping on the expository writing of middle school students with learning disabilities. Learning Disabilities: Research \& Practice, 17(2), $124-$ 139.

Swanson, H. L. (2000). Issues facing the field of learning disabilities. Learning Disability Quarter, 23, 37-50. Retrieved from http://dx.sagepub.com/content/37/3/189.full.pdf

Swanson, H. L., Harris, K. R., \& Graham, S. G. (Eds.). (2003). Handbook of learning disabilities. New York, NY: Guilford.

Troia, G., \& Graham, S. (2002). The effectiveness of a highly explicit, teacher directed strategy instruction routine: Changing the writing performance of students with learning disabilities. Journal of Learning Disabilities, 35, 290-305.

Unzueta, C., \& Barbetta, P. (2012). The effects of computer graphic organizers on the persuasive writing of Hispanic middle school students with specific learning disabilities. Manuscript in press (copy on file with author).

U.S. Department of Education. (2004). Individuals with Disabilities Education Improvement Act. Retrieved from http://www.idea.ed.gov/

U.S. Department of Education, National Center for Educational Statistics. (2008). Profiles of General Demographic Statistics. Retrieved from http://www.census.gov/prod/cen2000/dp1/2kh00.pdf

Vaughn, S., Bos, C. S., \& Schumm, J. S. (2011). Teaching students who are exceptional, diverse and at risk in the general education classroom. Upper Saddle River, NJ: Pearson Education. 
Wong, B. Y. L. (2000). Writing strategies instruction for expository essays for adolescents with and without learning disabilities. Topics in Language Disorders, 20(4), 29-44.

Yin, Y., Vanides, J., Ruiz-Primo M.A., Ayala C. C., and Shavelson R. J., (2005) Comparison of Two Construct-a-Concept-Map Science Assessments: Created Linking Phrases and Selected Linking Phrases. Journal of Research on Science Teaching.

Zollman, A. (2009). Mathematical graphic organizers. Teaching Children Mathematics, 16(4), 222-229. 
APPENDIX A

INSTITUTIONAL REVIEW BOARD APPROVAL 


\title{
MEMORANDLM
}

\author{
Fo: Mary Krislina Compalezelodo \\ (c: Dr. Patricat Barbetia \\ rile \\ From: Jada isixm, MPI IRIB Condinator fi. \\ Date: $\quad$ Sieptember 14.2011 \\ Proposal Title: "The lise of Computer (iraphic Organiser for Narrative Writing by Elementary \\ Schosl Stukents with specitic L caming Diwabilities"
}

IRB Exemption $\# \quad 0816,11-100$

The Social and Behavioral Institational Revie Board of forida Intemational Lniversity has revewed your study for the use of human subjects vat the Fiempt Revies process reur study was deemed Exempt hy the Instifutomal Revies Board un August 16. 2011

As a requirement of IRB approval you are required to:

1) Submif a completion report (10m B-2 l upon completion of vout project in order for the tile t" he closed.

2) Submit a proposal and receise approual for any additions or changes in the procedures involving human stojects.

i) Provide immediate written notificaton to the $I R B$ of every serious or unusual or unamticipated adverse event as well as problems with the rights or welfare of the human subjects. You must contim the seceipt of serious Al: repuns with the IRIB office.

4) Clase out your profect with the IRB olfice when the stlidy is timshed of alscomtinued.

Special Conditions: - Ipon approval from the Miami-Dade County Public Schools System IMI)CPSi. a copy of the M-DC(PS RRe approval letter must be submitted to the PII! IRB (iffice (Office of Intergrity) to complete process.

Please note that you IRB exemption number is indicated ahove. For further information. you

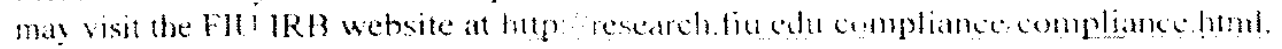


APPENDIX B

PARENT/ GUARDIAN LETTER OF INFORMED CONSENT 


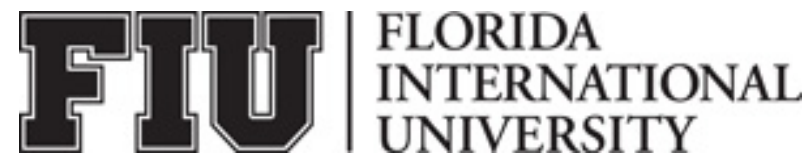

\author{
PARENTAL CONSENT TO PARTICIPATE IN A RESEARCH STUDY \\ THE USE OF COMPUTER GRAPHIC ORGANIZER FOR NARRATIVE WRITING BY \\ ELEMENTARY SCHOOL STUDENTS WITH SPECIFIC LEARNING DISABILITIES
}

\begin{abstract}
PURPOSE OF THE STUDY
You are being asked to give your permission for your child to be in a research study. The purpose of this study is to support and improve the narrative writing skills of students with the use of computer graphic organizers, as research has shown that they can assist students in organizing information and creating an increased understanding across subject areas.
\end{abstract}

\title{
NUMBER OF STUDY PARTICIPANTS
}

If you agree to allow your child to participate in this study, he/she will be one of 4 people in this research study.

\section{DURATION OF THE STUDY}

Your child's participation will require ten weeks.

\section{PROCEDURES}

If your child participates in this study, we will ask your child to do the following things:

1. Write a narrative compositions 4 days a week for approximately a half an hour afterschool

2. Work with software that will assist students in their narrative writing ability

\section{RISKS AND/OR DISCOMFORTS}

The following risks may be associated with your child's participation in this study: First, due to the nature of the study being held afterschool, then students will have less time to participate in extracurricular activities and or devote to home learning.

\section{BENEFITS}

The following benefits may be associated with your child's participation in this study: Improved writing ability that may impact a variety of subject areas. Grade four is a critical grade level in terms of standardized testing in writing and the increased attention could impact scores in a positive manner ALTERNATIVES

There are no known alternatives available to your child other than not taking part in this study. However, any significant new findings developed during the course of the research which may relate to your child's willingness to continue participation will be provided to you.

\section{CONFIDENTIALITY}

The records of this study will be kept private and will be protected to the fullest extent provided by law. In any sort of report we might publish, we will not include any information that will make it possible to identify your child as a subject. Research records will be stored securely and only the researcher team will have access to the records. However, your child's records may be reviewed for audit purposes by authorized University or other agents who will be bound by the same provisions of confidentiality. Students will be given an identity of a labeled alphabetical letter so that they can remain anonymous In accordance with Florida Law, the only exceptions to confidentiality are in cases where a) you disclose that you intend to harm yourself or others and $b$ ) information is obtained revealing that your child is being (or has been) abused or neglected. If we learn about serious harm to you or someone else, we will take steps to protect the person endangered even if it requires telling the authorities without your permission. If we have reason to believe that your child is being abused, we will report this to the Florida Abuse hotline. In these instances, we would only disclose information to the extent necessary to prevent harm. I

\section{COMPENSATION \& COSTS}

Your child will receive no compensation. Your child will not be responsible for any costs to participate in this study.

\section{MEDICAL TREATMENT}

Routinely, FIU, its agents, or its employees do not compensate for or provide free care for human subjects in the event that any injury results from participation in a research project. If your child becomes ill or 
injured as a direct result of participating in this study, contact your regular medical provider. If you have insurance, your insurance company may or may not pay for these costs. If you do not have insurance, or if your insurance company refuses to pay, you will be billed. Funds to compensate for pain, expenses, lost wages and other damages caused by injury are not routinely available.

\section{RIGHT TO DECLINE OR WITHDRAW}

Your child's participation in this study is voluntary. Your child is free to participate in the study or withdraw his/her consent at any time during the study. Your child's withdrawal or lack of participation will not affect any benefits to which he/she is otherwise entitled. The investigator reserves the right to remove your child from the study without your consent at such time that they feel it is in the best interest. RESEARCHER CONTACT INFORMATION If you have any questions about the purpose, procedures, or any other issues relating to this research study you may contact Mary Gonzalez-Ledo at FIU at (786)

262-3531,mkgonzalez@dadeschools.net

\section{IRB CONTACT INFORMATION}

If you would like to talk with someone about your child's rights of being a subject in this research study or about ethical issues with this research study, you may contact the FIU Office of Research Integrity by phone at 305-348-2494 or by email at ori@fiu.edu.

PARTICIPANT AGREEMENT I have read the information in this consent form and agree to allow my child to participate in this study. I have had a chance to ask any questions I have about this study, and they have been answered for me. I understand that I am entitled to a copy of this form after it has been read and signed.

Signature of Parent/Guardian

Date 
APPENDIX C

ASSENT FORM FOR PARTICIPANT 


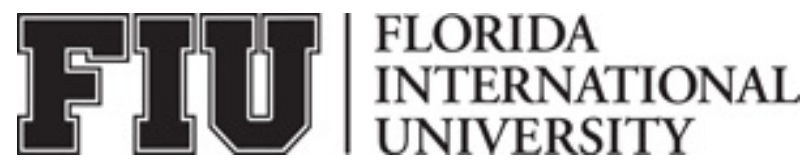

\section{PARTICIPANT CONSENT TO PARTICIPATE IN A RESEARCH STUDY THE USE OF COMPUTER GRAPHIC ORGANIZER FOR NARRATIVE WRITING BY ELEMENTARY SCHOOL STUDENTS WITH SPECIFIC LEARNING DISABILITIES}

My name is Mary K. Gonzalez-Ledo and I am a doctoral candidate at Florida International University. You are being asked to participate in a research study. The study will investigate the use of a computer graphic organizer to help you write persuasive essays.

I will need to get permission from your parent before you help with the study. If you decide to help, you will go to the computer lab four (4) times a week.

1) I will teach you how to write a narrative essay.

2) You will write several narrative essays.

3) I will collect information from your essays.

4) I will teach you how to use a computer graphic organizer to write your essay.

5) You will then be asked to write several more essays using the computer graphic organizers.

6) I will collect data again from your essays.

Each day will be afterschool for about a half of an hour you will be working with Dr. Unzueta in her classroom. Using the computer graphic organizer during your participation will not harm you in any way. It can only help make your writing better. If you help me it will not help or hurt your grades, but it may help you become a better writer. You or your parent may ask to stop participating at any time.

I will not let your scores or your name to anyone who is not involved in this study. Only I will know which scores are yours and I will write about them in my report using a fake name.

If you have questions you may ask at any time. If you have questions about the study, you or your parent can call me, Mary K. Gonzalez-Ledo at 786-262-3531. If you or your parent feels like you were not treated fairly during the study or you have questions regarding your rights as a volunteer in this research study you may call Dr. Patricia Price, the Chairperson of the Institutional Review Board at 305-348-2618 or 305-3482494.

If you would like to be in the study, sign below. You will get a copy of this form.

\begin{tabular}{cc}
\hline Sign Here & Date \\
Investigator: Mary K. Gonzalez-Ledo & Date
\end{tabular}


APPENDIX D

WRITING PROMPTS 
Writing Prompts * adapted from Miami Dade County Public Schools, District-wide

narrative prompts

1. Because you have been sick, out of town, busy at work, or working on other homework, you didn't have as much time to study for an important test as you needed. Everyone going to school has been in this situation. Think of a specific test that you took that you felt unprepared for and narrate the events. Tell your readers about the preparation that you were able to do, the reasons that you didn't get to prepare as well as you wanted, taking the test, and any significant events that happened after you took the test. Your paper should help readers understand what it felt like to be unprepared.

2. Think of an experience when you realized that you suddenly understood an idea, a skill, or a concept you had been struggling with -- it might be something related to a class that you took or a specific athletic skill you were trying to perfect. Write a narrative that tells the story of your movement toward understanding. How did you finally come to understand? What changed your perceptions and gave you a new understanding? Your paper should help readers understand how you felt to struggle with the idea or skill and then to understand.

3. Choose a vivid time from your childhood -- You might think of the first time that you rode a school bus, of a time when you went to the principal's office, the first A you earned on a test or paper, earning money to buy something that you really wanted, and so on. Narrate the events related to the childhood memory that you've chosen so that your readers will understand why the event was important and memorable.

4. Think of a time when you achieved a personal goal -- you might have finally completed a marathon or triathlon, or you might have bettered your score on the SATs or another test, or you might have learned how to use a piece of software like Microsoft Word or Excel. Tell your readers about the story of how you met your goal. Be sure that your readers understand why the goal is important to you.

5. Think about an event in your life that seemed bad but turned out to be good. Maybe you got injured and while you were waiting for your broken leg to heal, you learned how to use a computer. What makes the event change from bad to good may be something that you learned as a result, something that you did differently as a result, or something that happened that wouldn't have occurred otherwise. Tell the story of the event that you experienced and help your readers understand how an event that seemed negative turned out to have valuable consequences.

6. Teaching someone else how to do something can be rewarding. Think of a skill that you've taught someone else how to do. Perhaps you taught someone else how to swim, showed someone how to bake a soufflé, or helped someone learn how to study more effectively. Think about the events that made up the process of teaching the skill, and narrate the story for your readers. 
7. Every place has things that change -- sometimes as the result of economics, sometimes because different people are involved, and sometimes for no clear reason that you know about. Think of a change to a place that you know well. Think of a specific change and narrate the events that occurred. Readers should know the details of the change, and they should know how you feel about the changes that occurred.

8. Describe a personal ritual that you, your friends, or your family has. Think about the personal steps that you always go through when you prepare for an exam. Do you sit at a desk, spread books and notes across your bed, or use the kitchen table? Do you have to have something to drink...soda, water, jolt? There are numerous things that we do for which we create our own personal rituals. Choose one event -- studying for a test, writing a paper, dressing and warming up before a game, or preparing and having a special family meal. Narrate the events that take place when you complete your ritual so that your readers understand the steps that the ritual includes and why you complete them.

9. Choose a time when you did something that took a lot of nerve, a time when you didn't follow the crowd or a time when you stood up for your beliefs. think about the details of the event and write a story that tells about what happened. Your narrative should show your readers why you decided to make a stand or try something that took nerve, give specifics on the events, and share how you felt after the event.

10. You are walking home from a late movie, and you have to cut through a cemetery. Describe your experience.

11. You spent the day with your grandfather. Tell about your day.

12. You are visiting the zoo. You come across an animal that no one has ever seen before. Describe the animal.

13. If Superman came in and replaced your principal for a day, what would school be like? Tell about it.

14. You have 7 friends coming to your house to spend the night. What do you do to get ready?

15. Imagine you are walking outside. A spring storm is coming. Describe for your classmates what you see, hear, smell, taste, and touch.

16. Everyone needs help sometimes. Write a story about what happened one time when someone helped you.

17. Most of us have worn something we did not want to wear. Write a story about what happened one time when you had to wear something you did not want to wear.

18. Everyone has lost something. Tell about what happened the time you or someone else lost something.

19. Imagine you are on a magic carpet that takes you anywhere you choose. Think about where you would go and what you might do. Write a story about your adventure.

20. Pretend you are asked to spend the afternoon babysitting Howie, a pet monkey. Before you begin to write, think about the fun and adventures you have with 
Howie, the monkey. Now write a story about what happened the afternoon you babysat Howie, the monkey.

21. You are home babysitting your little brother. When you go out to get the paper, the door shuts and locks. Your baby brother is alone inside. Tell what you do.

22. You just got a new sled. When you wake up the next morning, it has snowed 2 feet! Tell about your day.

23. You find a baby bear on the school playground. Tell about that day at school.

24. Describe your feelings on waking up and seeing snow on the ground on a school day.

25. Describe how your classroom will look the day after the last day of school.

26. Think back to your first day in school (first grade or kindergarten) and relate what happened that day.

27. This weekend you are going to the Mall. Tell all that you will do.

28. Your little brother or sister is sick and can't sleep. Tell him/her a story that will help him/her go to sleep.

29. You have just been rescued after being lost for 24 hours. Relate what happened that made you scared.

30. Tell what happened when you felt proudest of yourself

31. Your pen pal from Antarctica sends you a penguin.

32. Tell about your first day with your new pet.

33. Your classroom's pet snake got loose inside the school. Tell what happened.

34. You and your mother are home alone when suddenly a tornado is spotted coming toward your house. Tell about your experience.

35. Think about a friend who has been an important part of your life. How did you become friends with this person? Think about when you met, what you did, and how your friendship grew. Write a story about this friendship. Give enough details to tell the reader about this friendship.

36. A change in the weather can be wonderful. Sometimes we are surprised at how a snowy, rainy, windy, or sunny day can change the way we feel. The weather can bring chances for fun, creativity, time alone, time with your family, or something out of the ordinary. Write a story about a day in which the weather made the day special for you. Give enough details to show the reader what happened on this day.

37. You woke up one morning and learned that it was snowing. School was closed for the day! It was a dream come true. Suddenly you had time to take a break from the usual routine and do what you wanted to do. Write a story about a snow day off from school that you remember. Give enough details in your story to show what you did and how wonderful the day was.

38. All of us have a favorite place where we get to do what we want. It could be an indoor place, an outdoor place, or even an imaginary place. What is your favorite place? Write a story about what you get to do in your favorite place. Give enough details in your story to show your favorite place and what you get to do there.

39. All of us have had a special time or adventure in our lives. It could be anything such as a visit with a friend or relative, a party you went to, or a game you watched or played. Or it could be something completely different. Write a story 
about a special time or adventure that you have had. Give enough details in your story to show what it was like and what made it so special.

40. Summer is a special time when children get to do fun things. You have more time during the day to choose activities that you enjoy doing with your friends or family, outdoors or indoors. There are many different ways to have fun in the summer. What ${ }^{1}$ s yours? Write a story about your favorite summer activity. Give enough details in your story to show what you were doing and what made this your favorite activity.

41. Think about people you know or have met. Choose ONE person who has made a big difference in your life. Write about that person AND describe his or her positive effect on your life.

42. Choose a vivid time from your childhood. Narrate the events related to the childhood memory that you've chosen so that your readers will understand why the event was important and memorable.

43. Think of an experience when you realized that you suddenly understood an idea, a skill, or a concept you had been struggling with. Write a narrative that tells the story of your movement toward understanding. Your paper should help readers understand how you felt to struggle with the idea or skill and then to understand.

44. Because you have been sick, out of town, or working on other homework, you didn't have as much time to study for an important test as you needed. Think of a specific test that you took that you felt unprepared for and narrate the events. Your paper should help readers understand what it felt like to be unprepared.

45. Think of a time when you achieved a personal goal. Tell your readers about the story of how you met your goal. Be sure that your readers understand why the goal is important to you.

46. Think about an event in your life that seemed bad but turned out to be good. Tell the story of the event that you experienced and help your readers understand how an event that seemed negative turned out to have valuable consequences.

47. Teaching someone else how to do something can be rewarding. Think of a skill that you've taught someone else how to do. Think about the events that made up the process of teaching the skill, and narrate the story for your readers.

48. Think of a change to a place that you know well, and narrate the events that occurred. Readers should know the details of the change, and they should know how you feel about the changes that occurred.

49. Think about your first day of school. Write a story to a friend telling about that day. Be sure to describe the atmosphere including three distinct details and identify what impressed you most about your experience.

50. You are a class president and have been asked to write an introduction for a person you admire greatly. Write an essay describing at least three distinct admirable qualities of the person.

51. Imagine yourself as a passenger on a bus. The bus driver announces "We're here! Everyone off." As the bus pulls away, you realize you don't know where you are. Describe to your family the surroundings in which you found yourself and the adventure you had trying to get home. 
52. Imagine that you find a page torn from a short story that has only two lines:

"That's how I became known as a 'Hero.' THE END" For a friend, create another story that could still end with this page

53. Suppose you woke up one morning to find that (everyone had disappeared, there was no electricity, telephones stopped working, the world had run out of gasoline, the Earth had left its orbit, etc.). Write a narrative for future generations of what life is like with this sudden change.

54. Describe how your classroom will look the day after the last day of school

55. Think back to your first day in school (first grade or kindergarten) and relate what happened that day.

56. This weekend you are going to the Mall. Tell all that you will do.

57. Your little brother or sister is sick and can't sleep. Tell him/her a story that will help him/her go to sleep.

58. You have just been rescued after being lost for 24 hours. Relate what happened that made you scared.

59. Tell what happened when you felt proudest of yourself

60. Your pen pal from Antarctica sends you a penguin. Tell about your first day with your new pet.

61. Your classroom's pet snake got loose inside the school. Tell what happened.

62. You and your mother are home alone when suddenly a tornado is spotted coming toward your house. Tell about your experience.

63. Think about a friend who has been an important part of your life. How did you become friends with this person? Think about when you met, what you did, and how your friendship grew. Write a story about this friendship. Give enough details to tell the reader about this friendship.

64. A change in the weather can be wonderful. Sometimes we are surprised at how a snowy, rainy, windy, or sunny day can change the way we feel. The weather can bring chances for fun, creativity, time alone, time with your family, or something out of the ordinary. Write a story about a day in which the weather made the day special for you. Give enough details to show the reader what happened on this day.

65. You woke up one morning and learned that it was snowing. School was closed for the day! It was a dream come true. Suddenly you had time to take a break from the usual routine and do what you wanted to do. Write a story about a snow day off from school that you remember. Give enough details in your story to show what you did and how wonderful the day was.

66. All of us have a favorite place where we get to do what we want. It could be an indoor place, an outdoor place, or even an imaginary place. What is your favorite place? Write a story about what you get to do in your favorite place. Give enough details in your story to show your favorite place and what you get to do there.

67. All of us have had a special time or adventure in our lives. It could be anything such as a visit with a friend or relative, a party you went to, or a game you watched or played. Or it could be something completely different. Write a story about a special time or adventure that you have had. Give enough details in your story to show what it was like and what made it so special. 
APPENDIX E

TREATMENT FIDELITY PROCEDURE SHEET AND CHECKLIST 


\section{Treatment Fidelity Procedure Sheet and Checklist}

Completed by:

Date:

Place a check mark next to the statement if the behavior is observed.

General Study Procedures

1. Open classroom to participants.

2. Provide snack.

3. Today, you will be given a writing prompt and asked to compose a narrative essay on a prompt. The writing prompt is [read from prompt]. Remember to include the 3 W's and 2 H's as you write your essays. W stands for Who your position, W2 stands for what, W3 stands from Where, $\mathrm{H}$ stands for how did it happen and H2 stands for how did it end. Those of you who have already practiced with Kidspiration 3.0 must use Kidspiration 3.0 for any planning. Those not trained may use the paper and pencil for any planning or prewriting. All final drafts must be typed on the computer. You will be given up to 10 minutes for your planning. After 10 minutes you will be asked to move on to the writing. You do not need to wait to move on, simply raise your hand and inform me. After 15 minutes you will be asked to begin your editing. Are there any questions? You may begin."

4. After 10 minutes remind the students to move on to the writing stage (if they have not done so).

5. After 15 more minutes remind the students to move on to the editing stage (if they have not done so).

6. After 5 more minutes ask the participants to stop if they have not done so. Save all of their essays on the thumb drive and all planning work done either by hand or on Kidspiration 3.0

Narrative Writing Instructions (Lesson might take more than 1 day)

1. Follow all of the General Study Procedures.

2. State: "Today I will teach you what narrative writing is.

3. Pass out the handouts. 
4. Teach the lesson.

5. State: "Now we will see an example of a good narrative essay and an example of poorly written essay. Together we will score the essays using an analytical scoring guide for narrative writing."

6. Pass out scoring rubric and read through it with the participants.

7. Pass out good Narrative Essay handout.

8. Read essay together.

9. Look for the common story elements.

10. Score essay together using the rubric.

11. Pass out poor Narrative Essay handout.

12. Read essay together.

13. Look for the common story elements.

14. Have each participant score essay individually and then have them share.

15. Give students writing prompt.

16. Have student practice writing a narrative essay.

17. Using the rubric, have the students score their own essays.

18. Save the essays onto the thumb drive and score the essays using the rubric.

19. If the participants are able to compose a narrative essay that included two or more common story elements, then move on to baseline. Otherwise explain the parts of narrative writing and have the student compose another essay using a writing prompt.

Baseline Procedures and Intervention Procedures

20. Follow all of the steps of the General Study Procedures.

21. Give each participant who is still on baseline, two sheets of unlined paper and two sharpened number 2 pencils.

22. Open Kidspiration 3.0 and the narrative writing template for the participants on intervention. 
23. State: "Today, you will be given a writing prompt and asked to compose a narrative essay on a prompt. The writing prompt is [read from prompt]. Remember to include the 3 W's and 2 H's as you write your essays. W stands for Who your position, W2 stands for what, W3 stands from Where, $\mathrm{H}$ stands for how did it happen and $\mathrm{H} 2$ stands for how did it end. Those of you who have already practiced with Kidspiration 3.0 must use Kidspiration 3.0 for any planning. Those not trained may use the paper and pencil for any planning or prewriting. All final drafts must be typed on the computer. You will be given up to 10 minutes for your planning. After 10 minutes you will be asked to move on to the writing. You do not need to wait to move on, simply raise your hand and inform me. After 15 minutes you will be asked to begin your editing. Are there any questions? You may begin."

24. After 10 minutes remind the students to move on to the writing stage (if they have not done so).

25. After 15 more minutes remind the students to move on to the editing stage (if they have not done so).

26. After 5 more minutes ask the participants to stop if they have not done so. Save all of their essays on the thumb drive and all planning work done either by hand or on Kidspiration 3.0

Intervention Training of Kidspiration 3.0

27. As soon as a participant is ready to get trained on the computer graphic organizer, Kidspiration 3.0 he will be given training on the program during the trainer's planning time.

28. The program Kidspiration 3.0 will be opened to the narrative writing template.

29. The participant will be taught how to create a main cluster, add and link clusters to it. He will also learn how to change the look of the clusters, font and colors.

30. After the participant has learned how to create clusters, the outline mode will be taught. Here the participant will learn how to move and reorganize sentences and the order of paragraphs.

Note any deviations or comments here. 


\section{APPENDIX F}

WRITING SAMPLE SCORING SHEET 


\section{Scoring Sheet}

Participant:

Date:

Phase: ___ Session \#:

1. Minutes Planning: Minutes Writing and Editing:

Start Time: End of Writing Time:

End of Planning: End of Editing Time:

\section{Common Story Elements}

For the purposes of this study, common story elements refer to the (1) setting or the "where" and 'when" of the story or novel, (2) characters, the "who" of the story, (3) conflict, the "what", and the (4) plot, the "how" of the story.

During Planning Stage:

\begin{tabular}{|l|l|}
\hline Characters & Beginning \\
& Middle \\
& End \\
\hline Setting & Climax \\
\hline
\end{tabular}

Total number of Story Elements

Present in the written essay.

\begin{tabular}{|l|l|}
\hline Characters & Beginning \\
& Middle \\
& End \\
\hline Setting & Climax \\
\hline
\end{tabular}

Total number of Story Elements

Total number of Story Elements present in planning and written essay:

\section{Writing Fluency}

The writing fluency is measured by the number of written words including misspelled or garbled words in the written essay. 
Total number of words in the essay:

\section{Overall Organization}

The Analytic Trait-Scoring Rubric (adapted from Monroe \& Trioa, 2006 and Unzueta \& Barbetta, 2010) is a means of scoring each essay individually. The focus of this rubric is on the essay's organization. Read each condition carefully and circle the corresponding score for each area below.

\section{Content}

6 Exceptionally clear, focused, and interesting: Writing holds the reader's attention throughout. Story elements stand out and are developed by strong support and rich details suitable to the audience.

5 Clear, focused, and interesting. Writing holds the reader's attention. Story elements are developed by some details.

4 Clear and focused: Reader can easily understand the story. Characters and some events are available

3 Reader can understand the story intention. Story details are often limited, insubstantial, overly general, or occasionally off topic.

2 Story flow is somewhat unclear or development is attempted but minimal.

1 Writing lacks appropriate story elements. Paper is too short to be considered a narrative piece.

\section{Organization}

6 Organization enhances the story and its development. Order and structure are compelling and move the reader through the text easily.

5 Organization enhances the developing story. Order and structure move the reader through the text.

4 Organization is clear and coherent. Order and structure are present but formulaic.

3 Attempt made to organize writing, however, the overall structure is inconsistent or skeletal.

2 Lacks structure. An occasional organizational device is discernible, however, the writing is either difficult to follow or the piece is simply too short to demonstrate organizational skills.

1 Writing lacks coherence. Organization seems haphazard and disjointed. Reader is confused.

Sentence Fluency

6 Writing has an effective flow and rhythm. Sentences show a high degree of craftsmanship, with consistently strong and varied structure that makes expressive oral reading easy and enjoyable.

5 Writing has an easy flow and rhythm. Sentences are carefully crafted, with strong and varied structure that makes expressive oral reading easy and enjoyable.

4 Writing flows, however, connections between phrases or sentences may be less than

fluid. Sentence patterns are somewhat varied, contributing to ease in oral reading.

3 Writing is mechanical rather than fluid. Occasional awkward constructions may force rereading.

2 Writing tends to be either choppy or rambling. Awkward constructions often force rereading. 
1 Writing is difficult to follow. Sentences tend to be incomplete, rambling, or very awkward.

\section{Word Choice}

6 Word choice is very well suited for the piece. The vocabulary is exceptionally clear and precise. Lively and memorable words paint a strong image in the reader's mind. 5 Word choice is well suited for the piece. The vocabulary is clear and precise. Some lively and memorable words help paint a strong image in the reader's mind.

4 Word choice is adequate for the piece. The vocabulary is mostly clear and concise, but economy of expression could be improved. Some well-chosen words help the reader paint a mental image.

3 Word choice lacks precision, although it is generally acceptable. Economy of expression could be greatly improved. The reader must struggle to create a mental image because so many words lack vividness.

2 Word choice is generally poor. Many words lack explicitness or are used incorrectly. Some redundancy is evident. A mental image is almost impossible to create given the vagueness of the chosen vocabulary.

1 Word choice is very poor and may be indicative of a limited vocabulary. The chosen words are vague or are used incorrectly. Much redundancy is evident. The reader is confused and unable to paint a mental image.

\section{Conventions}

6 Writing demonstrates exceptionally strong control of standard writing conventions (i.e., spelling, capitalization, and punctuation) and uses them effectively to enhance communication. Paper is free from errors or they are very minor.

5 Writing demonstrates strong control of standard writing conventions and uses them effectively to enhance communication. Errors are few and noticeable only if reader searches for them.

4 Writing demonstrates control of standard writing conventions. Minor errors, while perhaps noticeable, do not impede readability.

3 Writing demonstrates limited control of standard writing conventions. Errors impede readability.

2 Writing demonstrates little control of standard writing conventions. Frequent, significant errors impede readability.

1 Numerous errors in standard writing conventions make text very difficult to read. Severity and frequency of errors are overwhelming. Reader finds it difficult to focus on message and must reread.

Sum of Score:

Average score in writing from writing rubric:

(Sum of scores divided by 5 ) 
APPENDIX G

SAMPLE DATA LOGS 


\begin{tabular}{|c|c|c|c|c|c|c|}
\hline Participa & & 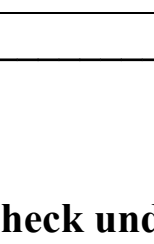 & \multicolumn{2}{|c|}{$\begin{array}{l}\text { Rater: } \\
\text { amon Story Elements }\end{array}$} & & $\begin{array}{l}\text { Climax } \\
\end{array}$ \\
\hline $\begin{array}{l}\text { Date/ } \\
\text { Sample } \\
\text { Number }\end{array}$ & Characters & Setting & Beginning & Middle & End & Climax \\
\hline & & & & & & \\
\hline & & & & & & \\
\hline & & & & & & \\
\hline & & & & & & \\
\hline & & & & & & \\
\hline & & & & & & \\
\hline & & & & & & \\
\hline & & & & & & \\
\hline & & & & & & \\
\hline & & & & & & \\
\hline & & & & & & \\
\hline
\end{tabular}


Writing Fluency And Total Planning Time

Participant:

Rater:

\begin{tabular}{|c|c|c|c|c|}
\hline Date & Condition & $\begin{array}{l}\text { Writing Prompt } \\
\text { Number }\end{array}$ & Total \# of Words & $\begin{array}{l}\text { Total } \\
\text { Planning } \\
\text { Time }\end{array}$ \\
\hline & & & & \\
\hline & & & & \\
\hline & & & & \\
\hline & & & & \\
\hline & & & & \\
\hline & & & & \\
\hline & & & & \\
\hline & & & & \\
\hline & & & & \\
\hline & & & & \\
\hline & & & & \\
\hline & & & & \\
\hline & & & & \\
\hline & & & & \\
\hline & & & & \\
\hline & & & & \\
\hline & & & & \\
\hline & & & & \\
\hline & & & & \\
\hline & & & & \\
\hline
\end{tabular}




\section{Overall Organization}

\section{Participant:}

Rater:

$\mathrm{CSE}=$ Common Story Elements $\mathrm{O}=$ Organization $\mathrm{S}=$ Sentence Fluency $\mathrm{W}=$ Word Choice $\mathrm{C}=$ Conventions

Rating Scale is from 1 to 6.

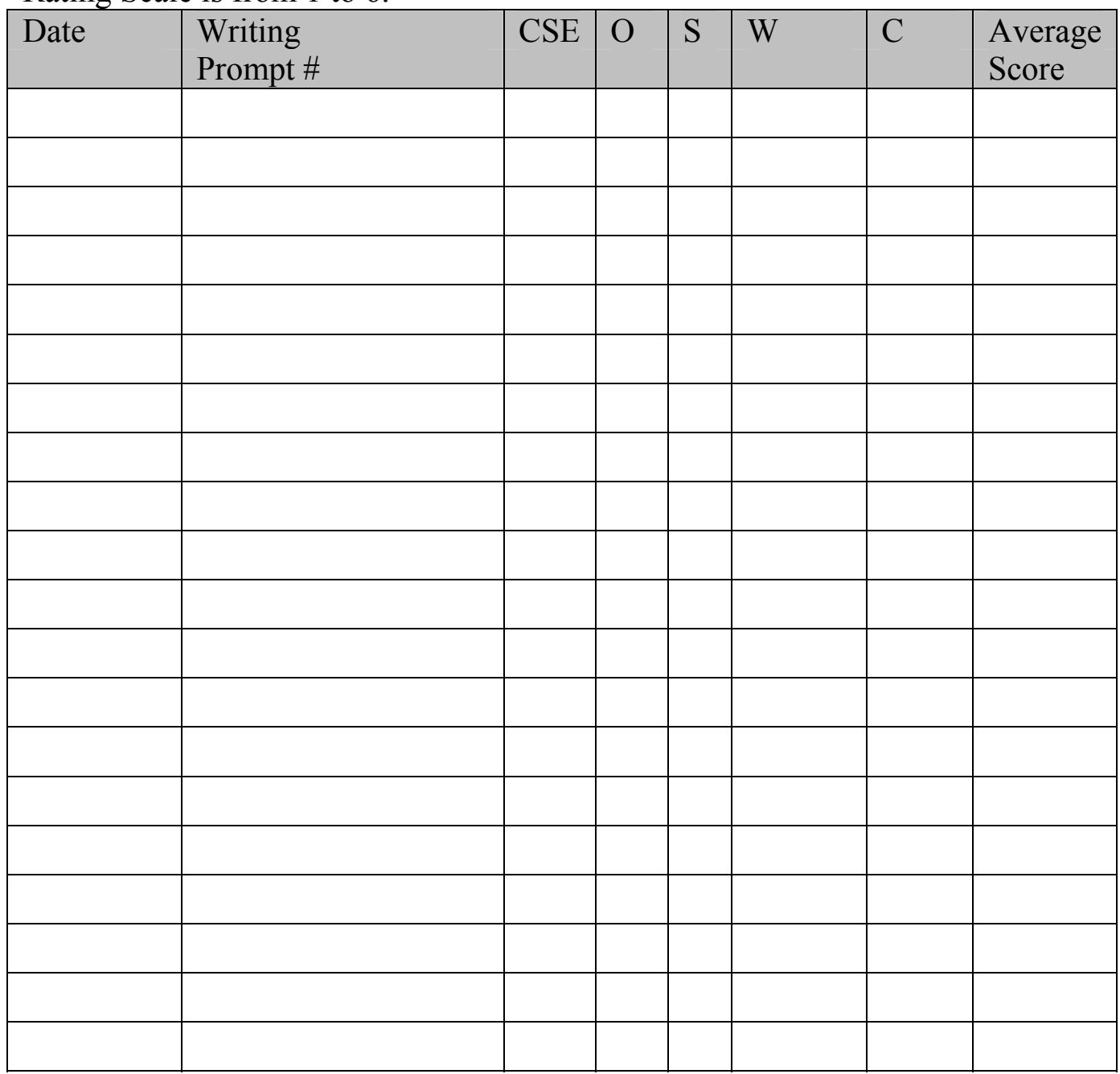


APPENDIX H

INTEROBSERVER AGREEMENT FORM 
Inter-Observer Agreement (IOA) Form

Participant:

Prompt \#:

Session Date:

Directions: This sheet compares the data collected by the researcher with the data collected by the second observer. Using the data sheets independently completed by the researcher and the observer, do a comparison of their marks in each of the following three categories.

\section{$\underline{\text { Total Planning Time }}$}

Time from rater 1 :

Time from rater 2:

Smaller \# of the 2 $\div$ greater $\times 100=$ $\%$ IOA

\section{Common Story Elements}

Common Story Elements in Planning Stage

\# of Elements agreed upon:

\# of Elements in disagreement:

\section{Common Story Elements in Written Essay}

\# of Elements agreed upon:

\# of Elements in disagreement:

Total \# of Agreements $\div$ \# Total \# of Disagreements with Agreements $x$

$100=$ $\%$ IOA

\section{$\underline{\text { Total Words Written }}$}

\# of words from rater 1:

\# of words from rater 2:

Smaller \# of the 2 $\div$ greater $\times 100=$ $\%$ IOA 


\section{Organization}

Total Score from Rater 1:

Total Score from Rater 2:

Smaller \# of the 2 $\div$ greater $\times 100=$

$\%$ IOA 
APPENDIX I

NARRATIVE WRITING GRAPHIC ORGANIZER EXAMPLE 


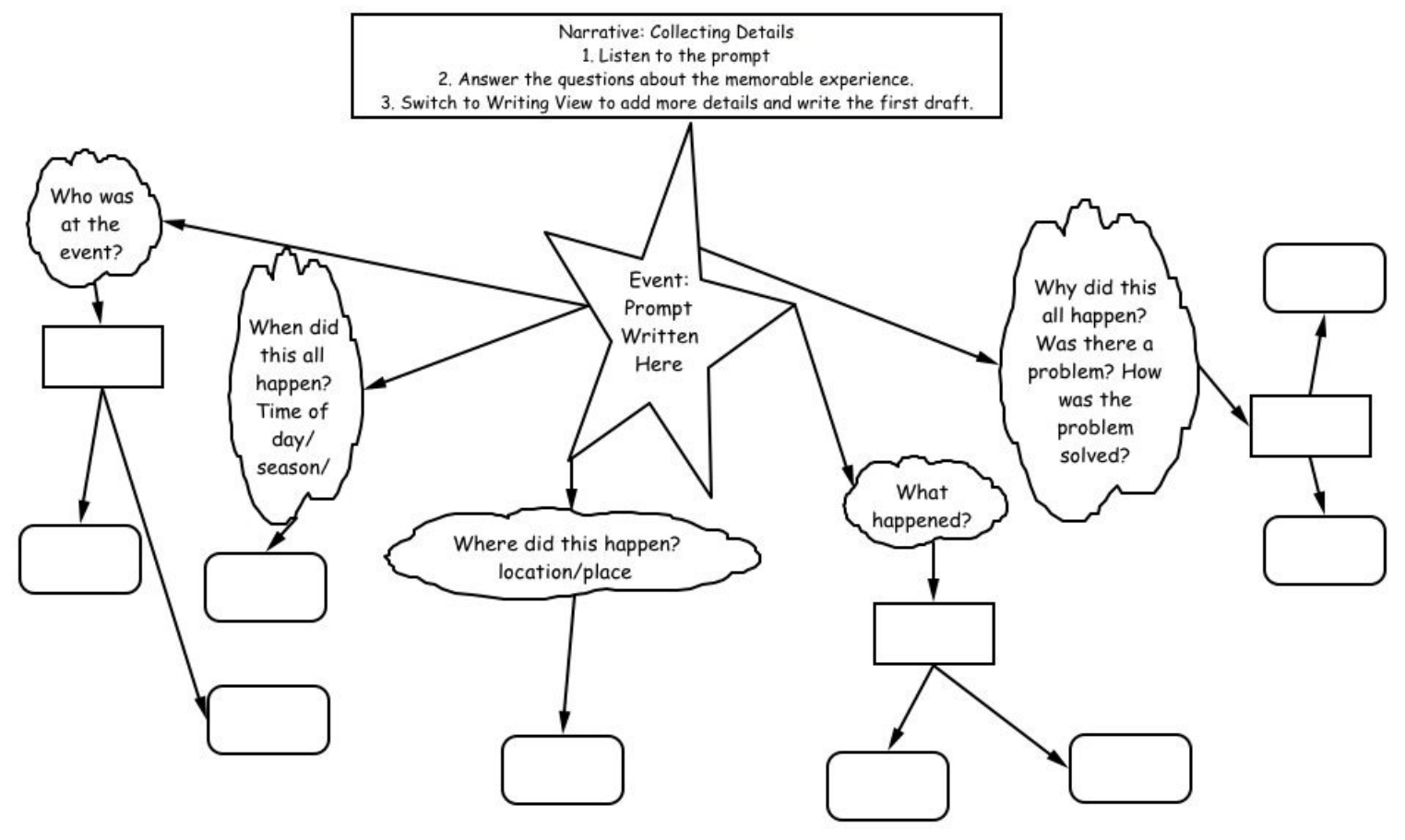


APPENDIX J

NARRATIVE WRITING LESSON PLAN 


\section{Narrative Writing Lesson}

\section{Summary:}

Students will produce a narrative about a personal experience, with a focus on the trait of organization. The text should have an inviting introduction and satisfying conclusion.

\section{Time Frame:}

2 class periods that run 30 minutes each.

\section{Materials:}

\section{Teacher Materials:}

- $\quad$ Articles of narrative writing samples dealing with best/worst experiences

- $\quad$ Graphic organizer (story map)

\section{Instructional Procedures:}

1. Read one or several of the suggested titles and model, thinking aloud. Pause throughout the reading to model personal thinking about similar experiences. Invite students to make connections also.

2. Demonstrate, using the graphic organizer, the organization of the book read in step 1 .

3. Model writing a best or worst experience by filling in experiences on the graphic organizer $3 \mathrm{~W}-\mathrm{s}$ and $2 \mathrm{H}$ 's

4. Show students the writing prompt for this lesson. Have them complete the graphic organizer for the 2 writing examples

5. Have the students plan their own stories for the same prompt

6. Give students time to draft their stories.

7. Craft story leads and conclusions by sharing both good and poor examples.

8. Give students time to revise and edit.

Writing Prompt: We all have good and bad days. Think of a time you had a really good or bad day. Think about what happened, how you felt, and why you still remember it. Write about your experience.

\section{EXAMPLE \#1}

The Deadly Penny (pdf)

\section{IDEAS AND CONTENT: [4]}

- The writer holds the reader's attention and is writing from experience. Ideas are reasonably clear, although they may lack detail.

\section{ORGANIZATION: [4]}

- The title is original. The organization flows, but the paper lacks a satisfying conclusion.

VOICE: [5] 
- $\quad$ The writing is honest, personal and engaging. The tone of the writing is appropriate and holds the reader's interest.

\section{WORD CHOICE: [3]}

- $\quad$ The writer makes attempts at colorful language. More precise wording could be used in a couple of places. It appears that the writer selected the first words that came into mind.

\section{SENTENCE FLUENCY: [3]}

- $\quad$ The writer gets the job done in a routine fashion. Sentence beginnings need more variety and energy.

\section{CONVENTIONS: [3]}

- $\quad$ The writer attempts the use of quotations but does not always punctuate them properly. Otherwise, spelling and punctuation are generally correct.

\section{EXAMPLE \#2}

The Wet Pants (pdf)

\section{IDEAS AND CONTENT: [5]}

- $\quad$ This paper is clear and focused and gives accurate details. The reader's questions are anticipated and answered.

\section{ORGANIZATION: [4]}

- $\quad$ The organization flows smoothly. The ending is satisfying, but paper could use a more compelling beginning.

\section{VOICE: [5]}

- $\quad$ The writer takes risk throughout the piece. The reader feels a strong interaction with the writer.

\section{WORD CHOICE: [3]}

- $\quad$ The writer attempts to use some colorful language, but the paper lacks memorable words and phrases. The writing could benefit from more active verbs.

\section{SENTENCE FLUENCY: [4]}

- $\quad$ This paper has an easy flow and rhythm. It could use more purposeful and varied sentence beginnings.

\section{CONVENTIONS: [5]}

- $\quad$ The writer demonstrates a good grasp of standard writing conventions. 
APPENDIX K

NARRATIVE WRITING COMPONENTS ASSESSMENT 


\section{Narrative Writing Components Assessment}

Participant:

Student was able to successfully:

1. Locate the characters.

2. Locate beginning of the narrative.

3. Locate the middle of the narrative

4. Locate the conclusion of the narrative.

5. Locate the conflict or climax of the narrative 
VITA

MARY KRISTINA GONZALEZ-LEDO

\section{EDUCATION}

$\underline{\text { Degree }}$

Ed.D

M.S. Ed $\underline{\text { Institution }}$

Florida International University

Florida State

University

B.S.
Florida State

University $\underline{\text { Dates }}$

2012

2002

2002

\section{ACADEMIC EXPERIENCE}

Institution

Florida International

University

$\underline{\text { Place of Employment }}$

Miami-Dade County Public

Schools, Miami, FL

Miami-Dade County Public

Schools, Miami, FL

Miami-Dade County Public

Schools, Miami, FL
Rank

Adjunct Instructor (n)

$\underline{\text { Title }}$

Exceptional Student Education Staffing Specialist

Department Chairperson

Exceptional Student Education

Lead Teacher

Exceptional Student Education
Field

Teaching and Learning

$\underline{\text { Dates }}$

2010-Present

2005-2010

2002-2005

\section{PUBLICATIONS}

Nevin, A., Gonzalez-Ledo. M.K. et al. (2006). Reviews of Single Subject Research Designs: Applications to Special Education and School Psychology. ERIC \# ED491545.

Nevin, A., Gonzalez-Ledo, M.K. et al. (2005). What Do Experts Say About Urban Special Education Issues? ERIC \# ED491410. 


\section{PRESENTATIONS}

Gonzalez-Ledo, M. K., Marshall, D. \& White-Lindsey, C. (April 2008) SOLO, Literacy Software. Presented at the ATAWARE - Assistive Technology Conference, Miami, FL.

Barbetta, P., Barrocas, L., Leong-Norona, K. \& Gonzalez-Ledo, M. K. (2008, October). Behavior Management: A Dozen Mistakes Teachers Make. Presented at the Florida Council for Exceptional Children (FCEC). Sarasota, FL. Gonzalez-Ledo, M. K., Marshall, D. \& White-Lindsey, C. (2007, October). SOLO, Literacy Software. Presented at the Florida Council for Exceptional Children Leadership Institute, Fort Lauderdale, FL.

\section{OTHER PROFESSIONAL ACTIVITIES AND PUBLIC SERVICE}

Council for Exceptional Children (CEC)

2000-present

Division of Teacher Education, Culturally and

Linguistically Diverse Exceptional Learners,

Learning Disabilities and Behavior

Disorders

\section{PROFESSIONAL DEVELOPMENT ACTIVITIES}

Leadership Certification for State of Florida

NBPTS certified instructor in Special Education, K-21

FCEC (Ft. Lauderdale, October 2007, October 2008)

FIN Annual Conference (December, 2005) 